
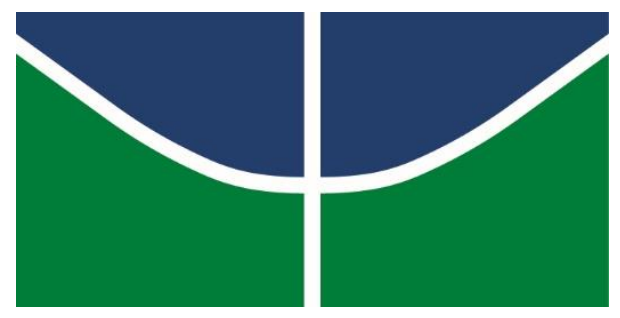

Universidade de Brasília

Instituto de Ciências Biológicas

Programa de Pós-Graduação em Ecologia

\title{
VARIAÇÕES SAZONAIS E ESPACIAIS DAS CONCENTRAÇÕES ELEMENTARES EM COMPARTIMENTOS BIOGEOQUÍMICOS DE LAGOAS NATURAIS RASAS DO CERRADO E SUAS INFLUÊNCIAS NO FUNCIONAMENTO ECOSSISTÊMICO
}

Elisa Araújo Cunha Carvalho Alvim

Orientadora: Profa. Dra. Mercedes Maria da Cunha Bustamante

Brasília - DF

Março de 2017. 

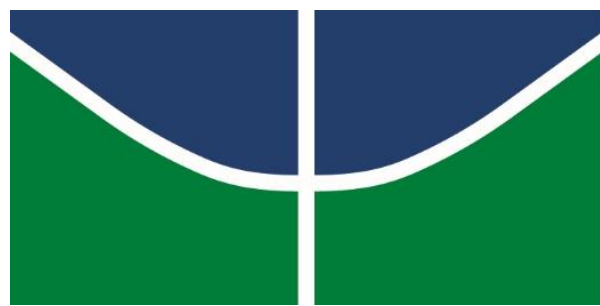

Universidade de Brasília

Instituto de Ciências Biológicas

Programa de Pós-Graduação em Ecologia

VARIAÇÕES SAZONAIS E ESPACIAIS DAS CONCENTRAÇÕES ELEMENTARES EM COMPARTIMENTOS BIOGEOQUÍMICOS DE LAGOAS NATURAIS RASAS DO CERRADO E SUAS INFLUÊNCIAS NO FUNCIONAMENTO ECOSSISTÊMICO

Elisa Araújo Cunha Carvalho Alvim

Orientadora: Profa. Dra. Mercedes Maria da Cunha Bustamante

Tese de Doutorado apresentada ao Programa de Pós-Graduação em Ecologia da Universidade de Brasília, como requisito para obtenção do título de Doutor em Ecologia.

Brasília - DF

Março de 2017. 
Ao combustivel da minha vida, mãe, irmãs e marido, com todo amor DEDICO! 
"O que tem de ser tem muita força."

(Guimarães Rosa) 


\section{Agradecimentos}

O encerramento de mais essa etapa me faz refletir sobre todos os caminhos, mesmo que às vezes tortuosos, que me trouxeram até aqui! Ao longo desses caminhos aprendi que ao atingir um objetivo, uma pessoa nunca luta sozinha, não sofre sozinha e não ganha sozinha. A colaboração de algumas pessoas foi essencial para que eu tivesse sucesso nessa árdua tarefa e merece a minha eterna gratidão!!!

A Deus, primeiramente, por guiar todos os meus passos e me dar forças para superar todas as dificuldades e por ter colocado todas essas pessoas em meu caminho!!!

A minha orientadora Prof. Dra. Mercedes Bustamante pelos aprendizados, ensinamentos, oportunidades, chamadas de atenção, além de sua orientação e suas contribuições durante mais uma etapa de minha formação acadêmica.

Às professoras Dra. Luciana de Mendonça Galvão, Dra. Bárbara Fonseca e Dra. Melina Guimarães por todas as discussões e desafios lançados que me motivaram a buscar respostas desse trabalho.

Ao prof. Dr. Mario Giordano por ter me recebido em seu laboratório na Università Politecnica delle Marche, Ancona - Itália, durante o período do doutorado sanduíche e por ter possibilitado as análises elementares desse trabalho.

Aos membros da banca examinadora, Dr. Plínio Camargo, Dra. Lourdes El-moor Loureiro, Dr. Geraldo Boaventura, Dr. Ludgero Vieira e Dr. Murilo Dias por terem aceitado o convite e pela leitura, sugestões e contribuições para um trabalho melhor.

Aos meus familiares pela cumplicidade, incentivo e imensurável amor! Enfim, por simplesmente ser a melhor família que eu poderia ter! Em especial, agradeço minha mãe, Ana Maria, pela disponibilidade incondicional e apoio nas horas difíceis! Com muito carinho, agradeço meu pai, Paulo, minhas irmãs, Olívia e Carol, meus primos/irmãos, Gui e Gabi, e meus avós, Hélcio e Clea, sempre presentes e agentes direto da minha formação pessoal.

Ao Diogo por estar ao meu lado em todos os momentos, pela paciência e por tornar meus dias, cada dia melhores. Obrigada pelo teu amor, meu mô da vida! Te amo elevado ao infinito!!!!! 
A minha família postiça: Lena, Anne, Favem, Faíne, tia Fafá e vozinha por todo o carinho e suporte! Em especial agradeço minha cumade, Anne, por ter me presenteado com a melhor função, a de madrinha da Bellinha!!

Aos meus amigos que sempre se fizeram presentes e que compartilharam comigo vários momentos de alegria, frustações, tristezas, angustias, medo, felicidade extrema, enfim... foram muitas emoções nesses últimos quatro anos (em ordem alfabética para evitar a confusão): Adriana, Amanda, Ana, Anne, Aurea, Beibinha, Bellinha, Binho, Caca, Cissa, Dani, Dieguito, Dudinha, Érica, Fábio, Gabi, Jimmy, João Paulo, Jhonantan, Joseph, Luciana, Nat, Paulinha, Queca, Ray, Regina, Renan, Taininha, Tiago, Tom, Vinícius e se eu me esqueci de alguém, me desculpa! Agradeço vocês por tudo e garanto que serão eternizados nas minhas memórias e na minha vida!!! Vocês sabem o quanto foram e continuam sendo importantes na minha caminhada!

À amiga, madrinha e eterna orientadora Dra. Luciana de Mendonça Galvão por nunca deixar de acreditar em mim e me apresentar às maravilhas do mundo da Limnologia. Além de me guiar nessa trajetória, saindo de comunidades bentônicas até alcançar os processos ecológicos! Com sua amizade e confiança aprendi a ser cientista!

Ao pessoal do laboratório de Ecologia da UCB pelo carinho, confiança e, principalmente, ajuda no campo! Sem vocês eu jamais conseguiria coletar tudo, além disso vocês faziam dos dias de campo momentos de descontração e sucesso: Luciana, Bárbara, Paloma, Gustavo D., Gustavo G., Deidson, Iara, Tatiane, Thalyta, Thamyres, Valter, Rebeca, Marcus, Lídia, Melina, Renan, Adriana. Além disso, gostaria de agradecer ao Felipe Prazeres, que ao decorrer desse trabalho, realizou iniciação científica com as diatomáceas das lagoas e me ajudou bastante nas coletas também!

Ao pessoal do laboratório de Ecologia de Ecossistemas por tornar meus dias de trabalho muito mais prazerosos e divertidos!! Muito obrigada pela convivência agradável e pelas excelentes horas de conversa: Francisco, Letícia, Rafa, Thiago, Sâmia, Maria, Davi, Lucas. Em especial a Regina pelas conversas, pelas dicas e por não permitir que eu surtasse ao longo do caminho, obrigada pela sua amizade!

Ao pessoal do laboratório de Fisiologia de algas da Università Politecnica delle Marche, Ancona - Itália, por tornar meus dias um pouco melhores, pelas discussões e pelos cafés para manter o foco: Min, Mari, Gio e Andrea. Em especial a Ale Norici por 
sempre ter um minuto para discutir meus dados e por todo o apoio emocional. Grazie mille a tutti!

Aos técnicos da UnB, Leandro e Wesley pela ajuda em campo e aos fiéis companheiros de campo, Vandélio e Mardônio, por saberem chegar em todos as lagoas sem GPS ou mapa!

Ao Gean e Prof. Jonatas Silva da Química da UCB pela ajuda nas análises de fósforo na água.

Ao pessoal do laboratório de Ecologia Isotópica no Centro de Energia Nuclear na Agricultura (CENA/USP) pelas análises isotópicas.

À Fundação de Apoio à Pesquisa do Distrito Federal (FAPDF), processo 193.000.567/2009, e ao Conselho Nacional de Desenvolvimento Científico e Tecnológico (CNPq), processo 312035/2013-6, pelos subsídios destinados ao desenvolvimento projeto.

Ao Instituto Chico Mendes de Conservação da Biodiversidade (ICMBio) e ao Instituto Brasília Ambiental (IBRAM) pela permissão concedida para amostragem no Parque Nacional de Brasília e Estação Ecológica de Águas Emendadas.

A todos os professores do programa de pós-graduação por todo o conhecimento ecológico transmitido e pela dedicação.

Ao Programa de Pós-Graduação em Ecologia da Universidade de Brasília pelo aperfeiçoamento profissional.

Ao Conselho Nacional de Desenvolvimento Científico e Tecnológico $(\mathrm{CNPq})$ e à Coordenação de Aperfeiçoamento de Pessoal de Nível Superior (CAPES) pela concessão da bolsa de doutorado.

A todos que, de alguma forma, contribuíram e auxiliaram na realização desse trabalho e a alguém que eventualmente posso ter esquecido.

\section{MUITO OBRIGADA!!!!!!!!}




\section{LISTA DE FigURAS}

\section{INTRODUČ̃̃O GERAL}

Figura 1. Mapa de localização das cinco lagoas naturais estudadas: Lagoa Bonita, localizadas na Estação Ecológica de Águas Emendadas (ESECAE), Lagoas do Exército e do Henrique localizadas no Parque Nacional de Brasília (PNB) e Lagoas Cabocla e Grande localizadas no Campo de Instrução de Formosa (CIF), com respectivas bacias hidrográficas (Paraná e São Francisco).

Figura 2. Distribuição da precipitação acumulada mensal em mm (indicada pelas linhas) e temperatura em ${ }^{\circ} \mathrm{C}$ (indicada pelas barras) durante o período de março de 2014 a setembro de 2015. Dados das estações do Parque Nacional de Brasília (83377), da Estação Ecológica de Águas Emendadas e de Formosa (83379) disponíveis pelo Instituto Nacional de Meteorologia (INMET, http://www.inmet.gov.br/portal/). 26

Figura 3. Lagoas naturais pertencentes à Bacia do Alto Rio Paraná, Distrito Federal. AB: Lagoa do Henrique, PNB; C-D: Lagoa do Exército, PNB; E-F: Lagoa Bonita, ESECAE.

Figura 4. Lagoas naturais pertencentes à Bacia do Rio São Francisco, Goiás. A: Imagem de satélite das duas lagoas naturais do Campo de Instrução de Formosa; B: Lagoa Cabocla; C: Lagoa Grande. 30

\section{CAPÍTUlo 1}

Figura 1. Distribuição da precipitação média mensal (mm) no período de janeiro de 1985 a dezembro de 2013 no Distrito Federal e Formosa (GO). Dados do Instituto Nacional de Meteorologia (INMET, http://www.inmet.gov.br/portal/) para as estações do Parque Nacional de Brasília (83377) e de Formosa (83379). As barras indicam o erro padrão.....39

Figura 2. Distribuição da precipitação acumulada mensal $(\mathrm{mm})$ no período de março de 2014 a março de 2015 no Parque Nacional de Brasília (PNB - DF), Estação Ecológica de Águas Emendadas (ESECAE - DF) e Campo de Instrução de Formosa (CIF - GO). Dados do Instituto Nacional de Meteorologia (INMET, http://www.inmet.gov.br/portal/). Setas vermelhas indicam os meses de coleta. 
Figura 3. Variação dos valores médios $(n=25, \pm \mathrm{EP})$ de temperatura da água $(\mathrm{A})$, oxigênio dissolvido (B), pH (C), turbidez (D), condutividade elétrica (E), clorofila-a (F) e matéria orgânica do sedimento $(G)$ nos períodos sazonais (transição chuva/seca, seca, transição seca/chuva e chuva) em cinco lagoas naturais rasas do Cerrado localizadas no Distrito Federal e em Goiás. Barras marcadas com a mesma letra não são significativamente diferentes $(\mathrm{p} \leq 0,05) \ldots$

Figura 4. Variação dos valores médios $(n=25, \pm \mathrm{EP})$ de formas de nitrogênio dissolvido (A-C) e total (D), fósforo total (E) e razão molar N:P (F) nos períodos sazonais (transição chuva/seca, seca, transição seca/chuva e chuva) em cinco lagoas naturais rasas do Cerrado localizadas no Distrito Federal e em Goiás. * amostras não analisadas. Barras marcadas com a mesma letra não são significativamente diferentes $(\mathrm{p} \leq 0,05)$

Figura 5. Concentração de carbono (A), nitrogênio (B), fósforo (C), Cálcio (D) e potássio (E) nos compartimentos macrófitas aquáticas, perifíton e sedimento nos períodos sazonais (transição chuva/seca, seca, transição seca/chuva e chuva) nas lagoas naturais rasas do Cerrado: Lagoa do Henrique (PNB-DF), Lagoa do Exército (PNB-DF), Lagoa Bonita (ESECAE-DF), Lagoa Cabocla (CIF-GO) e Lagoa Grande (CIF-GO). 51

Figura 6. Análise de componentes principais da concentração de carbono, nitrogênio, fósforo, cálcio e potássio nos compartimentos macrófitas aquáticas, perifíton e sedimento nas lagoas naturais rasas do Cerrado: Lagoa do Henrique (PNB-DF), Lagoa do Exército (PNB-DF), Lagoa Bonita (ESECAE-DF), Lagoa Cabocla (CIF-GO) e Lagoa Grande (CIF-GO) .52

Figura 7. Razão molar C:N (A), C:P (B) e N:P (C) dos compartimentos macrófitas aquáticas, perifíton e sedimento nos períodos sazonais (transição chuva/seca, seca, transição seca/chuva e chuva) nas lagoas naturais rasas do Cerrado: Lagoa do Henrique (PNB-DF), Lagoa do Exército (PNB-DF), Lagoa Bonita (ESECAE-DF), Lagoa Cabocla (CIF-GO) e Lagoa Grande (CIF-GO) .55

Figura 8. Estoque de nitrogênio (A) e fósforo (B) em $\mathrm{mg} / \mathrm{m}^{2}$ nos compartimentos macrófitas aquáticas e perifíton nos períodos sazonais (transição chuva/seca, seca, transição seca/chuva e chuva) nas lagoas naturais rasas do Cerrado: Lagoa do Henrique (PNB-DF), Lagoa do Exército (PNB-DF), Lagoa Bonita (ESECAE-DF), Lagoa Cabocla (CIF-GO) e Lagoa Grande (CIF-GO) . .56 


\section{CAPÍTULO 2}

Figura 1. Unidades geológicas do Parque Nacional de Brasília (PNB), sem a extensão referente a área da APA da Cafuringa. Fonte: CPRM.

Figura 2. Unidades geológicas da Estação Ecológica de Águas Emendadas (ESECAE). Fonte: CPRM.

Figura 3. Unidades geológicas do Campo de Instrução de Formosa - GO (CIF-GO). Fonte: CPRM

Figura 4. Concentração ( $\mu \mathrm{g} / \mathrm{g}$ PS) de alumínio (A), chumbo (B), titânio (C), cromo (D) e ferro (E) nos compartimentos macrófitas aquáticas, perifíton e sedimento nas duas bacias hidrográficas estudadas (Paraná e São Francisco) em lagoas rasas do Distrito Federal e Goiás agrupadas por bacia hidrográfica estudada (Paraná: Lagoas do Henrique, Exército e Bonita e São Francisco: Lagoas Cabocla e Grande).

Figura 5. Concentração de níquel ( $\mu \mathrm{g} / \mathrm{g}$ PS) nos compartimentos macrófitas aquáticas (A), perifíton (B) e sedimento (C) nos períodos sazonais (transição chuva/seca, seca, transição seca/chuva e chuva) nas duas bacias hidrográficas estudadas (Paraná - boxplot claro e São Francisco - boxplot escuro) em lagoas rasas do Distrito Federal e Goiás agrupadas por bacia hidrográfica estudada (Paraná - boxplot claro: Lagoas do Henrique, Exército e Bonita e São Francisco - boxplot escuro: Lagoas Cabocla e Grande). .78

Figura 6. Concentração ( $\mu \mathrm{g} / \mathrm{g}$ PS) de manganês (A), cobre (B) e zinco (C) nos compartimentos macrófitas aquáticas, perifíton e sedimento nos períodos sazonais (transição chuva/seca, seca, transição seca/chuva e chuva) em lagoas rasas do Distrito Federal e Goiás

\section{CAPÍtulo 3}

Figura 1. Localização da Lagoa do Henrique no Parque Nacional de Brasília, Distrito Federal, Brasil. a) Destaque para a zona de coleta de macrófitas aquáticas na lagoa........93

Figura 2. Assinatura isotópica de carbono $\left(\delta^{13} \mathrm{C}\right)$ das fontes alimentares macrófita emergente Cyperus sp., macrófita submersa Cabomba sp. e perifíton da Lagoa do Henrique, Parque Nacional de Brasília, Distrito Federal, Brasil. Box-plot com letras diferentes são estatisticamente diferentes $\alpha=0,05$ 
Figura 3. Comparação da clorofila-a do perifíton (A), massa seca livre de cinzas do perifíton (B) associado às macrófitas, biomassa das macrófitas aquáticas Cyperus sp. e Cabomba sp. (C) e razão C:N das fontes alimentares macrófita emergente Cyperus sp., macrófita submersa Cabomba sp. e perifíton associado (D) da Lagoa do Henrique, Parque Nacional de Brasília, Distrito Federal. Barras indicam o erro padrão.

Figura 4. Contribuição relativa das fontes alimentares macrófita emergente Cyperus sp., macrófita submersa Cabomba sp. e perifíton para os invertebrados aquáticos da Lagoa do Henrique, Parque Nacional de Brasília, Distrito Federal 104

Figura 5. Assinaturas isotópica de carbono $\left(\delta^{13} \mathrm{C}\right)$ e nitrogênio $\left(\delta^{15} \mathrm{~N}\right)$ da fauna associada e valores isotópicos médios de macrófita emergente (Cyperus sp.), macrófita submersa (Cabomba sp.) e perifíton da Lagoa do Henrique, Parque Nacional de Brasília, Distrito Federal, Brasil. Barras = desvio-padrão; $\mathrm{CG}=$ Coletores-Catadores, $\mathrm{Pr}=$ Predadores, $\mathrm{Sc}=$ Raspadores 105

Figura 6. Áreas de elipse padrão (SEA, linhas contínuas), representando o espaço do nicho isotópico central dos grupos tróficos da fauna associada, conforme determinado por modelos SIBER para a Lagoa do Henrique, Parque Nacional de Brasília, Distrito Federal, Brasil. As linhas tracejadas delimitam a área total dos conjuntos da fauna associada.....106 


\section{LiSTA DE TABELAS}

\section{INTRODUČ̃̃O GERAL}

Tabela 1. Características gerais das cinco lagoas naturais estudadas, nas bacias do Paraná, Distrito Federal, e São Francisco, Goiás. PNB: Parque Nacional de Brasília; ESECAE: Estação Ecológica de Águas Emendadas; CIF: Campo de Instrução de Formosa............26

\section{CAPÍtulo 1}

Tabela 1. Características gerais das cinco lagoas naturais estudadas, nas bacias do Paraná, Distrito Federal, e São Francisco, Goiás. PNB: Parque Nacional de Brasília; ESECAE: Estação Ecológica de Águas Emendadas; CIF: Campo de Instrução de Formosa .40

Tabela 2. Valores médios e, entre parênteses, coeficiente de variação das variáveis limnológicas das lagoas naturais rasas do Cerrado localizadas no Distrito Federal e em Goiás durante abril de 2014 a março de 2015. * indicam que as amostras não foram analisadas.

Tabela 3. Resultados dos modelos generalizados com efeito misto para avaliar se as concentrações de C, N, P, Ca e K; as razões molares e os estoques de N e P variam entre os compartimentos em função da sazonalidade nas lagoas naturais rasas do Cerrado: Lagoa do Henrique (PNB-DF), Lagoa do Exército (PNB-DF), Lagoa Bonita (ESECAEDF), Lagoa Cabocla (CIF-GO) e Lagoa Grande (CIF-GO).

Tabela 4. Razões molares médias $(\mathrm{C}: \mathrm{N}: \mathrm{P})$ dos compartimentos macrófitas aquáticas, perifíton e sedimento nos períodos sazonais nas lagoas naturais rasas do Cerrado: Lagoa do Henrique (PNB-DF), Lagoa do Exército (PNB-DF), Lagoa Bonita (ESECAE-DF), Lagoa Cabocla (CIF-GO) e Lagoa Grande (CIF-GO)

\section{CAPítulo 2}

Tabela 1. Espécies de macrófitas aquáticas encontradas nas lagoas naturais rasas estudadas nas duas bacias hidrográficas Paraná e São Francisco. Os dados foram obtidos dos seguintes estudos: Guedes et al., 2011; Sousa, 2012; observação pessoal. . .75 
Tabela 2. Resultados dos modelos generalizados com efeito misto para avaliar se as concentrações dos elementos variam entre os compartimentos em função da bacia hidrográfica e sazonalidade em lagoas naturais rasas do Cerrado. .80

Tabela 3. Concentração média dos elementos ( $\mu \mathrm{g} / \mathrm{g}$ PS) em cada compartimento avaliado (macrófita, perifíton e sedimento) nas duas bacias hidrográficas estudadas (Alto Rio Paraná e São Francisco) do Distrito Federal e Goiás .84

\section{CAPÍTULO 3}

Tabela 1. Valores médios e erro padrão das variáveis limnológicas da Lagoa do Henrique, Parque Nacional de Brasília, Distrito Federal, Brasil, durante as estações chuvosa e seca de 2015 .

Tabela 2. Valores de $\delta^{13} \mathrm{C}$ e $\delta^{15} \mathrm{~N}$ das macrófitas aquáticas coletadas na Lagoa do Henrique, Parque Nacional de Brasília, Distrito Federal, Brasil.

Tabela 3. Resultados estatísticos relacionados às assinaturas isotópicas dos recursos alimentares entre os períodos sazonais seca e chuva na Lagoa do Henrique, Parque Nacional de Brasília, Distrito Federal, Brasil

Tabela 4. Abundância média e erro padrão dos táxons encontrados associados às macrófitas aquáticas Cyperus sp. e Cabomba sp. na Lagoa do Henrique, Parque Nacional de Brasília, Distrito Federal, Brasil, durante as estações chuvosa e seca de 2015. 102

Tabela 5. Média e desvio padrão (DP) dos valores de $\delta^{13} \mathrm{C}$ e $\delta^{15} \mathrm{~N}$ dos táxons da fauna associada às macrófitas na Lagoa do Henrique, Parque Nacional de Brasília, Distrito Federal, Brasil. N= número de amostras, GTF= grupo trófico funcional, segundo Ramírez \& Gutiérrez-Fonseca (2014). CG = Coletores-Catadores, $\operatorname{Pr}=$ Predadores, $\mathrm{Sc}=$ Raspadores 105

Tabela 6. Comparação do range de $\delta^{13} \mathrm{C}(\%)$ e $\delta^{15} \mathrm{~N}(\%)$ das fontes alimentares entre estudos em ambientes tropicais e o presente estudo 108 


\section{SUMÁRIO}

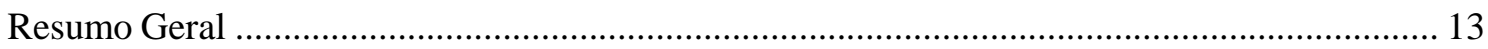

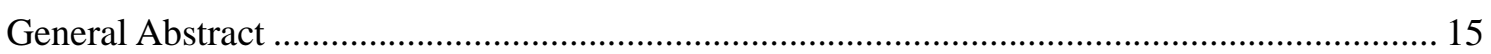

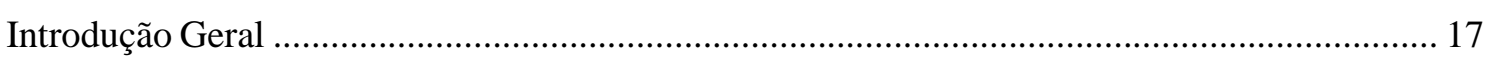

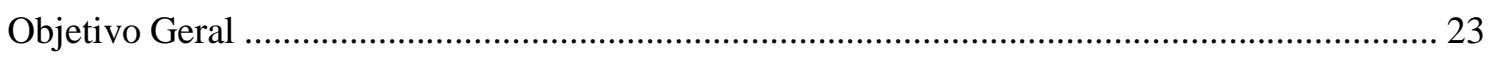

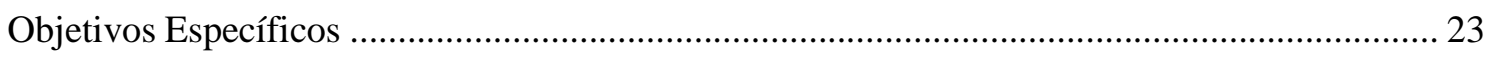

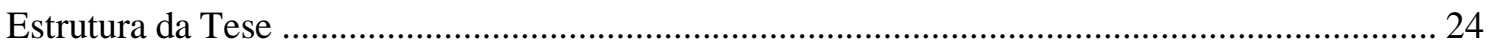

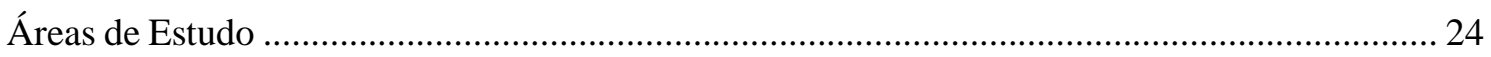

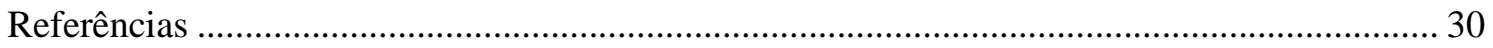

Capítulo 1 - Variações sazonais das concentrações de macronutrientes em compartimentos biogeoquímicos de lagoas naturais rasas do Cerrado

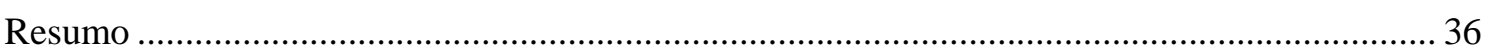

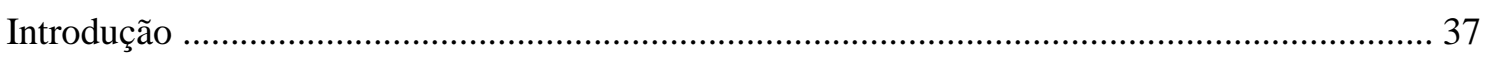

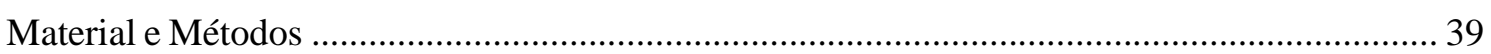

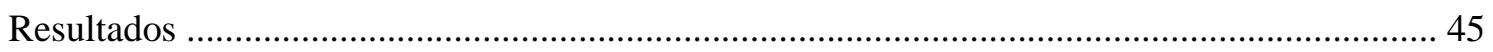

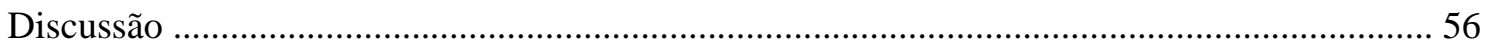

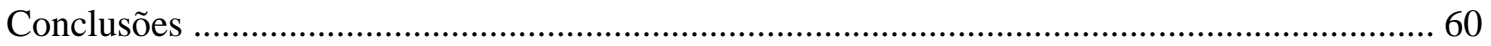

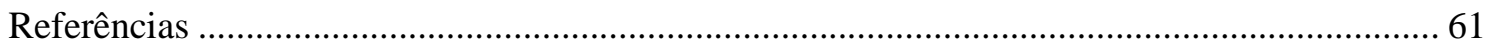

Capítulo 2 - Concentrações de elementos-traço em lagoas naturais rasas: relação entre compartimentos e bacias hidrográficas

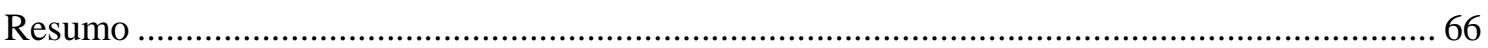

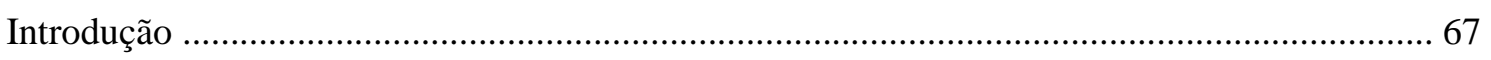

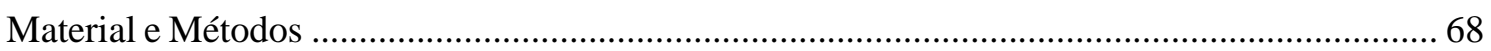

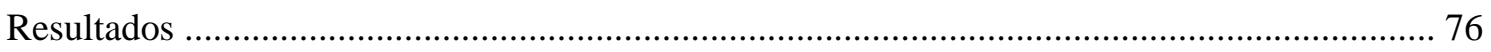

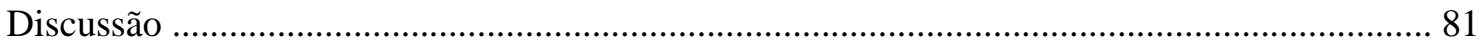

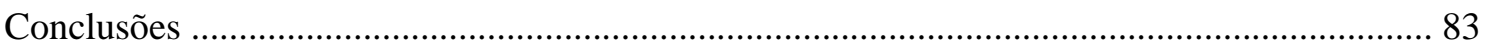

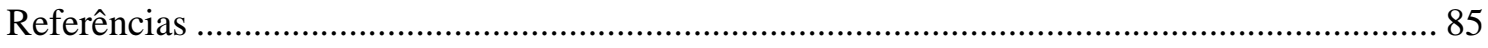

Capítulo 3 - Relações tróficas entre produtores primários e fauna associada em uma lagoa prístina do Cerrado do Brasil Central

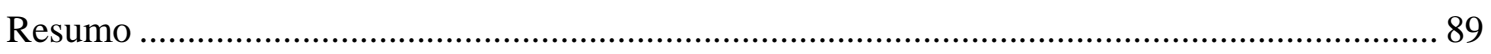

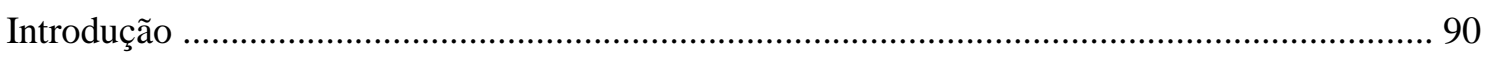

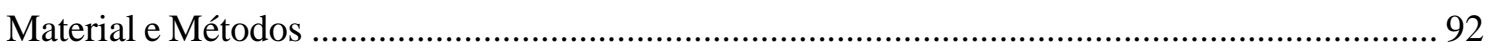

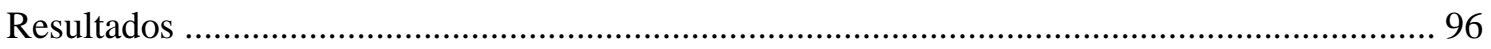

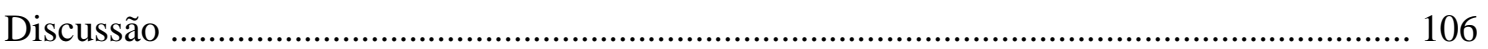

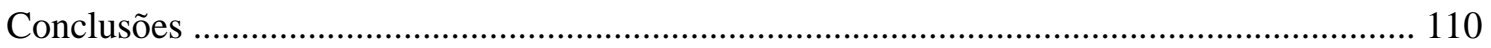

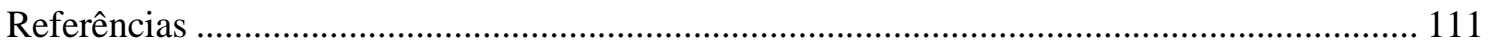

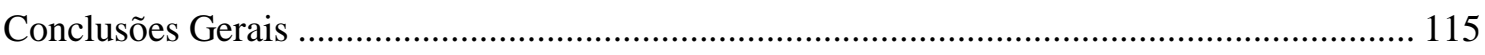




\section{RESUMO GERAL}

Sistemas lênticos pequenos e rasos acabam por constituir áreas de interação intensa entre meio terrestre e aquático, atuando como zona de ecótono similar à zona litorânea de grandes lagos. Os ecossistemas aquáticos do Cerrado são caracterizados por águas levemente ácidas e pobres em nutrientes, mas apresentam uma elevada diversidade biológica. Avaliar os compartimentos biogeoquímicos (sedimento, coluna d'água e biomassa) que compõem tais ecossistemas do Cerrado e como os nutrientes se distribuem e são transferidos é fundamental para o entendimento de seu funcionamento. O objetivo geral do presente estudo foi investigar a relação entre as concentrações elementares em diferentes compartimentos (macrófitas aquáticas, perifíton e sedimento) de cinco lagoas oligotróficas naturais do Cerrado e o papel das macrófitas aquáticas e do perifíton no fluxo de nutrientes e interações tróficas ao longo da cadeia alimentar, considerando a variação sazonal. As lagoas do Henrique, do Exército e Bonita pertencem à Bacia hidrográfica do Alto Rio Paraná, e as lagoas Cabocla e Grande pertencem à Bacia hidrográfica do São Francisco. A concentração de carbono e potássio foi maior nas macrófitas aquáticas, enquanto que a concentração de nitrogênio do perifíton foi o dobro das concentrações dos outros compartimentos em todos os períodos sazonais. Entre os compartimentos, a concentração de fósforo e cálcio também foi maior no perifíton. As macrófitas aquáticas apresentaram os maiores valores para a razão molar C:N e C:P, já a razão N:P foi maior no sedimento. As razões molares indicaram limitação por fósforo em todos os compartimentos. As macrófitas aquáticas podem ser consideradas uma fonte a longo prazo de nutrientes $(\mathrm{C}, \mathrm{N}$ e $\mathrm{P})$, enquanto o perifíton apresenta uma dinâmica mais lábil para esses nutrientes. As concentrações dos elementos $\mathrm{Al}, \mathrm{Pb}, \mathrm{Ti}, \mathrm{Cr}$ e $\mathrm{Fe}$ apresentaram diferença significativa entre as lagoas das duas bacias hidrográficas estudadas, enquanto as concentrações de $\mathrm{Mn}, \mathrm{Cu}$ e $\mathrm{Zn}$ variaram sazonalmente, mas sem diferenças significativas entre as lagoas das duas bacias. Grande parte desses elementos apresentou maiores concentrações na bacia do Paraná e as diferenças são mais evidentes entre os compartimentos macrófitas aquáticas e perifíton. As comunidades de macrófitas apresentam pouca similaridade entre as lagoas das duas bacias o que pode estar associado às diferenças nas concentrações de elementos-traço. Os valores de $\delta^{13} \mathrm{C}$ permitiram separar as macrófitas em função de seu hábito de vida (emergente x submersa) assim como o perifíton. As assinaturas isotópicas de $\mathrm{C}$ e $\mathrm{N}$ das fontes não apresentaram diferença significativa entre os períodos de chuva e seca. O perifíton predominou como 
principal fonte de alimento para a fauna associada, com contribuição média de $63 \%$, enquanto a macrófita emergente e a submersa contribuíram com $31 \%$ e $6 \%$, respectivamente. A macrófita submersa apresentou maior abundância de fauna associada e biomassa de algas (clorofila-a) quando comparada a macrófita emergente, mas não apresentou contribuição significativa para a teia trófica da lagoa. Essa macrófita pode ter um papel como abrigo e refúgio contribuindo para a estrutura física do ecossistema aquático. Esses ambientes tão peculiares do Cerrado têm recebido pouca atenção e o presente estudo permitiu o aprofundamento do conhecimento acerca de seu funcionamento biogeoquímico e das relações entre diferentes componentes da cadeia trófica.

Palavras-chave: estequiometria ecológica, elementos-traço, nutrientes, isótopos estáveis, sazonalidade, cadeias tróficas, savanas, sistemas lênticos 


\section{General AbStract}

Small and shallow lentic ecosystems present intense interaction between terrestrial and aquatic environments, acting as an ecotone, similarly to the coastal zone of deep lakes. Slightly acidic and oligotrophic waters characterize aquatic ecosystems of Cerrado. These ecosystems also shelter high biological diversity. The evaluation of the biogeochemical compartments (sediment, water column, and biomass) of oligotrophic aquatic ecosystems of the Cerrado is fundamental in order to understand how the nutrients are distributed and transferred and the potential influences on ecosystem functioning. The general objective of this study was to investigate the concentrations of elements within three compartiments (aquatic macrophytes, periphyton and sediment) of five natural oligotrophic ponds of Cerrado. We also investigated the role of the aquatic macrophytes and periphyton in the nutrient fluxes and trophic interactions along the food web, considering the seasonal variation of precipitation. The Henrique, Exército and Bonita ponds belong to the Upper Paraná River Basin, and the Cabocla and Grande ponds belong to the São Francisco River Basin. Carbon and potassium concentrations were highest in the aquatic macrophytes, while nitrogen, phosphorus and calcium concentrations were highest in the periphyton. The aquatic macrophytes exhibited the highest values of $\mathrm{C}: \mathrm{N}$ and $\mathrm{C}: \mathrm{P}$ molar ratios, while $\mathrm{N}: \mathrm{P}$ highest values were found in the sediment. The molar ratios indicated that all compartments are limited by phosphorus. Aquatic macrophytes can be considered a more recalcitrant source of nutrients $(\mathrm{C}, \mathrm{N}$ and $\mathrm{P})$, while the periphyton are more labile. The concentrations of the elements $\mathrm{Al}, \mathrm{Pb}, \mathrm{Ti}, \mathrm{Cr}$ and $\mathrm{Fe}$ differed significantly between the ponds of the two hydrological basins; while concentrations of $\mathrm{Mn}, \mathrm{Cu}$ and $\mathrm{Zn}$ varied seasonally but not as a function of the basin. Most of these elements showed the highest concentrations in the Paraná River Basin, and differences are more striking for aquatic macrophytes and periphyton compartments. Macrophyte communities have little similarity between ponds of the two basins, which may be associated with differences in trace element concentrations. The $\delta^{13} \mathrm{C}$ values separated the macrophytes according to their life habits (emergent vs. submerged). $\mathrm{C}$ and $\mathrm{N}$ isotopic signatures of the sources did not differ differences seasonally. Periphyton predominated as the main food source for the associated fauna, with an average contribution of $63 \%$, while the emergent and submerged macrophytes contributed with $31 \%$ and $6 \%$, respectively. Submerged macrophytes exhibited greater abundance of associated fauna and algal biomass (chlorophyll-a) when compared to emergent macrophytes, but did not significantly contribute to trophic web. This macrophyte can play a role as a shelter and refuge 
contributing to the physical structure of the aquatic ecosystem. These environments, which are so peculiar to the Cerrado, have received little attention and the present study indicated relevant aspects of their biogeochemical functioning and trophic relations.

Keywords: ecological stoichiometry, trace elements, nutrients, stable isotopes, seasonality, trophic web, savannas, lentic systems 


\section{INTRODUÇÃO GERAL}

Na região central do Brasil, é possível encontrar transições abruptas de formações savânicas para ambientes aquáticos como campos úmidos e lagoas naturais, que estão associados ao afloramento subterrâneo de água e flutuação do lençol freático (OliveiraFilho et al., 1989). Os ecossistemas aquáticos do Cerrado são caracterizados por águas levemente ácidas, com baixa condutividade elétrica e pobres em nutrientes, mas apresentam uma elevada diversidade biológica (Fonseca et al., 2014). Nesses ambientes de água normalmente muito transparente, a luz solar alcança o fundo, o que permite o crescimento de macrófitas aquáticas em toda a área das lagoas. A arquitetura e forma de vida das macrófitas representam componentes importantes conferindo heterogeneidade a esses ambientes, aumento da taxa de colonização e a diversidade local, com influência no metabolismo desses ambientes aquáticos (Santos et al., 2013).

Sistemas lênticos pequenos e rasos acabam por constituir áreas de interação intensa entre meio terrestre e aquático, atuando como zona de ecótono similar à zona litorânea, mas em toda sua extensão. Nesse sentido, as macrófitas aquáticas e o perifíton podem desempenhar um importante papel no metabolismo do sistema em função de sua grande contribuição para produtividade primária (Wetzel, 2001). Além disso, lagoas rasas representam sistemas dinâmicos em termos de ciclagem de nutrientes e conservação da biodiversidade (Thomaz \& Esteves, 2011).

O funcionamento de um ecossistema muitas vezes depende do recurso em menor disponibilidade, conceito chamado de lei do mínimo de Liebig (Odum \& Barret, 2007). A aplicação deste conceito parte de dois princípios: 1) as condições devem ser relativamente estáveis, ou seja, os fluxos médios de entrada de energia e matéria equilibram os fluxos de saída; e 2) a ação de algum fator que não seja o constituinte mínimo pode modificar a taxa de uso do fator limitante. Em ambientes aquáticos, por exemplo, a produção primária pode ser limitada por fatores como luz (considerando o efeito da atenuação vertical), carbono inorgânico e nutrientes minerais (Lampert \& Sommer, 1997). Estes últimos são usualmente divididos de acordo com as quantidades requeridas; aqueles que correspondem a $>0,1 \%$ da matéria orgânica são considerados macroelementos (N, P, S, K, Mg, Ca), enquanto aqueles utilizados em menor quantidade são chamados de elementos traços (Fe, Mn, Cu, Zn, B, Mo, V, Co). Na maioria dos lagos, os nutrientes limitantes em geral se restringem a N, P, alguns elementos traços e Si (este 
último referente, em especial, limitante a algas diatomáceas e crisofíceas) (Lampert \& Sommer, op. cit.).

O carbono é incorporado na biomassa das macrófitas aquáticas e algas, que compõem o perifíton, por meio da fotossíntese e funciona como esqueleto das estruturas bioquímicas das biomoléculas (Esteves et al., 2011). O nitrogênio é essencial para o metabolismo e síntese de biomoléculas-chave como proteínas e aminoácidos (Esteves \& Amado, 2011). Já o fósforo participa de processos fundamentais nos seres vivos, tais como: armazenamento de energia, estruturação da membrana celular, transferência da informação genética e metabolismo celular (Ferreira et al., 2005).

Nos ecossistemas aquáticos, a entrada de carbono orgânico ocorre, principalmente, por meio de processos biológicos de decomposição da matéria orgânica alóctone e da produção autóctone local (Thorp \& Delong, 1994; Amado et al., 2007). Apenas uma pequena fração do carbono total presente no ambiente aquático é suscetível a entrar nas cadeias alimentares aquáticas, pois, a maioria é formado por complexas moléculas estruturais, não palatáveis para os consumidores (Thorp \& Delong, 2002). Além disso, parte desse carbono não está disponível e outros fatores impedem o acesso a ele. Sob condições de elevadas concentrações de nutrientes, espera-se que apenas uma comunidade de produtores primários em lagos - macrófitas aquáticas ou fitoplâncton, domine o ambiente, por outro lado, ambientes oligotróficos possuem elevada diversidade de fontes de carbono para os consumidores: macrófitas aquáticas, perifíton, microflora no sedimento, material alóctone e fitoplâncton (Peckham et al., 2006; Jaschinski et. al., 2011).

Embora o $\mathrm{pH}$ relativamente baixo, normalmente encontrado nos ambientes aquáticos do Cerrado, favoreça a presença do $\mathrm{C}$ na forma de $\mathrm{CO}_{2}$, as temperaturas relativamente elevadas, por outro lado, potencializam sua difusão para a atmosfera. Desta forma, tem-se o ambiente propício para uma severa limitação por carbono na água, pois o pH ácido não favorece a manutenção de reservas de carbono inorgânico na forma de $\mathrm{HCO}_{3}{ }^{-}$ou $\mathrm{CO}_{3}{ }^{2-}$ (Maberly \& Madsen, 1998; Maberly et al., 2009).

A atividade geológica da enorme malha hidrográfica brasileira é responsável pela formação da maioria dos lagos brasileiros, que são, geralmente, ecossistemas pequenos e rasos (Esteves, 2011). Em ambientes de água doce, as concentrações diluídas de compostos alcalinos e alcalino-terrosos, em particular carbonatos, bicarbonatos, sulfatos 
e cloretos, constituem a maior parte da porção iônica desses ambientes (Wetzel, 2001). As concentrações desses compostos são influenciadas pela geologia, transporte pelas bacias hidrográficas, deposição atmosférica de atividades naturais e humanas e trocas entre água e sedimento (Wetzel, 2001). Os ambientes aquáticos naturais do Cerrado são tipicamente caracterizados por suas águas transparentes, levemente ácidas, pobres em nutrientes e com baixíssima condutividade elétrica, em geral, inferior a $10 \mu \mathrm{S} / \mathrm{cm}$ (Fonseca et al., 2014).

Nos ecossistemas lênticos, a produção primária é principalmente autóctone e é realizada pelas macrófitas aquáticas e perifíton. O perifíton é considerado um biofilme que se desenvolve na superfície de qualquer substrato submerso, vivo ou morto (Wetzel, 2001). São componentes desse biofilme algas de todas as classes taxonômicas, as quais podem corresponder a cerca de 95 a 99\% de todo o perifíton (Fernandes \& Esteves, 2011). Além disso, há muitos componentes heterotróficos nessa comunidade, como, por exemplo, protozoários, fungos, bactérias e microinvertebrados. A comunidade perifítica é considerada um dos principais produtores primários nos ecossistemas aquáticos continentais rasos (tanto lênticos quanto lóticos), além de ser o principal local de deposição de carbono orgânico, tendo importante papel na mineralização da matéria orgânica dissolvida e na ciclagem de nutrientes (Vadeboncoeur \& Steinman, 2002). Metabolismo, crescimento e produção primária da comunidade perifítica são controlados por vários fatores limitantes, entre eles destacam-se: 1) aquisição de recursos como luz e nutrientes; 2) uso de recursos obtidos de fontes bióticas ou abióticas; 3 ) reciclagem interna de nutrientes entre as algas e a microbiota associada (Wetzel, 2001).

Um dos pontos chave no desenvolvimento do perifíton é o tipo de substrato que colonizam, alguns autores ressaltam o papel das macrófitas aquáticas como principais locais de colonização (O’Farrel et al., 2009; Søndergaard et al., 2010). Os estudos que abordam a interação macrófita/perifíton apresentam resultados contraditórios. Alguns estudos relatam que ocorre competição por nutrientes e que algumas macrófitas aquáticas podem liberar substâncias alelopáticas que afetam negativamente o desenvolvimento do perifíton (Ervin \& Wetzel, 2003; Gross et al., 2003), enquanto outros afirmam que as macrófitas são fontes de nutrientes, principalmente fósforo (Burkholder \& Wetzel, 1990; Guariento et al., 2009). Além disso, as macrófitas podem servir de abrigo para o zooplâncton e macroinvertebrados que se alimentam do perifíton (Jeppesen et al., 1997; 
Thomaz \& Cunha, 2010), ou simplesmente são áreas de colonização e não interferem na composição química da comunidade perifítica (Cattaneo \& Kalff, 1979).

As macrófitas aquáticas incluem espécies de grupos taxonômicos distintos, desde algas (e.g. carofíceas), além de musgos, samambaias e angiospermas (Chambers et al., 2008). As macrófitas influenciam ecossistemas aquáticos de diversas formas e determinam sua estrutura e funcionamento. Esse grupo afeta as características físicas e químicas da água e do sedimento, influencia a ciclagem de nutrientes, representa uma fonte de matéria orgânica para os organismos aquáticos e, principalmente, altera a estrutura espacial dos ecossistemas aquáticos pelo aumento da complexidade espacial dos habitats (Thomaz \& Esteves, 2011).

A produção primária das macrófitas aquáticas é controlada por uma série de fatores limitantes, entre eles: temperatura, radiação fotossinteticamente ativa, variação do nível da água, nutrientes e disponibilidade de carbono inorgânico (Camargo et al., 2003). As macrófitas, principalmente as espécies enraizadas, podem influenciar o estado nutricional do perifíton, uma vez que podem funcionar como uma bomba, mobilizando os nutrientes a partir do sedimento, em contraste com o perifíton que não absorve os nutrientes estocados no sedimento (Hansson, 1992). Contudo, Cattaneo \& Kallf (1979) demonstraram que a contribuição dos nutrientes das macrófitas não foi significativa para o perifíton. Por outro lado, Burkholder \& Wetzel (1990) apontaram as macrófitas como fonte extra de nutrientes para a comunidade perifítica. Dessa forma, entender melhor a relação macrófita/perifíton ainda é uma questão em aberto, principalmente em ambientes tropicais, e implica no maior entendimento do funcionamento dos ecossistemas rasos.

Como mencionado anteriormente, as macrófitas aquáticas podem servir como abrigo para a fauna fitófila. Tais comunidades apresentam diferentes papeis funcionais tróficos, desde herbívoros, utilizando algas perifíticas, até detritívoros, utilizando detritos fornecidos pelas macrófitas aquáticas. A comunidade de macroinvertebrados fitófilos pode ser formada por insetos (larvas e ninfas), além de moluscos, anelídeos e platelmintos, entre outros. Essa comunidade apresenta muitas adaptações comportamentais e morfológicas, com destaque para a diversidade de grupos tróficos (e.g., coletores-filtradores, coletores-catadores, raspadores, predadores, fragmentadores herbívoros e fragmentadores detritívoros; Cummins et al., 2005). Já a microfauna fitófila tem como componentes principais microcrustáceos e rotíferos. Os microcrustáceos são representados pelos cladóceros, copépodos e ostrácodes que, em geral, são raspadores do 
perifíton, sobretudo os cladóceros das famílias Chydoridae, Eurycercidae e Macrothricidae (Fryer, 1968; 1974). Os rotíferos, por sua vez, são separados em dois grupos funcionais: organismos micrófagos filtradores e organismos raptoriais (Obertegger \& Manca, 2011).

Para compreender processos importantes nos ecossistemas muitas ferramentas têm sido utilizadas, sobretudo em função da complexidade e das propriedades emergentes de cada nível de organização biológica envolvido nesses processos, e uma abordagem importante é a estequiometria ecológica (Sterner \& Elser, 2002). Em 1934, Redfield realizou e publicou o primeiro trabalho sobre esse tema onde propôs a razão N:P do plâncton e da água dos oceanos de 16:1. Em um outro trabalho o autor propôs a razão $\mathrm{C}: \mathrm{N}: \mathrm{P}$ de 106:16:1 (razão de Redfield; razão molar) considerando as medidas da composição elementar do plâncton e do teor de $\mathrm{NO}_{3}{ }^{-} \mathrm{e} \mathrm{PO}_{4}{ }^{3-}$ da água do oceano Atlântico (Redfield et al., 1963). Diversos organismos podem apresentar diferenças nas razões $\mathrm{C}: \mathrm{N}: \mathrm{P}$; assim, a razão de Redfield não é um valor universalmente ótimo, mas representa uma média para diversos grupos de fitoplâncton marinho que crescem sob uma variedade de condições, aplicando diferentes estratégias de crescimento (Klausmeier et al., 2004).

Segundo Giordano (2013), a estequiometria celular parece revelar uma tendência à homeostase entre diferentes ambientes ou diferentes táxons. De acordo com este autor, já existem conjuntos de dados com um grande número de elementos químicos e ampla cobertura filogenética especialmente para algas marinhas e para as porções aéreas de plantas herbáceas (fanerógamas), que revelam razões estáveis entre os principais elementos constituintes dos organismos vivos, C:N:P. Por exemplo, a razão elementar atômica média registrada para 15 espécies de fitoplâncton marinho mantidas em cultura sob condições satisfatórias de nutrientes (ou seja, sem limitações) foi de: $\left.\mathrm{C}_{124} \mathrm{~N}_{16} \mathrm{P}_{1} \mathrm{~S}_{1,3} \mathrm{~K}_{1,7} \mathrm{Mg}_{0,56} \mathrm{Ca}_{0,5}\right)_{1000} \mathrm{Sr}_{0,5} \mathrm{Fe}_{7,5} \mathrm{Mn}_{3,5} \mathrm{Zn}_{0,8} \mathrm{Cu}_{0,38} \mathrm{Co}_{0,19} \mathrm{Cd}_{0,21} \mathrm{Mo}_{0,03}$. Ou seja, a razão C:N:P de 124:16:1 é bem próxima a de Redfield. Com exceção de um maior conteúdo relativo de $\mathrm{C}$, a estequiometria das plantas terrestres não é diferente. De acordo com revisão feita pelo autor supracitado, a razão elementar atômica média registrada para os ramos de plantas herbáceas terrestres com flores foi de $\left.\mathrm{C}_{144} \mathrm{~N}_{17} \mathrm{P}_{1} \mathrm{~S}_{0,86} \mathrm{~K}_{5,1} \mathrm{Mg}_{0,6} \mathrm{Ca}_{1,24}\right)_{1000} \mathrm{Sr}_{4} \mathrm{Fe}_{6,4} \mathrm{Mn}_{14} \mathrm{Zn}_{2,6} \mathrm{Cu}_{6,4} \mathrm{Co}_{0,01} \mathrm{Cd}_{0,12} \mathrm{Mo}_{0,16}, \quad$ ou seja, $\mathrm{C}: \mathrm{N}: \mathrm{P}$ de $144: 17: 1$.

A composição elementar dos organismos reflete a composição macromolecular das células (proteínas, carboidratos e lipídeos) que, por sua vez, reflete a integração dos 
diferentes processos envolvidos na absorção e assimilação de nutrientes (Sterner \& Elser, 2002). Nas algas, a limitação por nitrogênio geralmente resulta na diminuição do conteúdo de proteína e aumento do armazenamento de carboidratos e lipídeos, enquanto que a limitação por fósforo pode levar a maiores proporções de proteínas (Beardall et al., 2001). Por outro lado, os animais tendem a ter composições elementares muito mais homeostáticas e as diferenças encontradas estão associadas com as alterações intraespecíficas das características corporais (Sterner \& Elser, 2002).

Além da estequiometria ecológica, estudos sobre processos ecossistêmicos em ambientes terrestres e aquáticos têm utilizado a distribuição natural dos isótopos estáveis. Eles podem ser utilizados para compreender as vias fotossintéticas e processos fisiológicos em plantas, em estudos de migrações, na determinação da origem do alimento para os consumidores em teias tróficas, na determinação de fontes de poluição, entre outros (Martineli et al., 1988; Hobson \& Wassenaar, 1999; Fry, 2006).

A assimilação de carbono por plantas terrestres do tipo $\mathrm{C}_{3}$ origina uma biomassa vegetal com valor isotópico de carbono de aproximadamente $-28 \%$, enquanto que nas plantas $\mathrm{C}_{4}$ o valor é aproximadamente $-14 \%$ (O’Leary, 1988). Assim, a análise da composição isotópica do carbono tornou-se um valor padrão para determinar a via de fixação de $\mathrm{CO}_{2}$. As plantas aquáticas apresentam maior variabilidade no valor de $\delta^{13} \mathrm{C}$ do que as plantas terrestres. Farquhar et al. (1982) propuseram que, em ambientes aquáticos, essa ampla variação nos valores de $\delta^{13} \mathrm{C}$ é determinada por três fatores: a discriminação isotópica enzimática durante a fixação de carbono, a taxa de difusão do $\mathrm{CO}_{2}$ e a composição isotópica do pool de carbono inorgânico dissolvido.

O uso de isótopos estáveis de carbono em estudos de teias alimentares de ambientes aquáticos tem sido fundamental para demonstrar a importância de algas para os consumidores em ecossistemas que pareciam ser heterotróficos (France, 1995). O fracionamento de $\delta^{13} \mathrm{C}$ é baixo - máximo de $1 \%$ por nível trófico - e o $\delta^{13} \mathrm{C}$ é utilizado para identificação de diferentes fontes de carbono, enquanto que o conteúdo de $\delta^{15} \mathrm{~N}$ é enriquecido, em média, de 3-4\% por nível trófico e pode ser utilizado para a construção de cadeias alimentares (Eggers \& Jones, 2000). Para identificar a contribuição dos produtores primários nas teias alimentares e nos fluxos de energia, utilizando isótopos estáveis, é necessário entender como os fatores ambientais e fisiológicos afetam os valores isotópicos desses organismos (Doi et al., 2010). A composição isotópica desses organismos pode variar em função da velocidade da água, alterações na intensidade e 
penetração da luz e mudanças de temperatura (France, 1995; France \& Cattaneo, 1998). Além disso, o substrato onde o perifíton se desenvolve pode determinar os valores isotópicos, pois cada tipo de substrato possui uma comunidade de algas diferente (Doi et al., 2010).

Dessa forma, avaliar os compartimentos biogeoquímicos que compõem os ecossistemas aquáticos oligotróficos do Cerrado (sedimento, coluna d'água e biomassa) e como os nutrientes se distribuem e são transferidos é fundamental para o entendimento do funcionamento desses ecossistemas.

\section{OBJETIVO GERAL}

Investigar a relação entre as concentrações de nutrientes e sua distribuição em diferentes compartimentos (macrófitas aquáticas, perifíton e sedimento) de cinco lagoas naturais do Cerrado e o papel das macrófitas aquáticas e do perifíton no fluxo de nutrientes e interações tróficas ao longo da cadeia alimentar, considerando a variação sazonal.

\section{OBJETIVOS ESPECÍFICOS}

1) Mensurar as variáveis físicas e químicas de cinco lagoas naturais do Cerrado ao longo de quatro períodos sazonais distintos (seca, chuva e transições seca-chuva e chuva-seca).

2) Avaliar as concentrações de macronutrientes de diferentes compartimentos em lagoas naturais de Cerrado

3) Avaliar as razões estequiométricas de carbono, nitrogênio e fósforo de diferentes compartimentos em lagoas naturais de Cerrado.

4) Avaliar as concentrações de elementos-traço em diferentes compartimentos de lagoas naturais de bacias hidrográficas diferentes no Cerrado.

5) Avaliar as relações tróficas da comunidade perifítica e da fauna associada em uma lagoa natural de Cerrado. 


\section{ESTRUTURA DA TESE}

Neste estudo são apresentados os resultados de análises concentrações de macro e micronutrientes em compartimentos biogeoquímicos (macrófitas aquáticas, perifíton e sedimento) de lagoas naturais do Cerrado do Brasil Central, localizadas em três áreas que preservam fragmentos de Cerrado: o Parque Nacional de Brasília, a Estação Ecológica de Águas Emendadas e o Campo de Instrução de Formosa. O estudo foi divido em três capítulos redigidos em forma de artigos científicos.

O primeiro capítulo compara a variação sazonal das concentrações de carbono, nitrogênio, fósforo, cálcio e potássio entre os três compartimentos (macrófitas aquáticas, perifíton e sedimento) em cinco lagoas naturais rasas do Cerrado. O segundo capítulo descreve as concentrações dos elementos-traço em três compartimentos (macrófitas aquáticas, perifíton e sedimento) e compara essas concentrações entre as lagoas pertencentes a duas bacias hidrográficas. Por fim, o terceiro capítulo avalia as relações tróficas entre produtores primários e a fauna associada em uma lagoa natural do Cerrado por meio do uso de isótopos estáveis de carbono e nitrogênio.

\section{ÁREAS DE ESTUdo}

O estudo foi realizado em cinco lagoas oligotróficas naturais do Cerrado (Figura 1): Lagoa do Henrique $\left(15^{\circ} 41^{\prime} 17^{\prime \prime S} 47^{\circ} 56^{\prime} 25^{\prime \prime W}\right)$ e a Lagoa do Exército (1544'48"S 4758'46"W), localizadas no Parque Nacional de Brasília (PNB - DF); Lagoa Bonita $\left(15^{\circ} 35^{\prime} 01^{\prime \prime S} 47^{\circ} 41^{\prime} 19^{\prime \prime W}\right)$, localizada na Estação Ecológica de Águas Emendadas

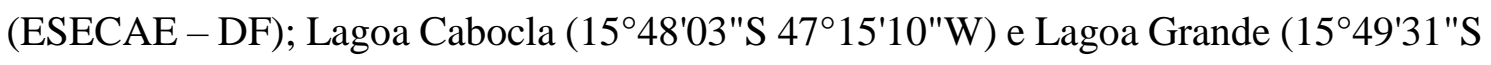
47¹3'56"W), localizadas no Campo de Instrução de Formosa (CIF - GO). As áreas do PNB e ESECAE localizam-se na Bacia do Alto Rio Paraná enquanto as demais áreas localizam- se na bacia do rio São Francisco (Tabela 1).

As lagoas encontram-se no bioma Cerrado, o qual apresenta sazonalidade bem marcada, com um período mais quente e chuvoso (outubro a março) e um período seco com temperaturas mais baixas (abril a setembro; Figura 2). O clima predominante é tropical, com precipitação média anual entre 1400 mm e 1600 mm no Distrito Federal e entre $1200 \mathrm{~mm}$ a $1400 \mathrm{~mm}$ na região de Formosa e temperatura média anual que varia entre $23^{\circ} \mathrm{C}$ e $27^{\circ} \mathrm{C}$ (Silva et al., 2008). A precipitação total no período de estudo (abril/14 a março/15) foi $1612,7 \mathrm{~mm}$ no PNB, 1458,8 mm na ESECAE e 1195,8 mm no CIF. 


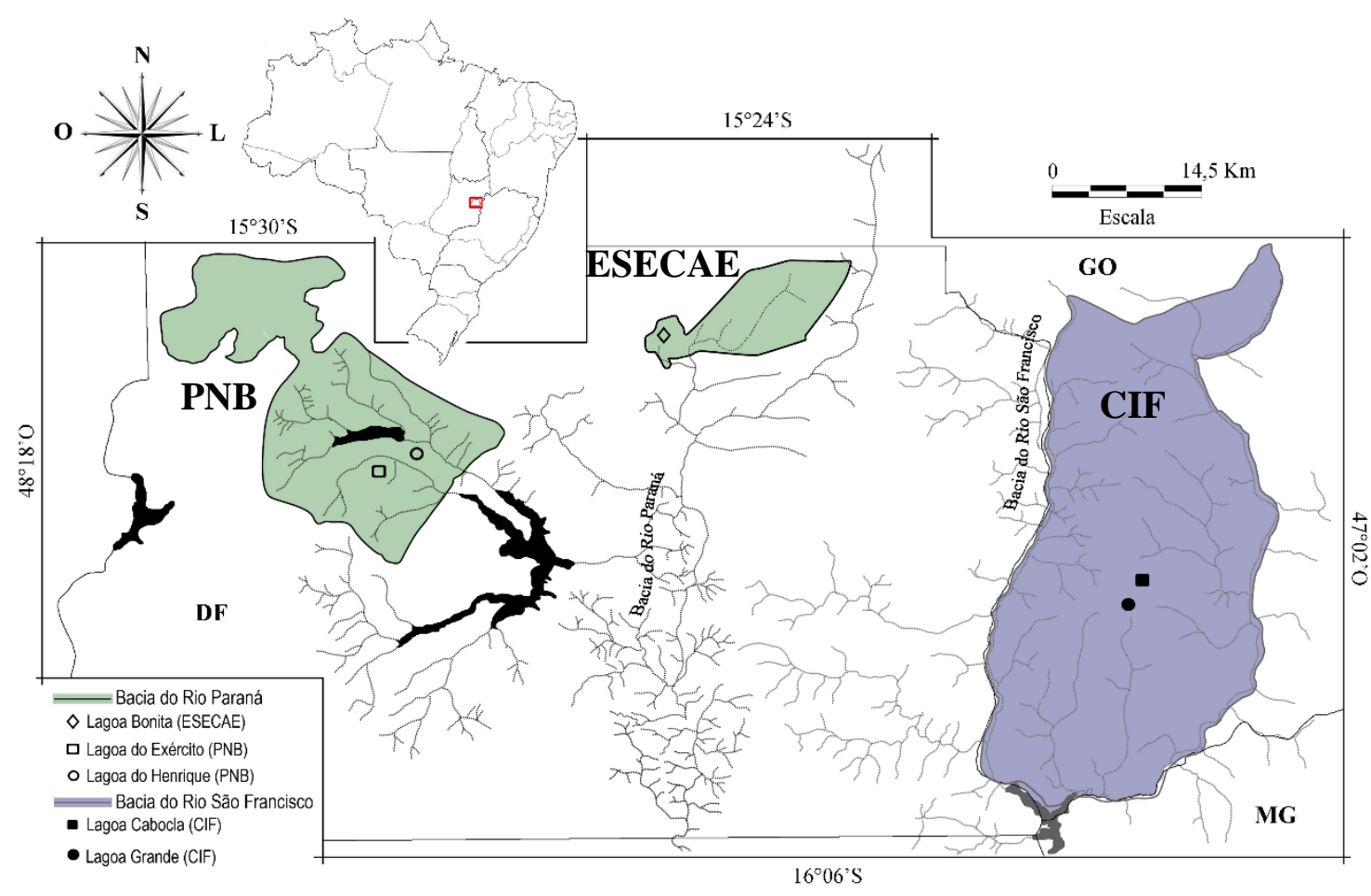

Figura 1. Mapa de localização das cinco lagoas naturais estudadas: Lagoa Bonita, localizadas na Estação Ecológica de Águas Emendadas (ESECAE), Lagoas do Exército e do Henrique localizadas no Parque Nacional de Brasília (PNB) e Lagoas Cabocla e Grande localizadas no Campo de Instrução de Formosa (CIF), com respectivas bacias hidrográficas (Paraná e São Francisco).

O Parque Nacional de Brasília é a maior Unidade de Conservação Integral do Distrito Federal, com área total de 42.389 ha (Aquino et al., 2009). O principal objetivo do PNB é a preservação de um fragmento de Cerrado, bem como da qualidade das águas da Barragem de Santa Maria (representa 25\% do abastecimento do DF) e também da qualidade dos córregos Torto e Bananal, tributários do Lago Paranoá (Salgado \& Galinkin, 2008). Entretanto, o PNB sofre intensa ação antrópica, pois está inserido em uma área altamente antropizada, cercado por grandes cidades do Distrito Federal, como Plano Piloto e Estrutural. Os ecossistemas aquáticos do PNB são constituídos por ambientes lóticos de pequeno porte e ambientes lênticos naturais provenientes do afloramento de lençol freático (Aquino et al., 2009; Sousa, 2012; Tabela 1). 
Tabela 1. Características gerais das cinco lagoas naturais estudadas, nas bacias do Paraná,

Distrito Federal, e São Francisco, Goiás. PNB: Parque Nacional de Brasília; ESECAE:

Estação Ecológica de Águas Emendadas; CIF: Campo de Instrução de Formosa.

\begin{tabular}{|c|c|c|c|c|c|c|}
\hline Lagoa & Bacia & $\begin{array}{c}\text { Unidade de } \\
\text { Conservação }\end{array}$ & Entorno & $\begin{array}{l}\text { Área } \\
\left(\mathrm{km}^{2}\right)^{1}\end{array}$ & $\begin{array}{l}\text { Profundidade } \\
\text { média }(\mathrm{m})^{2,3}\end{array}$ & $\begin{array}{l}\text { Riqueza de } \\
\text { Macrófitas }^{2}\end{array}$ \\
\hline Exército & $\begin{array}{l}\text { Alto Rio } \\
\text { Paraná }\end{array}$ & PNB & $\begin{array}{c}\text { Pouca } \\
\text { interferência } \\
\text { antrópica }\end{array}$ & 0,02 & 0,26 & 26 espécies \\
\hline Henrique & $\begin{array}{l}\text { Alto Rio } \\
\text { Paraná }\end{array}$ & PNB & $\begin{array}{c}\text { Pouca } \\
\text { interferência } \\
\text { antrópica }\end{array}$ & 0,04 & 0,66 & 26 espécies \\
\hline Cabocla & $\begin{array}{l}\text { Rio São } \\
\text { Francisco }\end{array}$ & CIF & $\begin{array}{c}\text { Pouca } \\
\text { interferência } \\
\text { antrópica }\end{array}$ & 0,97 & 0,39 & 44 espécies \\
\hline Bonita & $\begin{array}{l}\text { Alto Rio } \\
\text { Paraná }\end{array}$ & ESECAE & $\begin{array}{l}\text { Crescimento } \\
\text { urbano e aumento } \\
\text { de atividades } \\
\text { agrícolas }\end{array}$ & 1,92 & $\begin{array}{c}1,8 \\
\text { (máx. 3,5) }\end{array}$ & $*$ \\
\hline Grande & $\begin{array}{l}\text { Rio São } \\
\text { Francisco }\end{array}$ & CIF & $\begin{array}{c}\text { Pouca } \\
\text { interferência } \\
\text { antrópica }\end{array}$ & 4,32 & 5,0 (máx) & 22 espécies \\
\hline
\end{tabular}

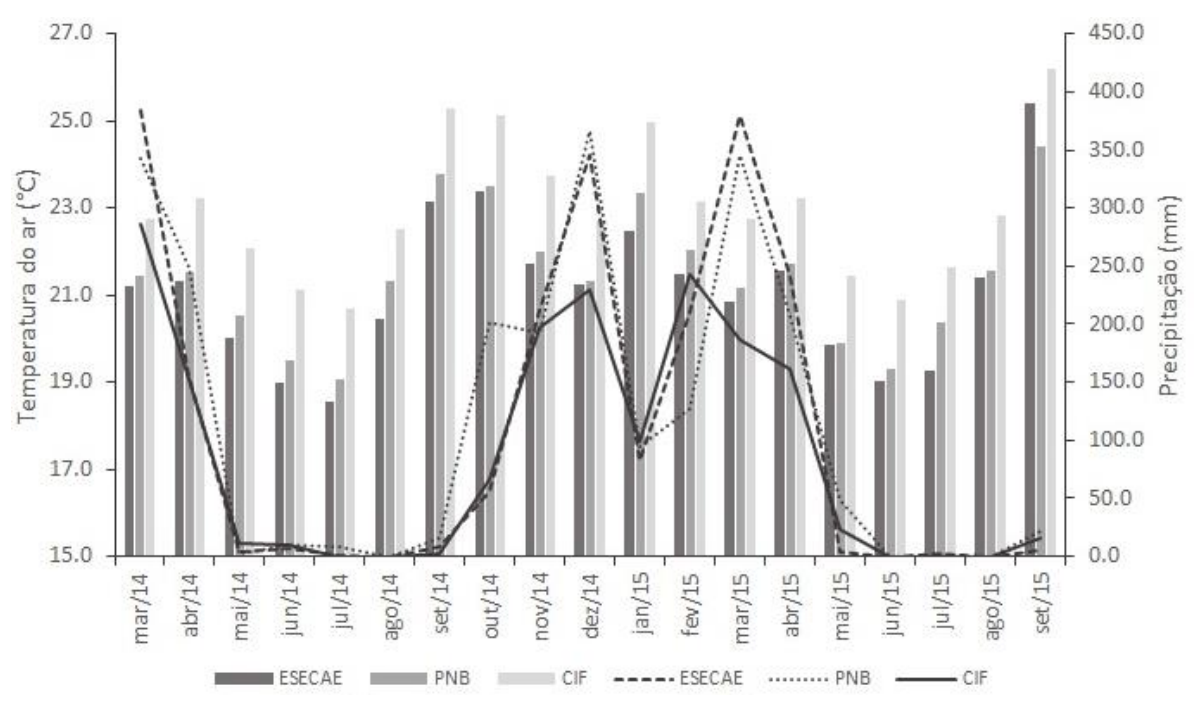

Figura 2. Distribuição da precipitação acumulada mensal em mm (indicada pelas linhas) e temperatura em ${ }^{\circ} \mathrm{C}$ (indicada pelas barras) durante o período de março de 2014 a setembro de 2015. Dados das estações do Parque Nacional de Brasília (83377), da Estação Ecológica de Águas Emendadas e de Formosa (83379) disponíveis pelo Instituto Nacional de Meteorologia (INMET, http://www.inmet.gov.br/portal/). 
As lagoas naturais rasas do PNB possuem mais de $80 \%$ da lâmina d'água ocupada por macrófitas aquáticas. Sousa (2012) traz alguns dados descritivos sobre tais lagoas. A Lagoa do Henrique (Figuras 3A e 3B) tem o formato mais oval, área de $0,04 \mathrm{~km}^{2}$ e a declividade do terreno permite o elevado acúmulo de água. Essa lagoa possui profundidade média de $0,66 \mathrm{~m}, \mathrm{pH}$ ácido $(5,1)$, baixa condutividade elétrica $(4,93 \mu \mathrm{S} / \mathrm{cm})$, concentração de oxigênio dissolvido de $4,88 \mathrm{mg} / \mathrm{L}$ e baixa concentração de nitrogênio e fósforo totais $(178,8 \mu \mathrm{g} / \mathrm{L}$ e $22,9 \mu \mathrm{g} / \mathrm{L}$, respectivamente). Ainda nesse estudo, foram encontradas 26 espécies de macrófitas aquáticas, entre elas Cyperus articulatus L., Rhynchospora globosa (Kunth) Roem.\& Schult, Xyris sp., Utricularia hispida Lam. e Panicum sp.

A Lagoa do Exército (Figuras 3C e 3D) possui área de 0,02 $\mathrm{km}^{2}$ e um afloramento na parte central formando um olho d'água cujo sedimento possui a cor mais esbranquiçada e não possui macrófitas nessa região. Essa lagoa possui profundidade média de 0,26m (não foi medida a profundidade no olho d'água, segundo Sousa, 2012), pH ácido $(5,5)$, baixa condutividade elétrica $(4,78 \mu \mathrm{S} / \mathrm{cm})$, concentração de oxigênio

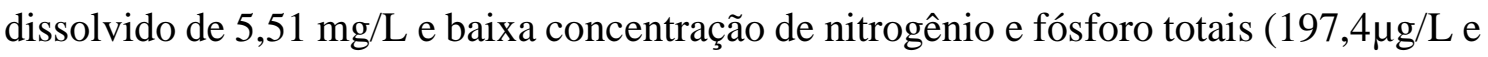
20,8 $\mu \mathrm{g} / \mathrm{L}$, respectivamente) (Sousa, 2012). Segundo Sousa (op. cit.), nesta lagoa foram encontradas 19 espécies de macrófitas aquáticas, entre elas Cyperus articulatus L., Lagenocarpus rigidus (Kunth) Ness, Syngonanthus sp., Utricularia nervosa Lam. e Nymphoides sp.

A Estação Ecológica de Águas Emendadas (ESECAE) abrange uma área de 10.547 ha e localiza-se na região administrativa de Planaltina, no extremo nordeste do Distrito Federal. Esta unidade abriga ecossistemas de grande relevância ecológica, como, por exemplo, a junção das nascentes de duas grandes bacias hidrográficas sul-americanas, a Tocantins/Araguaia e a Platina, que se interligam em uma vereda de $6 \mathrm{~km}$ de extensão (Salgado \& Galinkin, 2008). A pressão antrópica sobre a ESECAE é significativa, em decorrência de loteamentos e assentamentos urbanos em suas proximidades (principalmente Mestre D'Armas e Planaltina), além de grandes áreas cultivadas em seu entorno, cujas técnicas agrícolas empregadas agridem o meio ambiente (Gomes et al., 2010).

A Lagoa Bonita faz parte da ESECAE (Figuras 3E e 3F) é a maior lagoa natural da região, resultante do afloramento do lençol freático, com comprimento máximo de $1.730 \mathrm{~m}$ e largura máxima de $1.390 \mathrm{~m}$. Seu perímetro é equivalente a $4.800 \mathrm{~m}$, com 
profundidade máxima de 3,5m e média de 1,8m (Gomes, 2007). Na zona litoral da lagoa, o pH é ácido $(5,3-6,4)$, baixa condutividade elétrica $(3,2-12,8 \mu \mathrm{S} / \mathrm{cm})$, concentração de oxigênio dissolvido variando entre 4,5 e 8,9 mg/L e baixa concentração de nitrogênio e fósforo totais $(238-757 \mu \mathrm{g} / \mathrm{L}$ e $3-66 \mu \mathrm{g} / \mathrm{L}$, respectivamente) (Gomes et al., 2010). O espelho da água é circular, com pequenas variações no período de seca e chuva, apresenta fundo e superfície recobertos por macrófitas aquáticas representadas principalmente pelas famílias Cyperaceae e Pontederiaceae.

O Campo de Instrução de Formosa (CIF) é uma área sob gerenciamento do Exército Brasileiro, desde 1972, preserva um grande fragmento de Cerrado e está localizado no município de Formosa-GO, fazendo divisa ao sul com o Estado de Minas Gerais e a oeste com Distrito Federal e abrange uma área de aproximadamente 115.000 ha (Sena-Souza et al., 2016). A área foi obtida por meio de desapropriação de propriedades rurais e abriga formações vegetais com diferentes estágios de sucessão, áreas naturais de Cerrado e áreas modificadas, utilizadas para treinamento e exercícios táticos do Exército (Oliveira, 2006; Sousa, 2012). Os ecossistemas aquáticos do CIF são constituídos por ambientes lóticos e lênticos naturais (Tabela 1).

Todas as lagoas naturais rasas do CIF são formadas pelo afloramento de lençol freático e também possuem mais de $80 \%$ da lâmina d'água colonizada por macrófitas aquáticas (Figura 4A). A Lagoa Cabocla (Figura 4B) é formada por uma leve depressão topográfica circundada por campos de murundus e área de $0,97 \mathrm{~km}^{2}$. Essa lagoa possui profundidade média de $0,39 \mathrm{~m}, \mathrm{pH}$ ácido $(5,0)$, baixa condutividade elétrica $(5,74 \mu \mathrm{S} / \mathrm{cm})$, concentração de oxigênio dissolvido de $4,73 \mathrm{mg} / \mathrm{L}$ e baixa concentração de nitrogênio e fósforo totais $(123,8 \mu \mathrm{g} / \mathrm{L}$ e $15,3 \mu \mathrm{g} / \mathrm{L}$, respectivamente) (Sousa, 2012). Nesse mesmo estudo realizado em 2009, foram encontradas 44 espécies de macrófitas aquáticas, entre elas Cyperus sp., Drosera communis (Sundew), Curtia sp., Utricularia erectiflora A. St.Hil \& Girard e Ludwigia octovalis (Jacq.) P.H. Raven.

A Lagoa Grande (Figura 4C) possui uma área de $4,32 \mathrm{~km}^{2}$ e, durante o período chuvoso, pode chegar a 5,0m de profundidade (comunicação pessoal). Essa lagoa possui $\mathrm{pH}$ ácido $(5,7)$, baixa condutividade elétrica $(4,88 \mu \mathrm{S} / \mathrm{cm})$, baixa concentração de oxigênio dissolvido de $4,79 \mathrm{mg} / \mathrm{L}$ e baixa concentração de nitrogênio e fósforo totais (117,3 $\mu \mathrm{g} / \mathrm{L}$ e $13,7 \mu \mathrm{g} / \mathrm{L}$, respectivamente) (Sousa, 2012). Nesse mesmo estudo realizado em 2009, foram encontradas 22 espécies de macrófitas aquáticas, entre elas Eleocharis 
capillaceae Kunth, Utricularia neottioides A. St.-Hil \& Girard, Mayaca sellowiana Kunth, Andropogon virgatus Desv. ex Ham. e Xyris jupicai Rich.
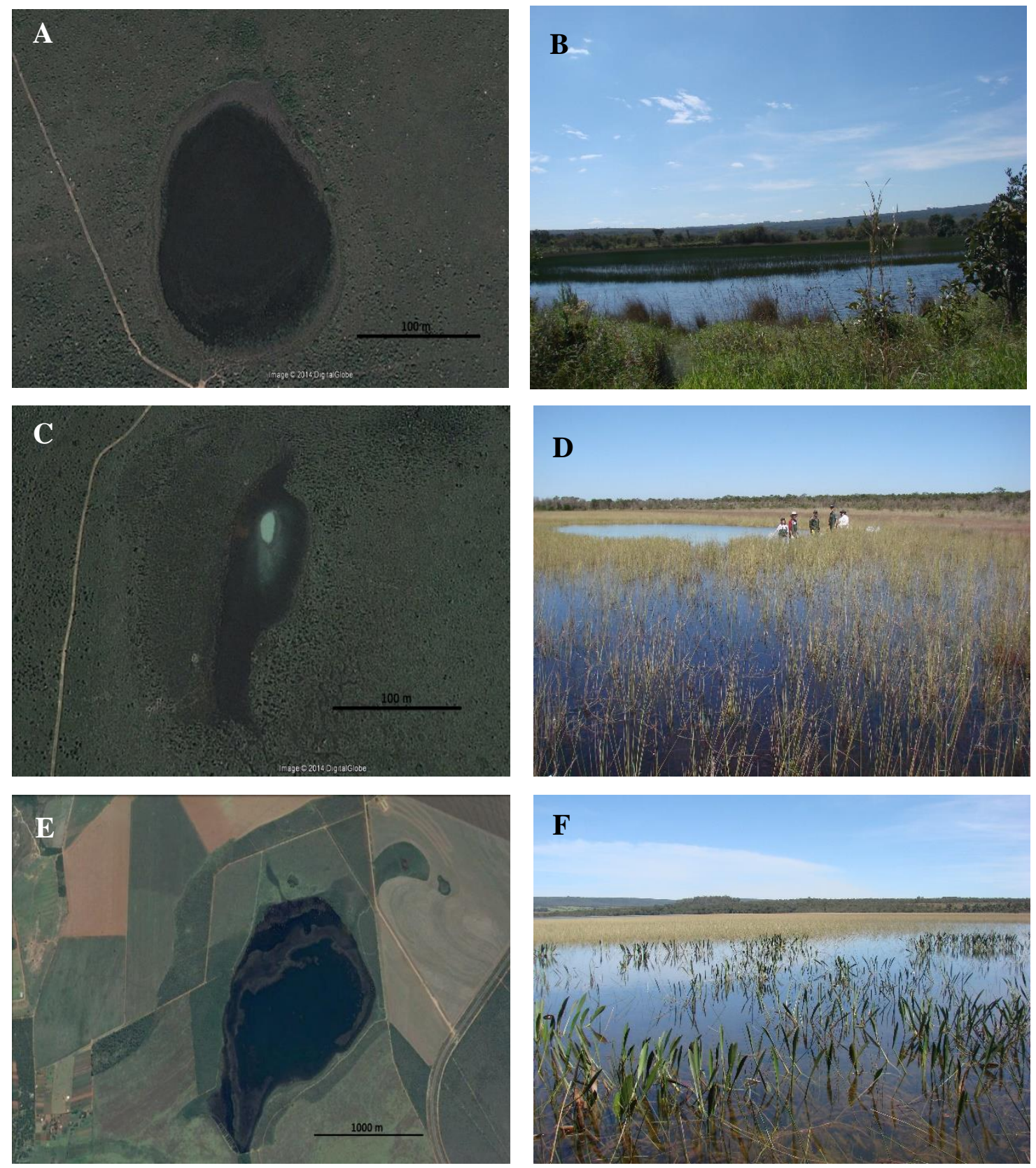

Figura 3. Lagoas naturais pertencentes à Bacia do Alto Rio Paraná, Distrito Federal. AB: Lagoa do Henrique, PNB; C-D: Lagoa do Exército, PNB; E-F: Lagoa Bonita, ESECAE. 

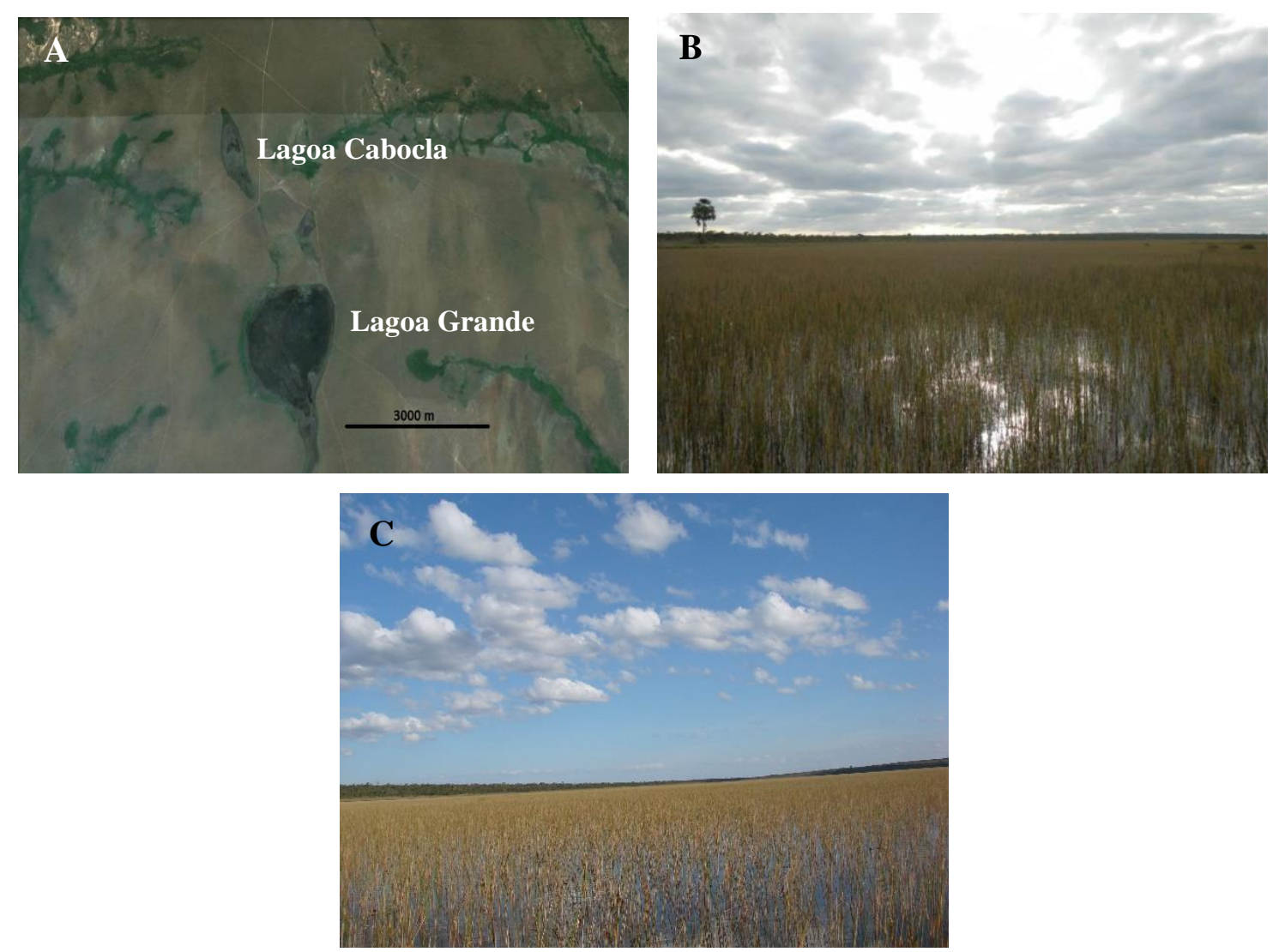

Figura 4. Lagoas naturais pertencentes à Bacia do Rio São Francisco, Goiás. A: Imagem de satélite das duas lagoas naturais do Campo de Instrução de Formosa; B: Lagoa Cabocla; C: Lagoa Grande.

\section{REFERÊNCIAS}

Amado, A. M., Cotner, J. B., Suhett, A. L., Esteves, F. A., Bozelli, R. L. \& Farjalla, V. F. 2007. Contrasting interactions mediate dissolved organic matter decomposition in tropical aquatic ecosystems. Aquatic Microbial Ecology, 49: 25-34.

Aquino, P. P. U., Schneider, M., Martins-Silva, M. J., Padovesi-Fonseca, C., Arakawa, H. B. \& Cavalcanti, D. R. 2009. Ictiofauna dos córregos do Parque Nacional de Brasília, bacia do Alto Rio Paraná, Distrito Federal, Brasil Central. Biota Neotropica, 9: 217-230.

Beardall, J., Young, E. \& Roberts S. 2001. Approaches for determining phytoplankton nutrient limitation. Aquatic Sciences, 63: 44-69.

Burkholder, J. M. \& Wetzel, R. G. 1990. Epiphytic alkaline phosphatase on natural and artificial plants in an oligotrophic lake: Re-evaluation of the role of macrophytes 
as a phosphorus source for epiphytes. Limnology and Oceanography, 35: 736747.

Camargo, A. F. M., Pezzato, M. M. \& Henry-Silva, G. G. 2003. Fatores limitantes à produção primária de macrófitas aquáticas. In: Ecologia e Manejo de Macrófitas Aquáticas (Eds. S. M. Thomaz \& L. M. Bini). pp. 59-83. Eduem, Maringá.

Cattaneo, A. \& Kalff, J. 1979. Primary production of algae growing on natural and artificial aquatic plants: A study of interactions between epiphytes and their substrate. Limnology and Oceanography, 24: 1031-1037.

Chambers, P. A., Lacoul, P., Murphy, K. J. \& Thomaz, S. M. 2008. Global diversity of aquatic macrophytes in freshwater. Hydrobiologia, 579: 1-13.

Cummins, K. W., Merrit, R. W. \& Andrade, P. C. N. 2005. The use of invertebrate functional groups to characterize ecosystem attributes in selected streams and rivers in south Brazil. Studies on Neotropical Fauna and Environment, 40: 6989.

Doi, H., Kikuchi, E., Shikano, S. \& Takagi, S. 2010. Differences in nitrogen and carbon stable isotopes between planktonic and benthic microalgae. Limnology, 11: 185192.

Eggers, T. \& Jones, T. H. 2000. You are what you eat or are you? Trends in Ecology \& Evolution, 15: 265-266.

Ervin, G. N. \& Wetzel, R. G. 2003. An ecological perspective of allelochemical interference in land-water interface communities. Plant and Soil, 256: 13-28.

Esteves, F. A. 2011. Gênese dos Ecossistemas Aquáticos. In: Fundamentos de Limnologia (Coord. F. A. Esteves). pp. 83-112. Interciência, Rio de Janeiro.

Esteves, F. A. \& Amado, A. M. 2011. Nitrogênio. In: Fundamentos de Limnologia (Coord. F. A. Esteves). pp. 239-258. Interciência, Rio de Janeiro.

Esteves, F. A., Amado, A. M., Figueiredo-Barros, M. P. \& Farjalla, V. F. 2011. Cabono Orgânico. In: Fundamentos de Limnologia (Coord. F. A. Esteves). pp. 193-208. Interciência, Rio de Janeiro.

Farquhar, G. D., O’Leary, M. H. \& Berry, J. A. 1982. On the relationship between carbon isotope discrimination and the intercellular carbon dioxide concentration in leaves. Australian Journal of Plant Physiology, 9: 121-137.

Fernandes, V. O. \& Esteves, F. A. 2011. Comunidade Perifítica. In: Fundamentos de Limnologia (Coord. F. A. Esteves). pp. 447-460. Interciência, Rio de Janeiro. 
Ferreira, R. M., Barros, N. O., Duque-Estrada, C. H. \& Roland, F. 2005. Caminhos do fósforo em ecossistemas aquáticos continentais. In: Lições de Limnologia (Eds. F. Roland, D. César \& M. Marinho). pp. 229-242. RiMa Editora, São Carlos.

Fonseca, B. M., Mendonça-Galvão, L., Padovesi-Fonseca, C., Abreu, L. M., Fernandes, A. C. M. 2014. Nutrient baselines of Cerrado low-order streams: comparing natural and impacted sites in the Central Brazil. Environmental Monitoring and Assessment, 186: 19-33.

France, R. L. 1995. Critical examination of stable isotope analysis as a means for tracing carbon pathways in stream ecosystems. Canadian Journal of Fisheries and Aquatic Sciences, 52: 651-656.

France, R. L. \& Cattaneo, A. 1998. $\delta^{13} \mathrm{C}$ variability of benthic algae: effects of water colour via modulation by stream current. Freshwater Biology, 39: 617-622.

Fry, B. 2006. Stable isotope ecology. Vol. 521. New York: Springer.

Fryer, G. 1968. Evolution and adaptive radiation in the Chydoridae (Crustacea: Cladocera): a study in comparative functional morphology and ecology. Philosophical Transations of the Royal Society London Serie B, 254: 221-384.

Fryer, G. 1974. Evolution and adaptive radiation in the Macrothricidae (Crustacea, Cladocera): a study in comparative functional morphology and ecology. Philosophical Transations of the Royal Society London Serie B, 269: 137-274.

Giordano, M. 2013. Homeostasis: an underestimated focal point of ecology and evolution. Plant Science, 211: 92-101.

Gomes, P. P. 2007. Variação espacial e temporal da comunidade fitoplanctônica da Lagoa Bonita, DF. Brasília, Universidade de Brasília, 76p. Dissertação de Mestrado.

Gomes, P. P., Ibañez, M. S. R. \& Freitas, J. S. 2010. Spatial and temporal variation of Peridinium umbonatum F. Stein, 1883 (Dinophyceae) and its relationship with total phytoplankton of a shallow, oligotrophic lake in central Brazil (Lagoon Bonita, Distrito Federal). Acta Limnologica Brasiliensia, 22: 317-324.

Gross, E. M., Erhard, D. \& Ivanyi, E. 2003. Allelopathic activity of Ceratophyllum demersum L. and Najas marina ssp intermedia (Wolfgang) Casper. Hydrobiologia, 506: 583-589.

Guariento, R. D., Caliman, R., Esteves, F. A., Bozelli, R. L., Enrich-Prast, A. \& Farjalla, R. F. 2009. Substrate influence and temporal changes on periphytic biomass accrual and metabolism in a tropical humic lagoon. Limnologica, 39: 209-218. 
Hansson, L. A. 1992. Factors regulating periphytic algal biomass. Limnology and Oceanography, 37: 322-328.

Hobson, K. A. \& Wassenaar, L. I. 1999. Stable isotope ecology: an introduction. Oecologia, 120: 312-313.

Jaschinski, S., Brepohl, D. C. \& Sommer, U. 2011. The trophic importance of epiphytic algae in a freshwater macrophyte system (Potamogeton perfoliatus L.): stable isotope and fatty acid analyses. Aquatic Sciences, 73: 91-101.

Jeppesen, E., Jensen, J. P., Sãndergaard, M., Lauridsen, T., Pedersen, L. J. \& Jensen, L. 1997. Top-down control in freshwater lakes: the role of nutrient state, submerged macrophytes and water depth. Hydrobiologia, 342-343: 151-164.

Klausmeier, C. A., Litchman, E., Daufresne, T. \& Levin, S. A. 2004. Optimal nitrogento-phosphorus stoichiometry of phytoplankton. Nature, 429: 171-174.

Lampert, W. \& Sommer, U. 1997. Limnoecology: the Ecology of Lakes and Streams. Oxford University Press, New York.

Maberly, S. C. \& Madsen, T. V. 1998. Affinity for $\mathrm{CO}_{2}$ in relation to the ability of freshwater macrophytes to use $\mathrm{HCO}_{3}^{-}$. Functional Ecology, 12: 99-106.

Maberly, S. C., Ball, L. A. Raven, J. A. \& Sültemeyer, D. 2009. Inorganic carbon acquisition by chrysophytes. Journal of Phycology, 45: 1052-1061.

Martinelli, L. A., Victória, R. L., Matsui, E., Forsberg, B. R. \& Mozeto, A. A. 1988. Utilização das variações naturais de $\delta^{13} \mathrm{C}$ no estudo de cadeias alimentares em ambientes aquáticos: princípios e perspectivas. Acta Limnologica Brasiliensia, 1: 859-882.

O’Farrel, I., Pinto, P. T., Rodríguez, P. L., Chaparro, G. \& Pizarro, H. N. 2009. Experimental evidence of the dynamic effect of free-floating plants on phytoplankton ecology. Freshwater Biology, 54: 363-375.

O'Leary, M. H. 1988. Carbon Isotopes in Photosynthesis. BioScience, 38: 328-336.

Obertegger U. \& Manca M. 2011. Response of rotifer functional groups to changing trophic state and crustacean community. Journal of Limnology, 70: 231-238.

Odum, E. P. \& Barret, G. W. 2007. Fundamentos de Ecologia. Thomson Learning, São Paulo.

Oliveira, I. C. S. 2006. Uso da análise espacial no processo de integração terreno, condições meteorológicas e inimigo (PITCI) do Exército brasileiro. Brasília, Universidade de Brasília, 94p. Dissertação de Mestrado. 
Oliveira-Filho, A. T., Shepherd, G. J., Martins, F. R. \& Stubblebine, W. H. 1989. Environmental Factors Affecting Physiognomic and Floristic Variation in an Area of Cerrado in Central Brazil. Journal of Tropical Ecology, 5: 413-431.

Peckham, S. D., Chipman, J. W., Lillesand, T. M. \& Dodson, S. I. 2006. Alternate stable states and the shape of the lake trophic distribution. Hydrobiologia, 571: 401407.

Redfield, A. C. 1934. On the proportions of organic derivatives in seawater and relation to the composition of the plankton. In: James Johnstone memorial volume (Ed R.I. Daniel). pp. 176-192. Liverpool University Press, Liverpool.

Redfield, A. C., Ketchum, B. H. \& Richards, F. A. 1963. The influence of organisms on the composition of sea-water. In: The sea, vol 2 (Ed M.N. Hill). pp. 26-77. Wiley, New York.

Salgado, G. S. M. \& Galinkin, M. 2008. Reserva da Biosfera do Cerrado - Fase I (RBCDF). In: Águas Emendadas (Org. F. O. Fonseca). pp. 79-86. Seduma, Brasília.

Santos, T. R., Ferragut, C. \& Bicudo, C. E. M. 2013. Does macrophyte architecture influence periphyton? Relationships among Utricularia foliosa, periphyton assemblage structure and its nutrient (C, N, P) status. Hydrobiologia, 714: 71-83.

Sena-Souza, J. P., Júnior, O. A. B., Martins, E. S., Vasconcelos, V., Júnior, A. F. C., Gomes, R. A. T. \& Guimarães, R. F. 2016. Comparação dos métodos de classificação por ângulo espectral e distância euclidiana no mapeamento das formas de terreno. Revista Brasileira de Geomorfologia, 17: 591-613.

Silva A. M., Assad, E. D. \& Evangelista, B. A. 2008. Caracterização Climática do Bioma Cerrado. In: Cerrado Ecologia e Flora (Eds. S. M Sano, S. P. Almeida \& J. F. Ribeiro). pp. 69-88. Embrapa Cerrado, Brasília.

Søndergaard, M., Johansson, L. S., Lauridsen, T. L., Jørgensen, T. B., Liboriussen, L. \& Jeppesen, E. 2010. Submerged macrophytes as indicators of the ecological quality of lakes. Freshwater Biology, 55: 893-908.

Sousa, F. D. R. 2012. Diversidade da fauna de Cladocera (Crustacea, Branchiopoda) associada à macrófitas em áreas úmidas naturais do Cerrado do Brasil Central. Brasília, Universidade de Brasília, 147p. Dissertação de Mestrado.

Sterner R. W. \& Elser, J. J. 2002. Ecological stoichiometry. Princeton University Press, Princeton.

Thomaz, S. M. \& Cunha, E. R. 2010. The role of macrophytes in habitat structuring in aquatic ecosystems: methods of measurement, causes and consequences on 
animal assemblages' composition and biodiversity. Acta Limnologica Brasiliensia, 22: 218-236.

Thomaz, S. M. \& Esteves, F. A. 2011. Comunidade de Macrófitas Aquáticas. In: Fundamentos de Limnologia (Coord. F.A. Esteves). pp. 461-522. Interciência, Rio de Janeiro.

Thorp, J. H. \& Delong, M. D. 1994. The riverine productivity model: an heuristic view of carbon sources and organic processing in large river ecosystems. Oikos, 70: 305-308.

Thorp, J. H. \& Delong, M. D. 2002. Dominance of autochthonous autotrophic carbon in food webs of heterotrophic rivers. Oikos, 96: 543-550.

Vadeboncoeur, Y. \& Steinman. A. D. 2002. Periphyton Function in Lake Ecosystems. The Scientific World Journal, 2: 1-20.

Wetzel, R. G. 2001. Limnology: Lake and river ecosystems. 998 p. Academic Press: San Diego. 


\section{Capítulo 1 - VARiações SAZONAis das CONCENTRAÇões DE MACRONUTRIENTES EM COMPARTIMENTOS BIOGEOQUÍMICOS DE LAgOAS NATURAIS RASAS DO CERRADO}

\section{RESUMO}

Em ambientes lênticos rasos de Cerrado, a relação entre os compartimentos biogeoquímicos ainda é uma questão em aberto com implicações para o entendimento do funcionamento desses ecossistemas. No presente estudo, avaliou-se como diferem as concentrações de $\mathrm{C}, \mathrm{N}, \mathrm{P}, \mathrm{Ca}$ e $\mathrm{K}$ e as razões $\mathrm{C}: \mathrm{N}, \mathrm{C}: \mathrm{P}$ e N:P em macrófitas aquáticas, perifíton e sedimento de lagoas rasas naturais do Cerrado. O estudo foi realizado em cinco lagoas oligotróficas naturais e as coletas foram realizadas em quatro períodos distintos, contemplando as estações seca e chuvosa e as transições entre estações. Grande parte das variáveis limnológicas avaliadas apresentou influência da sazonalidade da precipitação. A concentração de carbono foi maior nas macrófitas, evidenciando o investimento em sustentação e em tecidos estruturais. Por outro lado, as concentrações de nitrogênio, fósforo e cálcio no compartimento perifíton foram maiores que as concentrações nos dois outros compartimentos em todos os períodos sazonais. As razões molares C:N e C:P nas macrófitas aquáticas foram maiores em comparação aos demais compartimento. Já a razão N:P apresentou maior valor no sedimento. Com relação aos estoques, tanto de nitrogênio quanto de fósforo, os maiores valores encontrados foram nas macrófitas aquáticas. Além disso, houve diferença significativa entre os períodos de coleta, em que os maiores valores observados das concentrações de nitrogênio, fósforo, cálcio e potássio foram nas transições, tanto na seca/chuva quanto na chuva/seca, e estação chuvosa, evidenciando a importância da variação sazonal na dinâmica desses nutrientes em ambientes lênticos rasos. Apesar das macrófitas aquáticas apresentarem menores concentrações de nitrogênio e fósforo quando comparadas ao perifíton, as mesmas representam um importante estoque desses elementos em função da maior biomassa.

Palavras-chave: precipitação, biomassa, estequiometria ecológica, nitrogênio 


\section{INTRODUÇÃOO}

As interações entre a história de vida dos organismos e a estrutura e funcionamento dos ecossistemas podem ser investigadas pela estequiometria ecológica ao comparar as razões de elementos químicos presentes no meio abiótico e na biota (Sardans et al., 2012; Giordano, 2013). Carbono, nitrogênio e fósforo são, normalmente, os elementos mais estudados em estequiometria ecológica, em função de sua forte interação nos processos bioquímicos, além de terem uma maior demanda metabólica e estrutural.

Os fatores que determinam a razão C:N:P diferem em ecossistemas de água doce e marinhos. O menor volume de água em lagos em comparação aos oceanos indica que a razão estequiométrica pode ser mais influenciada pelas características particulares do meio ambiente, tais como tipo de rocha ou impacto humano (Sardans et al., 2012). Organismos de água doce podem variar suas razões C:P e N:P como resposta a fatores como eutrofização, estágios de crescimento e grupos funcionais (Xing et al., 2013).

No bioma Cerrado, os ambientes aquáticos prístinos são muito pobres em nutrientes e apresentam condutividade elétrica, em geral, inferior a $10 \mu \mathrm{S} / \mathrm{cm}$ (Silva et al., 2011; Fonseca et al., 2014; Fonseca \& Mendonça-Galvão, 2014). As baixas concentrações de íons observadas nesses ambientes são resultado dos solos altamente intemperizados e de suas baixas concentrações de nutrientes (Silva et al., 2011). Além disso, a vegetação terrestre adjacente pode reter boa parte do escoamento de nitrogênio e fósforo durante a estação chuvosa, contribuindo para a baixa concentração desses nutrientes nos ecossistemas aquáticos do Cerrado (Parron et al., 2011).

Nos ambientes aquáticos lênticos, a comunidade perifítica inclui diferentes organismos e desempenha importantes funções ecossistêmicas nos fluxos de energia e matéria (Vadeboncoeur \& Steinman, 2002). A composição química do perifíton reflete as condições nutricionais do ambiente, evidenciando a capacidade de retenção de nutrientes dessa comunidade (Borduqui et al., 2008) e sua biomassa e composição de espécies são influenciadas pelo tipo de substrato onde a comunidade se estabelece (Townsend \& Gell, 2005). Estudos demonstraram que o biofilme perifítico formado nos sedimentos desempenha um papel significativo na migração de nutrientes na interface sedimento-água, principalmente fósforo, devido à sua alta afinidade com esse nutriente (Scinto \& Reddy, 2003; Lu et al., 2016). O sedimento pode ser considerado como o 
resultado da interação de todos os processos (biológicos, físicos e/ou químicos) que ocorrem no ecossistema aquático, principalmente em ambientes lênticos (Esteves \& Camargo, 2011). As macrófitas aquáticas são também apontadas como locais principais de colonização para perifíton (O’Farrel et al., 2009; Søndergaard et al., 2010). As macrófitas aquáticas têm a capacidade de mobilizar os nutrientes tanto do sedimento quanto da coluna d'água, podendo reter esses nutrientes, especialmente nitrogênio e fósforo. Burkholder \& Wetzel (1990) apontaram as macrófitas como fonte extra de nutrientes para a comunidade perifítica.

As concentrações de nutrientes dissolvidos na água mostram variação considerável durante o período de crescimento das comunidades aquáticas em lagoas e outros sistemas rasos devido à rápida reciclagem de nutrientes, sendo que uma parte significativa dos nutrientes é mobilizada pela biota e não é mensurável na água (Sager, 2009). Dessa forma, a contribuição da produtividade primária por esses componentes pode ser importante em sistemas rasos (Sager, 2009), principalmente em ambientes oligotróficos, onde macrófitas e perifíton podem representar mais de $90 \%$ da produção primária (Vadeboncoeur et al., 2002).

Segundo Silva et al. (2011), o ciclo de nutrientes em ecossistemas aquáticos lóticos do Cerrado é mais conservador comparado à Amazônia, sendo os fluxos e estoques de nutrientes menores no Cerrado, indicando uma limitação de nitrogênio e fósforo nesses sistemas do bioma. Em ambientes lênticos rasos de Cerrado, a relação entre os compartimentos biogeoquímicos (biota, sedimento e coluna de água) ainda é uma questão em aberto, com implicações para o entendimento do funcionamento desses ecossistemas. No presente estudo, avaliou-se como diferem as concentrações de C, N, P, Ca e K e as razões $\mathrm{C}: \mathrm{N}, \mathrm{C}: \mathrm{P}$ e $\mathrm{N}: \mathrm{P}$ em macrófitas aquáticas, perifíton e sedimento de lagoas rasas naturais do Cerrado. Partiu-se do pressuposto de que esses diferentes compartimentos respondem de forma diferenciada às condições de limitação de nutrientes, apresentando variações em relação às razões previstas na literatura (e.g., razões de Redfield), especialmente no caso do perifíton. A hipótese do estudo é que as concentrações de $\mathrm{N}$ e $\mathrm{P}$ serão maiores no perifíton, seguido pelas macrófitas aquáticas e, finalmente, no sedimento das lagoas naturais do Cerrado, em função das condições de limitação de nutrientes, investimento em estruturas de sustentação e variações sazonais, em que a entrada de nutrientes será maior em função da precipitação (transição das estações seca e chuvosa e estação chuvosa). 


\section{MATERIAL E MÉtodos}

Áreas de Estudo

O estudo foi realizado em cinco lagoas oligotróficas naturais na porção central do Cerrado: Lagoa do Henrique $\left(15^{\circ} 41^{\prime} 17^{\prime \prime S} 47^{\circ} 56^{\prime} 25^{\prime \prime W}\right)$ e a Lagoa do Exército (1544'48"S 4758'46"W), localizadas no Parque Nacional de Brasília (PNB - DF); Lagoa Bonita $\left(15^{\circ} 35^{\prime} 01\right.$ 'S 4741'19"W), localizada na Estação Ecológica de Águas Emendadas (ESECAE - DF); Lagoa Cabocla (1548'03"S 47¹5'10"W) e Lagoa Grande (1549'31"S 47¹3'56"W), localizadas no Campo de Instrução de Formosa (CIF - GO).

A região apresenta sazonalidade bem marcada, com um período mais quente e chuvoso (Outubro a Março) e um período seco com temperaturas mais baixas (Abril a Setembro). O clima predominante é tropical e temperatura média anual que varia entre $23^{\circ} \mathrm{C}$ e $27^{\circ} \mathrm{C}$ (Silva et al., 2008). Dados de precipitação entre os anos 1985 e 2013 no Distrito Federal e Formosa (GO) foram obtidos do Instituto Nacional de Meteorologia (INMET) e a precipitação média anual varia entre $1400 \mathrm{~mm}$ e $1500 \mathrm{~mm}$ nas áreas estudadas (Figura 1). As cinco lagoas naturais rasas estudadas possuem mais de $80 \%$ da lâmina d'água ocupada por macrófitas aquáticas e a profundidade média varia entre 0,26 $\mathrm{m}$ a 5,0 m (Tabela 1$)$.

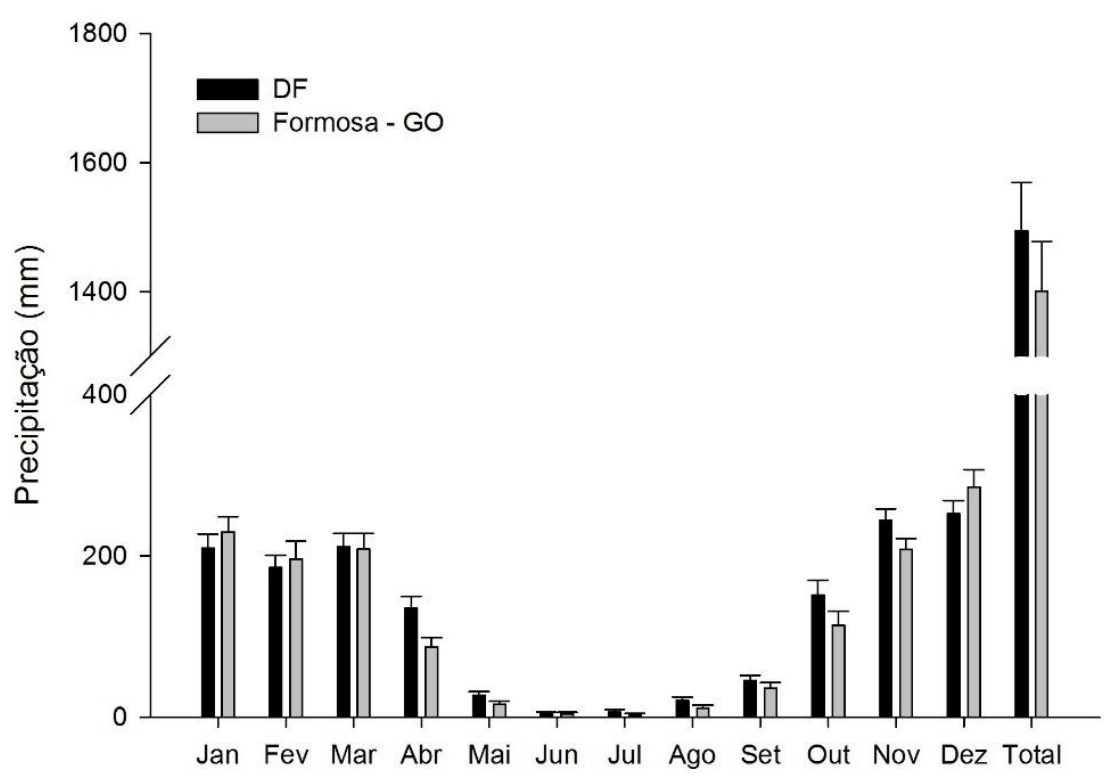

Figura 1. Distribuição da precipitação média mensal (mm) no período de janeiro de 1985 a dezembro de 2013 no Distrito Federal e Formosa (GO). Dados do Instituto Nacional de Meteorologia (INMET, http://www.inmet.gov.br/portal/) para as estações do Parque Nacional de Brasília (83377) e de Formosa (83379). As barras indicam o erro padrão. 
Tabela 1. Características gerais das cinco lagoas naturais estudadas, nas bacias do Paraná,

Distrito Federal, e São Francisco, Goiás. PNB: Parque Nacional de Brasília; ESECAE:

Estação Ecológica de Águas Emendadas; CIF: Campo de Instrução de Formosa.

\begin{tabular}{|c|c|c|c|c|c|c|}
\hline Lagoa & Bacia & $\begin{array}{c}\text { Unidade de } \\
\text { Conservação }\end{array}$ & Entorno & $\begin{array}{l}\text { Área } \\
\left(\mathrm{km}^{2}\right)^{1}\end{array}$ & $\begin{array}{l}\text { Profundidade } \\
\text { média }(\mathrm{m})^{2,3}\end{array}$ & $\begin{array}{l}\text { Riqueza de } \\
\text { Macrófitas }^{2}\end{array}$ \\
\hline Exército & $\begin{array}{l}\text { Alto Rio } \\
\text { Paraná }\end{array}$ & PNB & $\begin{array}{c}\text { Pouca } \\
\text { interferência } \\
\text { antrópica }\end{array}$ & 0,02 & 0,26 & 26 espécies \\
\hline Henrique & $\begin{array}{l}\text { Alto Rio } \\
\text { Paraná }\end{array}$ & PNB & $\begin{array}{c}\text { Pouca } \\
\text { interferência } \\
\text { antrópica }\end{array}$ & 0,04 & 0,66 & 26 espécies \\
\hline Cabocla & $\begin{array}{l}\text { Rio São } \\
\text { Francisco }\end{array}$ & CIF & $\begin{array}{l}\text { Pouca } \\
\text { interferência } \\
\text { antrópica }\end{array}$ & 0,97 & 0,39 & 44 espécies \\
\hline Bonita & $\begin{array}{l}\text { Alto Rio } \\
\text { Paraná }\end{array}$ & ESECAE & $\begin{array}{l}\text { Crescimento } \\
\text { urbano e aumento } \\
\text { de atividades } \\
\text { agrícolas }\end{array}$ & 1,92 & $\begin{array}{c}1,8 \\
\text { (máx. 3,5) }\end{array}$ & - \\
\hline Grande & $\begin{array}{l}\text { Rio São } \\
\text { Francisco }\end{array}$ & CIF & $\begin{array}{c}\text { Pouca } \\
\text { interferência } \\
\text { antrópica }\end{array}$ & 4,32 & 5,0 (máx) & 22 espécies \\
\hline
\end{tabular}

\section{Período de Amostragem}

As coletas foram realizadas em quatro períodos distintos com o objetivo de avaliar a influência da variação da pluviosidade na dinâmica dos nutrientes nos diferentes compartimentos avaliados. Os períodos de coletas foram definidos utilizando-se as séries históricas de dados pluviométricos para o Distrito Federal disponíveis no site do Instituto Nacional de Meteorologia - INMET (http://www.inmet.gov.br). O primeiro período de coleta foi o de transição chuva-seca (abril e maio de 2014; precipitação média de 95,5 $\mathrm{mm}$ ), seguido pelo período de seca (junho a agosto de 2014; precipitação média de 3,9 $\mathrm{mm}$ ), período de transição seca-chuva (setembro a novembro de 2014; precipitação média de 105,7 mm) e, finalmente, o período de chuva (dezembro de 2014 a março de 2015; precipitação média de 225,7 mm; Figura 2). De março de 2014 a março de 2015, a precipitação total 1954,6 mm no PNB, 1843,2 na ESECAE e 1482,3 no CIF. 


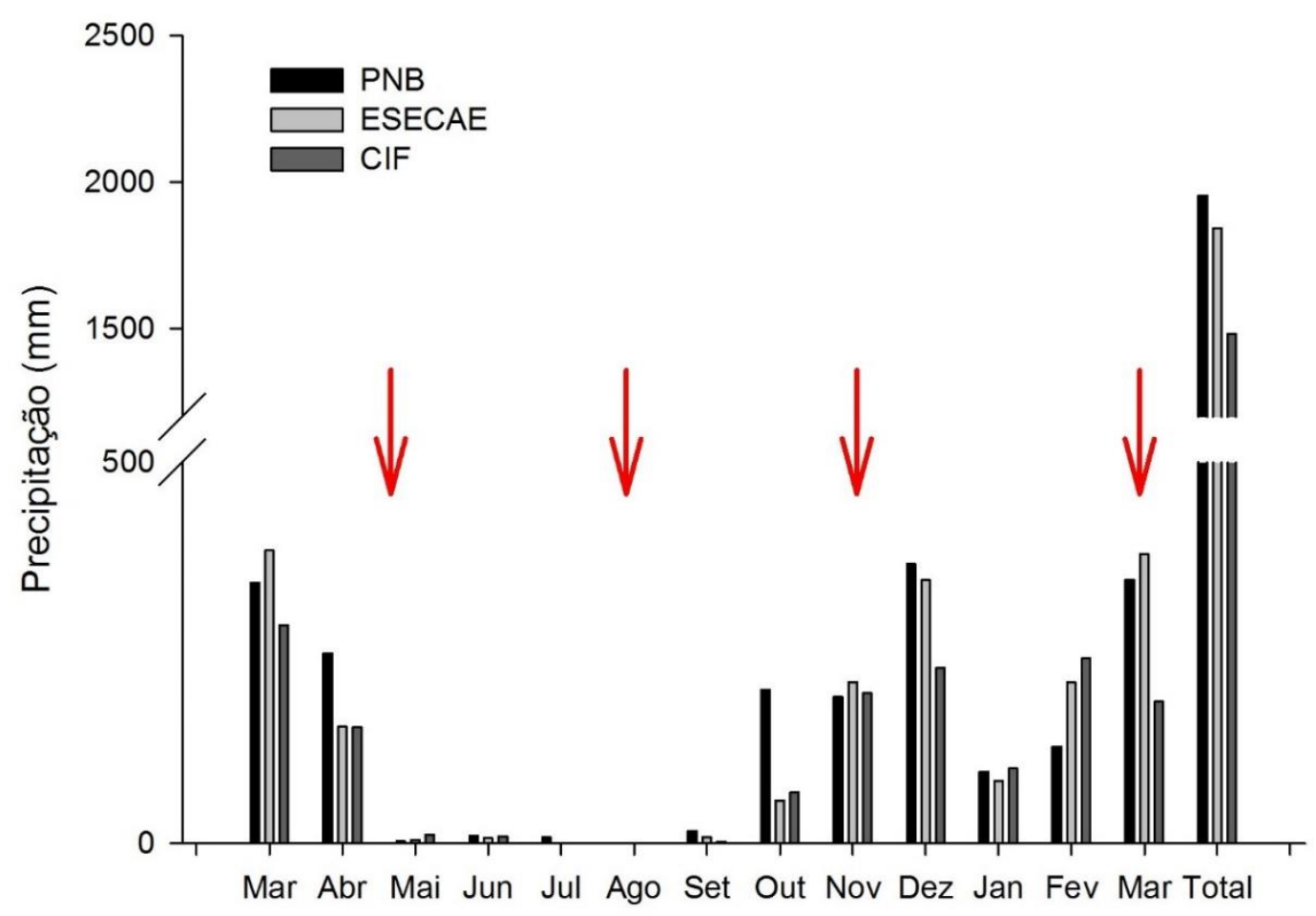

Figura 2. Distribuição da precipitação acumulada mensal $(\mathrm{mm})$ no período de março de 2014 a março de 2015 no Parque Nacional de Brasília (PNB - DF), Estação Ecológica de Águas Emendadas (ESECAE - DF) e Campo de Instrução de Formosa (CIF - GO). Dados do Instituto Nacional de Meteorologia (INMET, http://www.inmet.gov.br/portal/). Setas vermelhas indicam os meses de coleta.

\section{Coleta dos compartimentos}

Cinco pontos de coleta em cada lagoa foram sorteados utilizando-se grades georreferenciadas das lagoas, elaboradas no programa ArcGis. As células que compõem a grade possuem área de $20 \mathrm{~m}$ x $20 \mathrm{~m}$. Dessa forma, a grade da Lagoa do Henrique foi constituída por 122 células, a da Lagoa do Exército por 51 células, a da Lagoa Bonita por 5156 células, a da Lagoa Grande por 10989 células e a da Lagoa Cabocla por 2667 células. As coletas incluíram três compartimentos biogeoquímicos dos ecossistemas lênticos: macrófitas aquáticas, perifíton e sedimento. Considerando-se cinco lagoas, cinco pontos por lagoa, três compartimentos e quatro períodos sazonais, avaliou-se um total de 300 amostras. A seguir, apresenta-se o detalhamento das coletas dos diferentes compartimentos. 
Macrófitas aquáticas: foi utilizado um quadrado de $20 \mathrm{~cm}$ x $20 \mathrm{~cm}$ e todas as plantas (incluindo as raízes) presentes dentro do quadrado foram recolhidas. Em laboratório, as macrófitas foram lavadas com $600 \mathrm{~mL}$ de água deionizada para remover todo o material aderido em sua superfície, agitando-se vigorosamente o frasco. $\mathrm{Na}$ sequência, as macrófitas foram raspadas com auxílio de uma escova de dente com cerdas macias para remoção das algas firmemente aderidas. As macrófitas foram retiradas da bandeja para separação do material do perifíton lavadas abundantemente com água destilada para a total remoção de algas aderidas, e então congeladas.

Perifiton: foi raspado das macrófitas coletadas no quadrado de $20 \mathrm{~cm} \times 20 \mathrm{~cm}$, com auxílio de escova de dente de cerdas macias e jatos de água deionizada. Após a lavagem das macrófitas, o restante do material foi passado em peneira de $250 \mu \mathrm{m}$ para retirar pedaços de macrófitas.

Sedimento: foi coletado utilizando um amostrador de sedimento tubular de gravidade do tipo Kajak. As amostras correspondem à profundidade de 0-20 cm. Em laboratório, as amostras foram triadas para a remoção de macrófitas e raízes. Após essa triagem, o sedimento foi homogeneizado e colocado em tubo falcon de $50 \mathrm{~mL}$ e congelado.

\section{Determinação das concentrações e estoques de $C, N, P$, Ca e $K$}

Para as análises elementares, amostras de macrófitas, perifíton e sedimento foram liofilizadas durante 72 horas. Após a liofilização, as amostras de macrófitas foram trituradas usando um moinho de bola (Planetary Mill PULVERISETTE 5, Fritsch); as amostras de perifíton foram maceradas em um homogeneizador de bancada de alta velocidade (FastPrep®-24), utilizando-se tubos de plástico tipo eppendorf com pérolas de vidro; e as amostras de sedimento foram trituradas usando um almofariz de porcelana e pistilo.

A matéria orgânica do sedimento em triplicatas foi analisada para cada ponto de coleta. A secagem prévia das amostras de sedimento foi feita em estufa a $60{ }^{\circ} \mathrm{C}$, por um período de $72 \mathrm{~h}$, visando eliminar toda a água presente nas amostras. Após a secagem em estufa, foram pesados $10 \mathrm{~g}$ de sedimento em uma balança de precisão de 0,001 g. Depois de pesadas, as sub-amostras foram armazenadas em cadinhos de porcelana, e incineradas a $500^{\circ} \mathrm{C}$ no forno-mufla por seis horas, segundo Luczak et al. (1997). Posteriormente, as 
amostras foram novamente pesadas para determinação da quantidade de massa queimada, correspondente à matéria orgânica presente nas amostras.

Sub-amostras de 1,5 a 5 mg de macrófitas e perifíton e de 15 a 40 mg de sedimento foram acondicionadas em cápsulas de estanho, juntamente com uma pequena quantidade de pentóxido de Vanádio $\left(\mathrm{V}_{2} \mathrm{O}_{5}\right)$, que facilita a oxidação completa de amostras. As concentrações de $\mathrm{C}$ e $\mathrm{N}$ foram calculadas com base na curva padrão de Sulfanilamida (C: 41,84\%, N: 16,27\%, S: 18,62\%), de acordo com Norici et al. (2011). O conteúdo de C e $\mathrm{N}$ foi determinado por cromatografia gasosa com analisador elementar (EA1108, Carlo Erba Instruments, Milão, Itália) no laboratório de Fisiologia de algas e plantas da Universidade Politécnica de Marche, Itália, em colaboração com o Prof. Mario Giordano.

Sub-amostras de 1 a $3 \mathrm{mg}$ de cada material foram colocadas em tubos de plástico tipo eppendorf e foi acrescentado $0,5 \mathrm{~mL}$ de água ultra-pura. Para cada 0,5 $\mathrm{mL}$ de amostra ressuspensa em água ultra-pura, 2,5 $\mu \mathrm{L}$ de padrão de Ga (1.442.495, Sigma) foram adicionados. Após homogeneizar as amostras, $10 \mu \mathrm{L}$ da mistura foram colocados em um disco de acrílico sobre uma placa aquecedora a cerca de $50^{\circ} \mathrm{C}$. Após a evaporação do material, o disco foi levado imediatamente para o espectro de fluorescência de raios $\mathrm{X}$ por reflexão total, S2 PICOFOX (Bruker AXS Microanalysis GmbH, Ettlingen, Alemanha). O tempo de leitura foi de 1000 s. A quantificação de fósforo, cálcio e potássio foi realizada com o software S2 PICOFOX (Bruker AXS Microanalysis GmbH, Ettlingen, Alemanha) no laboratório de Fisiologia de algas e plantas da Universidade Politécnica de Marche.

Para os cálculos de estoque de nitrogênio e fósforo $\left(\mathrm{em} \mathrm{mg} / \mathrm{m}^{2}\right)$ nas macrófitas aquáticas e perifíton, utilizou-se a massa coletada de cada um desses compartimentos e as concentrações dos nutrientes. Os estoques foram determinados pela expressão: concentração de $\mathrm{N}$ ou $\mathrm{P}$ (mg/g de peso seco) x massa do compartimento pela área coletada $\left(\mathrm{g} / \mathrm{m}^{2}\right)$.

\section{Variáveis físicas e químicas da água}

Avaliou-se, em cada período de coleta, a temperatura da água (Oximeter YSI 55), a concentração de oxigênio dissolvido (Oximeter YSI 55), pH (Digimed MD 20), condutividade elétrica (Minipa MCD-2000) e profundidade, utilizando medidores in situ. Além disso, foi coletada uma amostra de água (cinco litros) para análise de alcalinidade 
total, turbidez (HACH 2100 NA), clorofila-a e nutrientes (totais e dissolvidos). Tal amostra foi mantida refrigerada durante o transporte até o laboratório. A determinação da alcalinidade total foi feita pelo método de Gram (Carmouze, 1994). As concentrações de nitrito $\left(\mathrm{NO}_{2}^{-}\right)$, nitrato $\left(\mathrm{NO}_{3}^{-}\right)$e amônio $\left(\mathrm{NH}_{4}{ }^{+}\right)$foram determinadas por colorimetria em um sistema de injeção de fluxo com o espectrofotômetro marca FIA-STAR, Foss Tecator, modelo 5000 A. A concentração de nitrogênio total (NT) foi determinada em analisador de gases não dispersivo, marca Shimadzu, modelo TOC-VCPH. Estas análises foram realizadas no Laboratório de Análise Ambiental e Geoprocessamento do CENA-USP. A concentração de fósforo total (PT) foi determinada segundo metodologia descrita no "Standard Methods for the Examination of Water and Wastewater" (American Public Health Agency, 2005) no Laboratório de Ecologia da Universidade Católica de Brasília.

Para análise da clorofila-a, foram filtrados cerca de $1000 \mathrm{~mL}$ de água (o volume filtrado variou dependendo da amostra) utilizando-se microfiltro de fibra de vidro GF-5 calcinado, com abertura de malha de 0,6-0,7 $\mu \mathrm{m}$. Para cada ponto amostral, esse procedimento foi realizado em duas réplicas e os filtros foram identificados e congelados. A extração da clorofila-a (corrigida da feofitina) foi feita com etanol (90\%) segundo Marker et al. (1980) e Sartory \& Grobblelar (1984).

\section{Análise dos dados}

A análise descritiva dos dados abióticos utilizou média aritmética como medida da tendência central. O grau de dispersão dos dados limnológicos foi calculado usando o erro padrão (EP) e a dispersão relativa através do coeficiente de variação $(\mathrm{CV})$. Para a análise inferencial, aplicou-se a análise de variância (ANOVA 1-fator) para comparar as variáveis limnológicas entre períodos sazonais. Para comparar as médias e determinar a diferença mínima significativa utilizou-se o teste de comparação múltipla de Tukey para os dados paramétricos $(\alpha=0,05)$. Modelos generalizados com efeito misto (glme) foram utilizados para comparar as concentrações e razões dos elementos entre os compartimentos e entre os períodos sazonais.

Todos os dados obtidos foram previamente verificados utilizando a curva de Gauss no programa R. Para as análises estatísticas todos os dados foram transformados em $\log \mathrm{x}+1$, exceto os dados de $\mathrm{pH}$. Os pacotes lsmeans e pbkrtest do programa $\mathrm{R}$ versão 3.2.2 (R Development Core Team, 2015) foram utilizados. 
As concentrações de carbono, nitrogênio, fósforo, cálcio e potássio nos diferentes períodos sazonais foram analisadas por meio da Análise dos Componentes Principais (PCA) a partir de matriz de covariância e dos dados transformados por log $(x+1)$. A PCA foi realizada usando o programa PAST (Paleontological Statistics) versão 2.17c (Hammer et al., 2001).

\section{RESULTADOS}

Variáveis físico-químicas da água

As variáveis temperatura da água, $\mathrm{pH}$, condutividade elétrica, concentração de oxigênio dissolvido, turbidez, alcalinidade, clorofila-a, nitrato, nitrito, amônio e nitrogênio total diferiram significativamente entre os períodos estudados $(\mathrm{p}<0,001)$, indicando a influência da sazonalidade sobre as variáveis analisadas (Tabela 2). A temperatura da água variou entre $19,4^{\circ} \mathrm{C}$ na estação seca e $29,6^{\circ} \mathrm{C}$ na estação chuvosa (Figura 3A). As lagoas estudadas apresentaram valores de oxigênio dissolvido variando entre 3,82 (transição seca/chuva) e 8,23 mg/L (transição chuva/seca; Figura 3B). Os valores de pH variaram de 4,87 (transição chuva/seca) a 7,62 (transição seca/chuva), caracterizando os ambientes com águas com $\mathrm{pH}$ levemente ácido a neutro, pode-se observar um aumento de $\mathrm{pH}$ entre os períodos sazonais (transição chuva/seca $<$ seca $<$ transição seca/chuva; Figura 3C). Esse aumento entre os períodos sazonais (transição chuva/seca < seca) também pode ser observada para a condutividade elétrica (maior valor médio observado no período de seca $(11,8 \mu \mathrm{S} / \mathrm{cm})$ e menor valor observado na transição chuva/seca (5,6 $\mu \mathrm{S} / \mathrm{cm}$; Figura 3E). Os maiores valores médios de turbidez (2,27 NTU) e clorofila- $a(5,07 \mu \mathrm{g} / \mathrm{L})$ foram encontrados na transição seca/chuva (Figuras 3D e 3F, respectivamente). 
Tabela 2. Valores médios e, entre parênteses, coeficiente de variação das variáveis limnológicas das lagoas naturais rasas do Cerrado localizadas no Distrito Federal e em Goiás durante abril de 2014 a março de 2015. * indicam que as amostras não foram analisadas.

\begin{tabular}{|c|c|c|c|c|}
\hline & $\begin{array}{c}\text { Transição } \\
\text { Chuva/Seca }\end{array}$ & Seca & $\begin{array}{c}\text { Transiç̧ão } \\
\text { Seca/Chuva }\end{array}$ & Chuva \\
\hline Profundidade (m) & $\begin{array}{c}0,81 \\
(68,8 \%)\end{array}$ & $\begin{array}{c}0,74 \\
(76,5 \%)\end{array}$ & $\begin{array}{c}0,60 \\
(85,7 \%)\end{array}$ & $\begin{array}{c}0,64 \\
(48,9 \%)\end{array}$ \\
\hline Temperatura $\left({ }^{\circ} \mathrm{C}\right)$ & $\begin{array}{c}25,2 \\
(7,8 \%)\end{array}$ & $\begin{array}{c}22,9 \\
(8,5 \%)\end{array}$ & $\begin{array}{c}25,9 \\
(5,6 \%)\end{array}$ & $\begin{array}{c}26,4 \\
(6,3 \%)\end{array}$ \\
\hline $\mathrm{pH}$ & $\begin{array}{c}5,84 \\
(7,2 \%)\end{array}$ & $\begin{array}{c}5,98 \\
(6,8 \%)\end{array}$ & $\begin{array}{c}6,40 \\
(6,8 \%)\end{array}$ & $\begin{array}{c}5,68 \\
(5,5 \%)\end{array}$ \\
\hline $\begin{array}{c}\text { Condutividade elétrica } \\
\qquad(\mu \mathrm{S} / \mathrm{cm})\end{array}$ & $\begin{array}{c}5,6 \\
(54,8 \%)\end{array}$ & $\begin{array}{c}11,8 \\
(91,0 \%)\end{array}$ & $\begin{array}{c}9,7 \\
(57,5 \%)\end{array}$ & $\begin{array}{c}6,7 \\
(46,9 \%)\end{array}$ \\
\hline $\begin{array}{c}\text { Oxigênio Dissolvido } \\
(\mathrm{mg} / \mathrm{L})\end{array}$ & $\begin{array}{c}6,59 \\
(16,0 \%)\end{array}$ & $\begin{array}{c}6,76 \\
(10,4 \%)\end{array}$ & $\begin{array}{c}5,64 \\
(12,6 \%)\end{array}$ & $\begin{array}{c}5,95 \\
(5,6 \%)\end{array}$ \\
\hline Turbidez (NTU) & $\begin{array}{c}0,83 \\
(182,1 \%)\end{array}$ & $\begin{array}{c}0,91 \\
(115,7 \%)\end{array}$ & $\begin{array}{c}2,27 \\
(98,0 \%)\end{array}$ & $\begin{array}{c}1,41 \\
(111,8 \%)\end{array}$ \\
\hline $\begin{array}{l}\text { Alcalinidade }(\mathrm{mg} \\
\left.\mathrm{CaCO}^{3} / \mathrm{L}\right)\end{array}$ & $\begin{array}{c}1,60 \\
(36,1 \%)\end{array}$ & $\begin{array}{c}1,63 \\
(36,7 \%)\end{array}$ & $\begin{array}{c}2,38 \\
(41,6 \%)\end{array}$ & $\begin{array}{c}2,12 \\
(34,4 \%)\end{array}$ \\
\hline Clorofila-a $(\mu \mathrm{g} / \mathrm{L})$ & $\begin{array}{c}0,43 \\
(212,4 \%)\end{array}$ & $\begin{array}{c}3,40 \\
(200,0 \%)\end{array}$ & $\begin{array}{c}5,07 \\
(151,7 \%)\end{array}$ & $\begin{array}{c}2,64 \\
(124,6 \%)\end{array}$ \\
\hline $\begin{array}{l}\text { Matéria Orgânica do } \\
\text { Sedimento }(\%)\end{array}$ & $\begin{array}{c}34,7 \\
(54,4 \%)\end{array}$ & $\begin{array}{c}36,3 \\
(47,6 \%)\end{array}$ & $\begin{array}{c}34,2 \\
(41,2 \%)\end{array}$ & $\begin{array}{c}40,4 \\
(31,7 \%)\end{array}$ \\
\hline $\mathrm{NO}_{3}^{-}(\mu \mathrm{g} / \mathrm{L})$ & $\begin{array}{c}12,6 \\
(186,1 \%)\end{array}$ & $\begin{array}{c}52,0 \\
(99,0 \%)\end{array}$ & $\begin{array}{c}32,6 \\
(138,6 \%)\end{array}$ & $*$ \\
\hline $\mathrm{NO}_{2}{ }^{-}(\mu \mathrm{g} / \mathrm{L})$ & $\begin{array}{c}5,0 \\
(120,3 \%)\end{array}$ & $\begin{array}{c}21,3 \\
(26,7 \%)\end{array}$ & $\begin{array}{c}11,2 \\
(98,7 \%)\end{array}$ & * \\
\hline $\mathrm{NH}_{4}{ }^{+}(\mu \mathrm{g} / \mathrm{L})$ & $\begin{array}{c}56,0 \\
(32,9 \%)\end{array}$ & $\begin{array}{c}65,8 \\
(32,6 \%)\end{array}$ & $\begin{array}{c}78,3 \\
(60,5 \%)\end{array}$ & $*$ \\
\hline Nitrogênio Total $(\mu \mathrm{g} / \mathrm{L})$ & $\begin{array}{c}172,6 \\
(59,4 \%)\end{array}$ & $\begin{array}{c}160,0 \\
(42,1 \%)\end{array}$ & $\begin{array}{c}289,4 \\
(56,8 \%)\end{array}$ & $*$ \\
\hline Fósforo Total $(\mu \mathrm{g} / \mathrm{L})$ & $\begin{array}{c}12,9 \\
(40,2 \%)\end{array}$ & $\begin{array}{c}16,1 \\
(81,7 \%)\end{array}$ & $\begin{array}{c}23,2 \\
(96,3 \%)\end{array}$ & $\begin{array}{c}14,0 \\
(38,9 \%)\end{array}$ \\
\hline $\mathrm{N}: \mathrm{P}$ Molar & $\begin{array}{c}34,7 \\
(45,9 \%)\end{array}$ & $\begin{array}{c}28,3 \\
(46,4 \%)\end{array}$ & $\begin{array}{c}41,2 \\
(69,8 \%)\end{array}$ & $*$ \\
\hline
\end{tabular}


Em contraste, profundidade, teores de matéria orgânica do sedimento, fósforo total na água e razão N:P da água não diferiram entre os períodos (Tabela 2). A menor profundidade encontrada foi $0,03 \mathrm{~m}$ na seca e a maior $2,07 \mathrm{~m}$ na transição chuva/seca. Tanto o menor quanto o maior teor de matéria orgânica do sedimento foram mensurados na transição chuva/seca $(12,8 \%$ e 79,4\%, respectivamente, ambas na Lagoa Grande CIF/GO). A maior concentração de fósforo total da água $(95,4 \mu \mathrm{g} / \mathrm{L})$ foi medida na transição seca/chuva. A razão molar N:P da água indicou limitação por P em todos os períodos amostrados $(\mathrm{N}: \mathrm{P}>18$; Figura 4F).

As maiores concentrações das formas nitrogenadas inorgânicas dissolvidas (nitrato e nitrito) foram medidas no período de seca, exceto do $\mathrm{NH}_{4}{ }^{+}$cuja maior concentração foi observada na transição seca/chuva (Figura 4A-C) assim como a maior concentração de nitrogênio total (Figura 4D). 

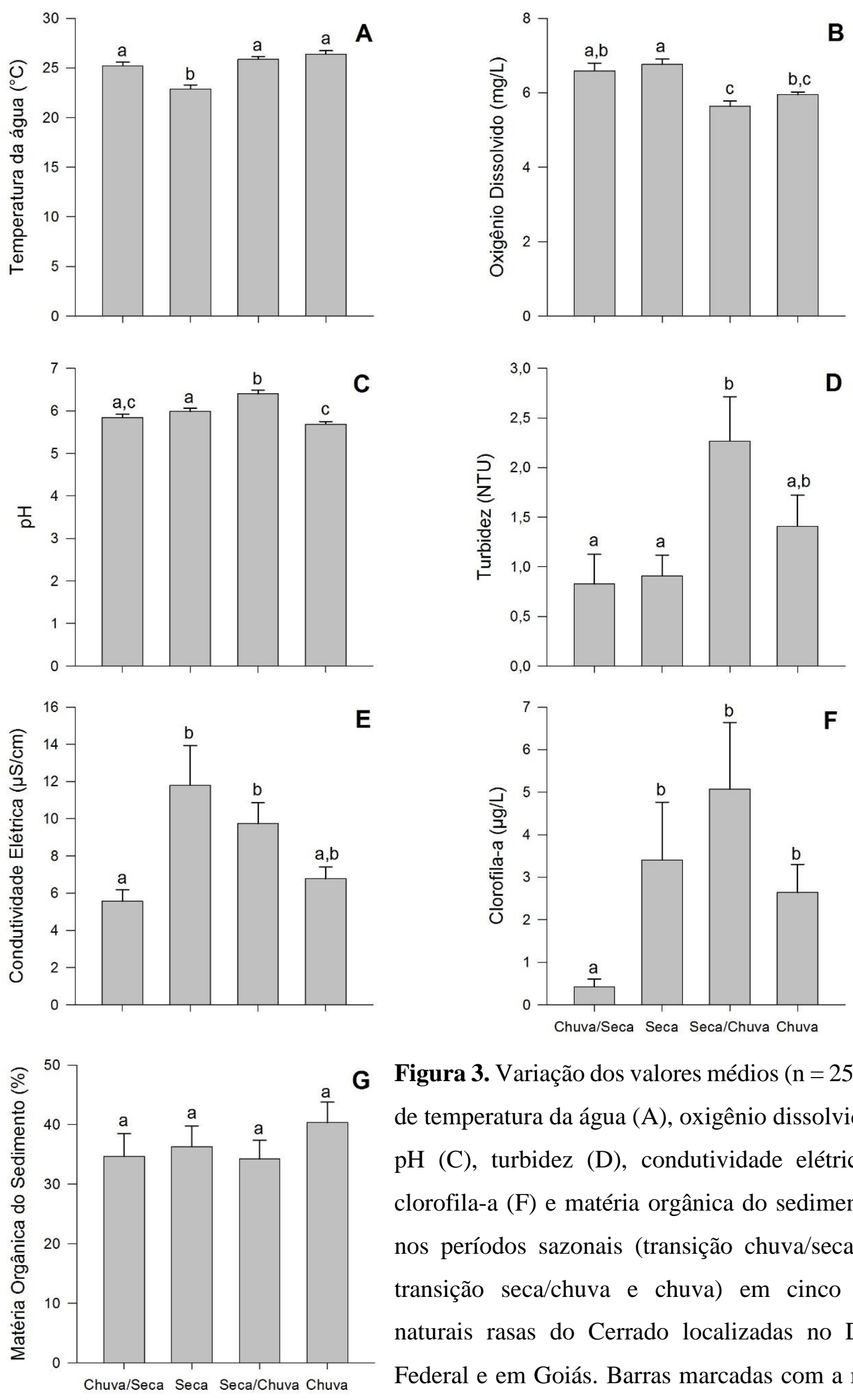

G Figura 3. Variação dos valores médios $(\mathrm{n}=25, \pm \mathrm{EP})$ de temperatura da água (A), oxigênio dissolvido (B), $\mathrm{pH}(\mathrm{C})$, turbidez (D), condutividade elétrica (E), clorofila-a (F) e matéria orgânica do sedimento (G) nos períodos sazonais (transição chuva/seca, seca, transição seca/chuva e chuva) em cinco lagoas naturais rasas do Cerrado localizadas no Distrito Federal e em Goiás. Barras marcadas com a mesma letra não são significativamente diferentes $(\mathrm{p} \leq 0,05)$. 

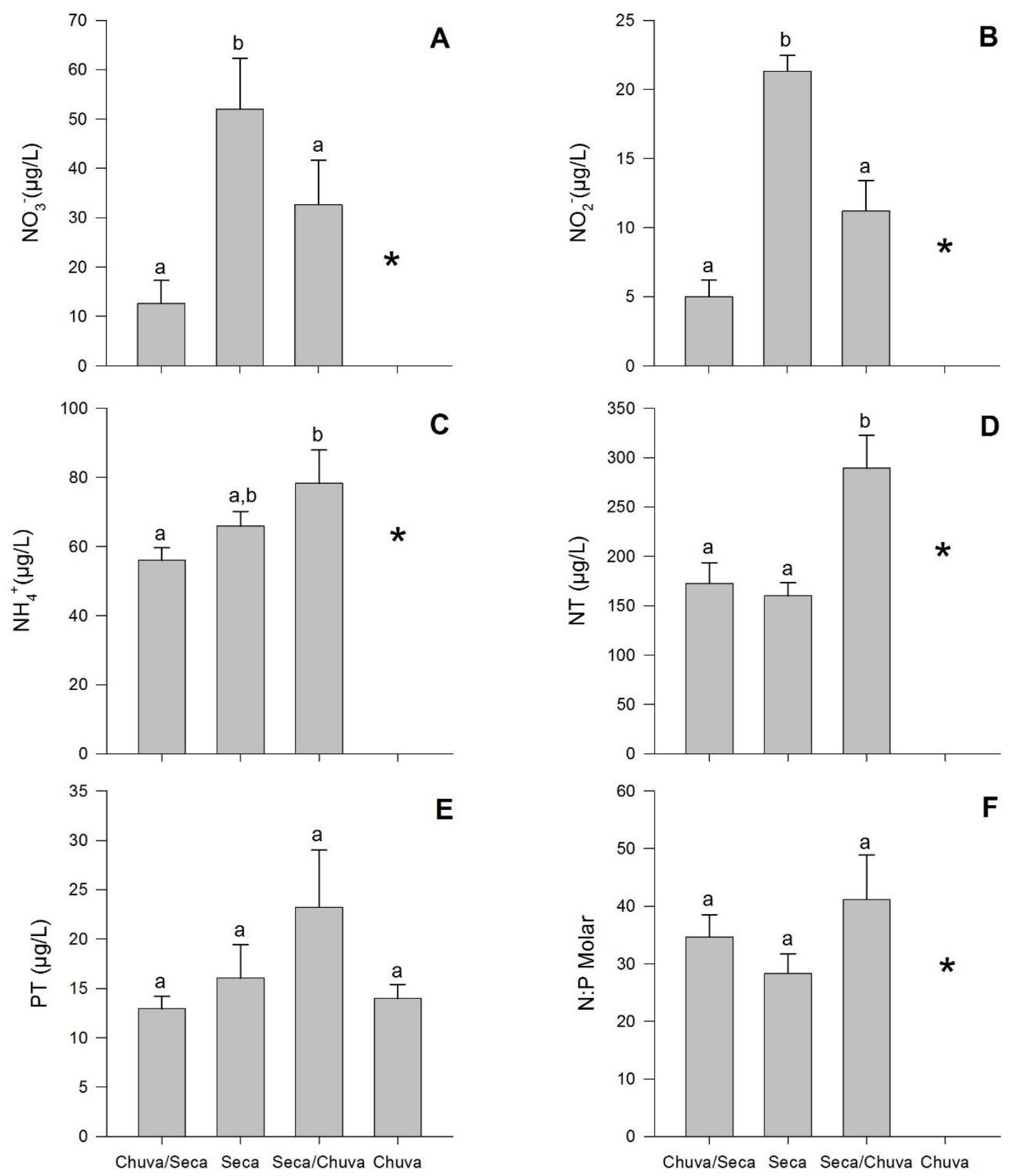

Figura 4. Variação dos valores médios $(n=25, \pm$ EP) de formas de nitrogênio dissolvido (A-C) e total (D), fósforo total (E) e razão molar N:P (F) nos períodos sazonais (transição chuva/seca, seca, transição seca/chuva e chuva) em cinco lagoas naturais rasas do Cerrado localizadas no Distrito Federal e em Goiás. * amostras não analisadas. Barras marcadas com a mesma letra não são significativamente diferentes $(\mathrm{p} \leq 0,05)$. 
Concentrações de macronutrientes nos compartimentos (macrófitas, perifíton $e$ sedimento)

A análise conjunta das lagoas, indicou que as concentrações de carbono, nitrogênio, fósforo, cálcio e potássio diferiram significativamente entre os compartimentos (Tabela 3). A concentração de carbono foi maior nas macrófitas aquáticas $(420,40 \pm 2,29 \mathrm{mg} / \mathrm{g}$ peso seco) que no perifíton $(280,30 \pm 9,03 \mathrm{mg} / \mathrm{g}$ peso seco)

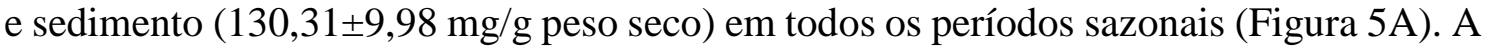
concentração de nitrogênio e de fósforo diferiram significativamente tanto entre os compartimentos como entre os períodos sazonais (Tabela 3). A concentração de nitrogênio do perifíton foi o dobro das concentrações dos outros compartimentos em todos os períodos sazonais (Figura 5B), sendo que a maior concentração de nitrogênio do perifíton foi observada na transição seca/chuva $(27,45 \pm 1,79 \mathrm{mg} / \mathrm{g}$ peso seco). A concentração de fósforo também foi maior no perifíton $(0,48 \pm 0,04 \mathrm{mg} / \mathrm{g}$ peso seco) que em macrófitas $(0,35 \pm 0,04 \mathrm{mg} / \mathrm{g}$ peso seco) e sedimento $(0,16 \pm 0,01 \mathrm{mg} / \mathrm{g}$ peso seco; Figura 5C). Em todas as estações, as menores concentrações de fósforo foram observadas no sedimento. Tanto entre os compartimentos quanto entre as estações (seca e chuva), a concentração de fósforo apresentou diferença significativa.

Tanto a concentração de cálcio quanto a de potássio diferiram significativamente entre os compartimentos e entre os períodos sazonais (Tabela 3). A concentração de cálcio foi maior no perifíton $(4,26 \pm 0,44 \mathrm{mg} / \mathrm{g}$ peso seco) que nos outros compartimentos em todos os períodos sazonais (Figura 5D). A maior concentração média de cálcio no perifíton foi observada na transição chuva/seca $(5,53 \pm 0,69 \mathrm{mg} / \mathrm{g}$ peso seco) e a menor concentração média foi no sedimento na transição seca/chuva $(0,13 \pm 0,03 \mathrm{mg} / \mathrm{g}$ peso seco). A concentração de potássio foi maior nas macrófitas aquáticas $(5,67 \pm 0,44 \mathrm{mg} / \mathrm{g}$ peso seco) que nos outros compartimentos em todos os períodos sazonais (Figura 5E). A maior concentração média de potássio foi observada nas macrófitas aquáticas na estação chuvosa $(7,67 \pm 1,11 \mathrm{mg} / \mathrm{g}$ peso seco) e a menor concentração média foi no sedimento também na chuva $(0,40 \pm 0,39 \mathrm{mg} / \mathrm{g}$ peso seco). 

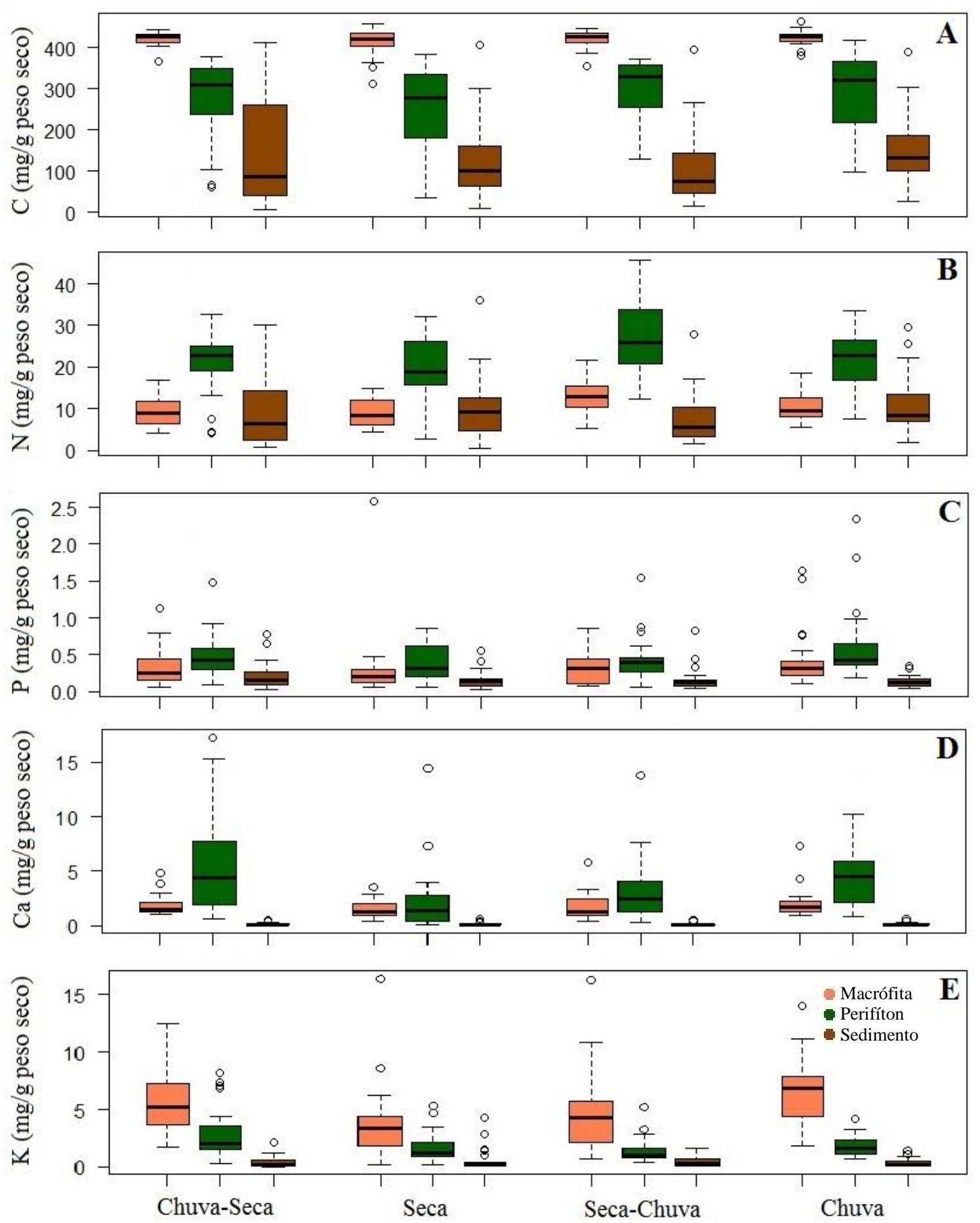

Figura 5. Concentração de carbono (A), nitrogênio (B), fósforo (C), Cálcio (D) e potássio (E) nos compartimentos macrófitas aquáticas, perifíton e sedimento nos períodos sazonais (transição chuva/seca, seca, transição seca/chuva e chuva) nas lagoas naturais rasas do Cerrado: Lagoa do Henrique (PNB-DF), Lagoa do Exército (PNB-DF), Lagoa Bonita (ESECAE-DF), Lagoa Cabocla (CIF-GO) e Lagoa Grande (CIF-GO). 
A análise de componentes principais evidenciou a separação dos compartimentos com relação às concentrações de carbono, nitrogênio, fósforo, cálcio e potássio com $80,4 \%$ da variabilidade dos dados explicada pelos dois primeiros eixos (Figura 6). No lado positivo do eixo 1, foram ordenadas as amostras de macrófitas aquáticas, que apresentaram alta correlação com carbono $(r=0,976)$ e potássio $(r=0,529)$. Em oposição, no lado negativo do eixo 1 foram ordenadas as amostras de sedimento. As amostras de perifíton foram ordenadas no lado positivo do eixo 2 , estando correlacionadas com a concentração de nitrogênio $(r=0,828)$ embora o referido eixo tenha apresentado menor explicabilidade.

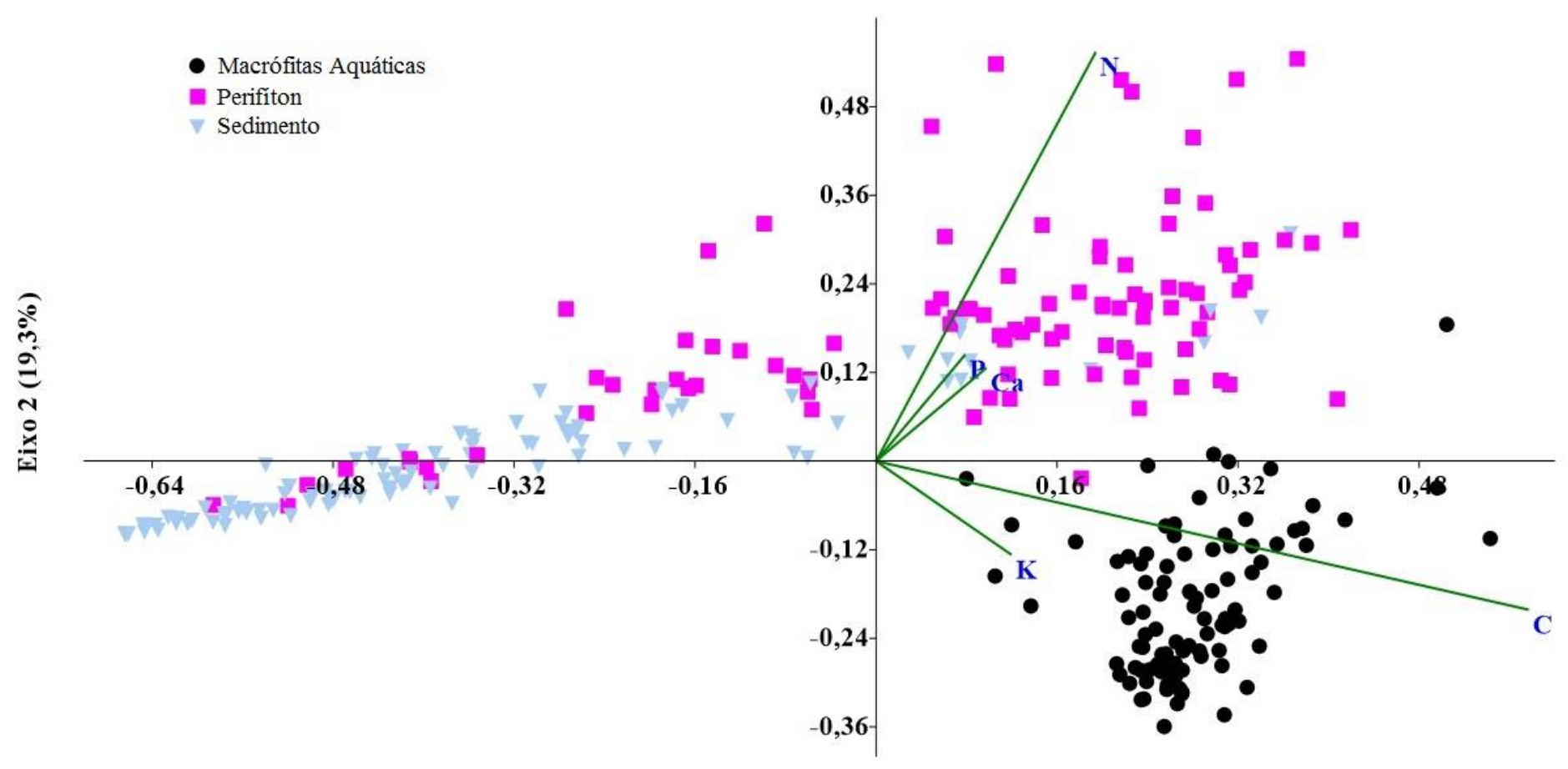

Eixo $1(61,1 \%)$

Figura 6. Análise de componentes principais da concentração de carbono, nitrogênio, fósforo, cálcio e potássio nos compartimentos macrófitas aquáticas, perifíton e sedimento nas lagoas naturais rasas do Cerrado: Lagoa do Henrique (PNB-DF), Lagoa do Exército (PNB-DF), Lagoa Bonita (ESECAE-DF), Lagoa Cabocla (CIF-GO) e Lagoa Grande (CIF-GO). 
Para todas as razões molares calculadas houve diferença significativa entre os compartimentos (Tabela 3). As macrófitas aquáticas apresentaram os maiores valores

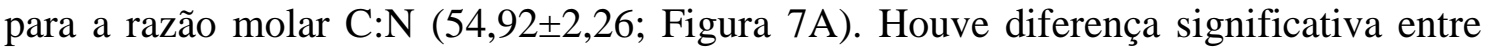
macrófitas e perifiton $(\mathrm{p}<0,0001)$ e entre macrófitas e sedimento $(\mathrm{p}<0,0001)$, mas não entre perifíton e sedimento $(\mathrm{p}=0,51)$. Com relação à razão molar $\mathrm{C}: \mathrm{P}$, as maiores razões também foram observadas em macrófitas, 5563,05£427,36, com diferença significativa entre os compartimentos (Figura 7B). A razão molar $\mathrm{N}: \mathrm{P}$ apresentou diferença significativa entre os compartimentos, sendo o maior valor encontrado no sedimento $(287,67 \pm 96,81)$ e o menor encontrado em macrófitas $(72,63 \pm 8,14$; Figura $7 \mathrm{C})$. As razões molares médias de $\mathrm{C}: \mathrm{N}: \mathrm{P}$ para os compartimentos ao longo dos períodos sazonais podem ser observadas na tabela 4. A maior razão molar média encontrada foi em macrófitas aquáticas (6781:108:1, na estação seca) e a menor no perifíton (1600:103:1, na estação chuvosa; Tabela 4). 
Tabela 3. Resultados dos modelos generalizados com efeito misto para avaliar se as concentrações de C, N, P, Ca e K; as razões molares e os estoques de N e P variam entre os compartimentos em função da sazonalidade nas lagoas naturais rasas do Cerrado: Lagoa do Henrique (PNB-DF), Lagoa do Exército (PNB-DF), Lagoa Bonita (ESECAEDF), Lagoa Cabocla (CIF-GO) e Lagoa Grande (CIF-GO).

\begin{tabular}{|c|c|c|c|c|}
\hline Variável resposta & Variável explicativa & DF & $\mathbf{F}$ & $\mathbf{p}$ \\
\hline \multirow{3}{*}{ Carbono } & Compartimento & 2 & 140,84 & $<0,001$ \\
\hline & Período & 3 & 2,22 & 0,090 \\
\hline & Compartimento x Período & 6 & 0,58 & 0,073 \\
\hline \multirow{3}{*}{ Nitrogênio } & Compartimento & 2 & 61,84 & $<0,001$ \\
\hline & Período & 3 & 2,93 & $\mathbf{0 , 0 3 8}$ \\
\hline & Compartimento x Período & 6 & 2,62 & $\mathbf{0 , 0 1 4}$ \\
\hline \multirow{3}{*}{ Fósforo } & Compartimento & 2 & 75,09 & $<0,001$ \\
\hline & Período & 3 & 3,81 & $\mathbf{0 , 0 1 1}$ \\
\hline & Compartimento x Período & 6 & 1,55 & 0,146 \\
\hline \multirow{3}{*}{ Cálcio } & Compartimento & 2 & 431,57 & $<0,001$ \\
\hline & Período & 3 & 7,55 & $<0,001$ \\
\hline & Compartimento x Período & 6 & 2,18 & $\mathbf{0 , 0 3 8}$ \\
\hline \multirow{3}{*}{ Potássio } & Compartimento & 2 & 219,75 & $<0,001$ \\
\hline & Período & 3 & 4,66 & 0,005 \\
\hline & Compartimento x Período & 6 & 3,61 & $\mathbf{0 , 0 0 1}$ \\
\hline \multirow{3}{*}{ C:N molar } & Compartimento & 2 & 503,16 & $<0,001$ \\
\hline & Período & 3 & 4,81 & 0,004 \\
\hline & Compartimento x Período & 6 & 3,37 & $\mathbf{0 , 0 0 2}$ \\
\hline \multirow{3}{*}{ C:P molar } & Compartimento & 2 & 32,36 & $<0,001$ \\
\hline & Período & 3 & 0,95 & 0,447 \\
\hline & Compartimento x Período & 6 & 3,67 & 0,001 \\
\hline \multirow{3}{*}{$\mathrm{N}: P$ molar } & Compartimento & 2 & 6,23 & 0,003 \\
\hline & Período & 3 & 2,59 & 0,068 \\
\hline & Compartimento x Período & 6 & 3,68 & $<0,001$ \\
\hline \multirow{3}{*}{ Estoque $\mathbf{N}$} & Compartimento & 1 & 81,58 & 0,001 \\
\hline & Período & 3 & 2,54 & 0,061 \\
\hline & Compartimento x Período & 3 & 3,06 & $\mathbf{0 , 0 2 5}$ \\
\hline \multirow{3}{*}{ Estoque $P$} & Compartimento & 1 & 126,52 & $<0,001$ \\
\hline & Período & 3 & 1,89 & 0,138 \\
\hline & Compartimento x Período & 3 & 3,19 & $\mathbf{0 , 0 2 1}$ \\
\hline
\end{tabular}



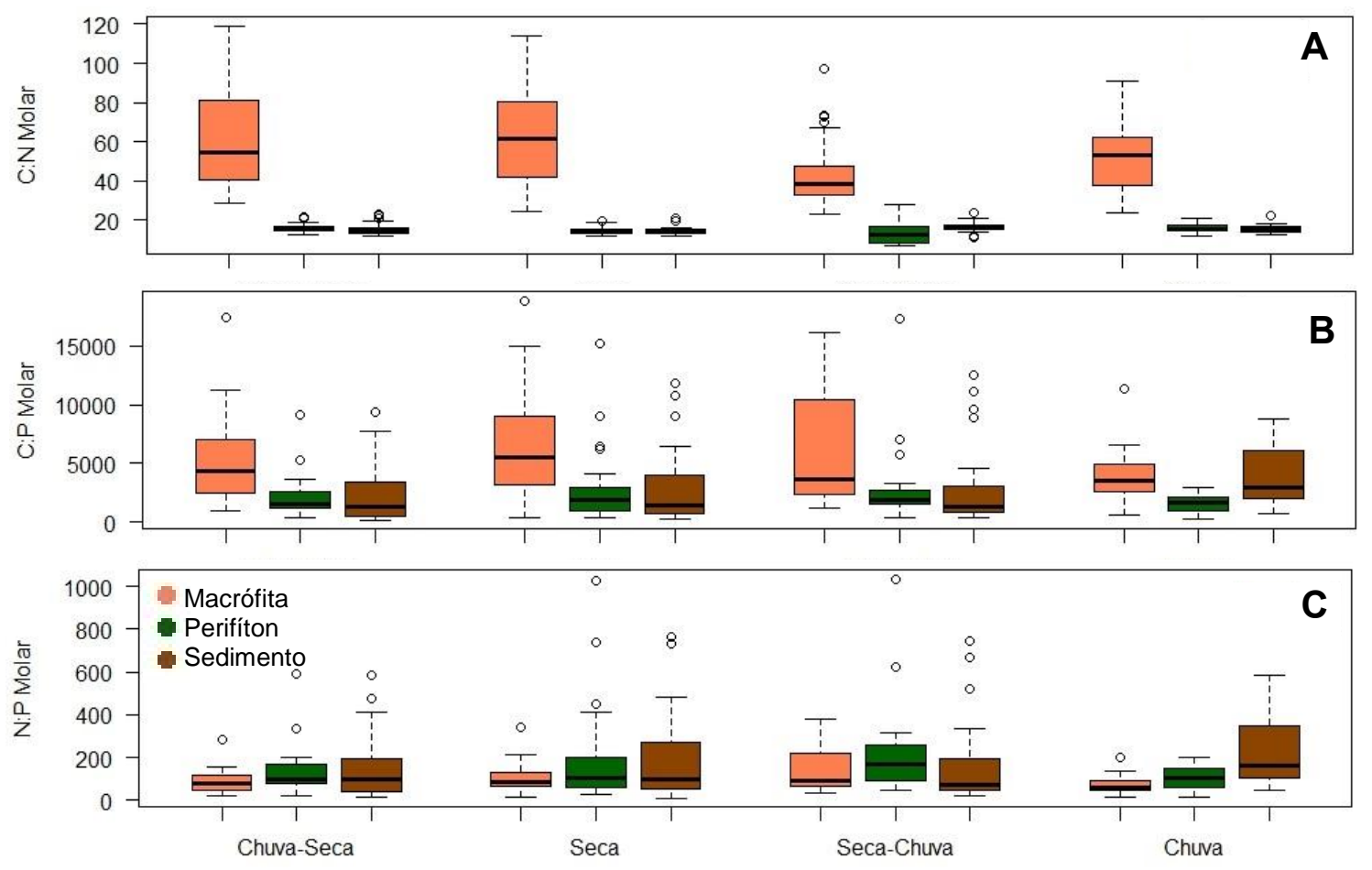

Figura 7. Razão molar C:N (A), C:P (B) e N:P (C) dos compartimentos macrófitas aquáticas, perifíton e sedimento nos períodos sazonais (transição chuva/seca, seca, transição seca/chuva e chuva) nas lagoas naturais rasas do Cerrado: Lagoa do Henrique (PNB-DF), Lagoa do Exército (PNB-DF), Lagoa Bonita (ESECAE-DF), Lagoa Cabocla (CIF-GO) e Lagoa Grande (CIF-GO).

Tabela 4. Razões molares médias (C:N:P) dos compartimentos macrófitas aquáticas, perifíton e sedimento nos períodos sazonais nas lagoas naturais rasas do Cerrado: Lagoa do Henrique (PNB-DF), Lagoa do Exército (PNB-DF), Lagoa Bonita (ESECAE-DF), Lagoa Cabocla (CIF-GO) e Lagoa Grande (CIF-GO).

\begin{tabular}{llcll}
\hline & $\begin{array}{c}\text { Transição } \\
\text { Chuva/Seca }\end{array}$ & Seca & $\begin{array}{c}\text { Transição } \\
\text { Seca/Chuva }\end{array}$ & \multicolumn{1}{c}{ Chuva } \\
\hline Macrófita & $5198: 88: 1$ & $6781: 108: 1$ & $6480: 136: 1$ & $3826: 72: 1$ \\
Perifíton & $2131: 135: 1$ & $2859: 198: 1$ & $2993: 219: 1$ & $1600: 103: 1$ \\
Sedimento & $2530: 158: 1$ & $3036: 200: 1$ & $2948: 181: 1$ & $4073: 231: 1$ \\
\hline
\end{tabular}

Com relação aos estoques, tanto de nitrogênio quanto de fósforo, houve diferença significativa entre os compartimentos macrófitas aquáticas e perifíton, sendo os maiores valores médios encontrados nas macrófitas aquáticas (Tabela 3; Figura 8). Os valores 
médios do estoque de nitrogênio variaram de $1485,9 \mathrm{mg} / \mathrm{m}^{2}$ a $2250,7 \mathrm{mg} / \mathrm{m}^{2}$ nas macrófitas aquáticas, enquanto que no perifíton a variação foi entre 534,8 mg/m² e 1069,3 $\mathrm{mg} / \mathrm{m}^{2}$ (Figura 8A). Já para o estoque de fósforo, os valores médios variaram de 47,6 $\mathrm{mg} / \mathrm{m}^{2}$ a $72,9 \mathrm{mg} / \mathrm{m}^{2}$ nas macrófitas e no perifíton entre $13,6 \mathrm{mg} / \mathrm{m}^{2}$ e $23,5 \mathrm{mg} / \mathrm{m}^{2}$ (Figura 8B).
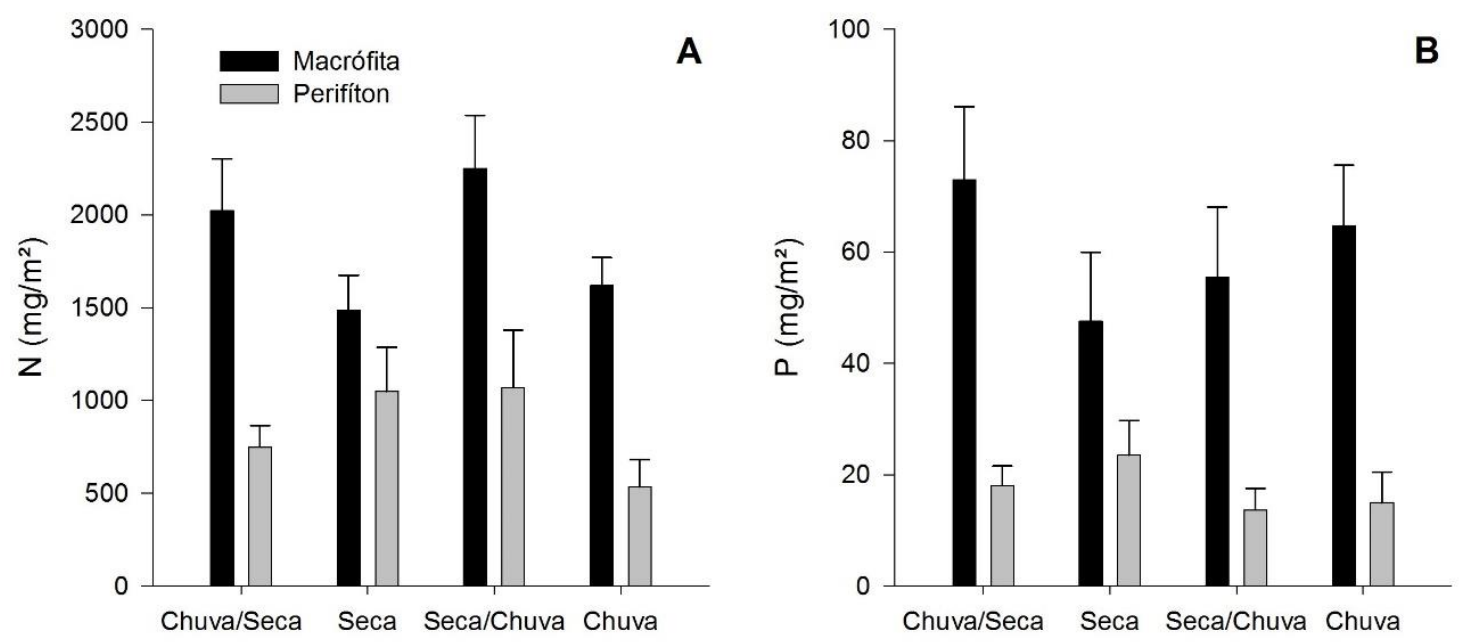

Figura 8. Estoque de nitrogênio (A) e fósforo (B) em $\mathrm{mg} / \mathrm{m}^{2}$ nos compartimentos macrófitas aquáticas e perifíton nos períodos sazonais (transição chuva/seca, seca, transição seca/chuva e chuva) nas lagoas naturais rasas do Cerrado: Lagoa do Henrique (PNB-DF), Lagoa do Exército (PNB-DF), Lagoa Bonita (ESECAE-DF), Lagoa Cabocla (CIF-GO) e Lagoa Grande (CIF-GO).

\section{DISCUSSÃo}

As variações na disponibilidade de nutrientes na água das lagoas rasas estudadas, principalmente a série nitrogenada, estão associadas às variações sazonais de precipitação no Cerrado. Nitrito e nitrato apresentaram as maiores concentrações no período de seca, enquanto amônio e nitrogênio total na transição seca/chuva, evidenciando a importância dos primeiros eventos de precipitação para a dinâmica de nutrientes. Estudos em ambientes tropicais apontam uma maior concentração de nutrientes na estação seca em sistemas lóticos (Soares et al., 2007; Fonseca \& Mendonça-Galvão, 2014; Moura \& Henry-Silva, 2015), enquanto que para sistemas lênticos, a maior concentração é encontrada na estação chuvosa (Borduqui et al., 2008; Dantas et al., 2008; Cordeiro et al., 2016). Entretanto, sistemas lóticos apresentam respostas diferentes na dinâmica de 
nutrientes devido à maior velocidade de corrente e transporte mais rápido dos nutrientes que entram com a chuva, ao contrátrio de ambientes lênticos que podem armazenar tais nutrientes provenientes do escoamento dos solos adjacentes.

A concentração de carbono foi bem mais elevada em macrófitas aquáticas que nos outros compartimentos, independente dos períodos sazonais. Isso pode estar relacionado ao investimento em sustentação desses organismos, mesmo em ambientes aquáticos e/ou a assimilação de carbono que ocorre nos tecidos fotossintetizantes. Sterner \& Elser (2002) afirmam que as concentrações de carbono em organismos autotróficos geralmente não apresentam grandes variações, entretanto, plantas vasculares apresentam maiores valores devido às altas concentrações de carbono em tecidos estruturais. As macrófitas aquáticas desempenham um papel fundamental no funcionamento de ambientes lênticos e influenciam outras comunidades aquáticas, podendo fornecer área para colonização e servir como fonte extra de nutrientes (Kahlert \& Pettersson, 2002; Murdock \& Dodds, 2007).

As concentrações de nitrogênio e fósforo foram maiores no perifíton, seguido pelas macrófitas e sedimento, corroborando a hipótese proposta. Além disso, houve diferença significativa entre os períodos de coleta, em que os maiores valores observados foram na transição seca/chuva e chuva, evidenciando a importância da variação sazonal na dinâmica desses nutrientes em ambientes lênticos rasos. A concentração de nitrogênio e fósforo total na água é bem menor que a concentração encontrada no perifíton, indicando o uso de diversas fontes pela comunidade perifítica, corroborando resultados encontrados em outros estudos (Dodds, 2003; Santos et al., 2013). O perifíton contribui para a produtividade total dos ecossistemas aquáticos, especialmente em lagoas rasas, uma vez que esse biofilme perifítico pode afetar significativamente a migração de nutrientes (especialmente fósforo), tanto entre a coluna d'água quanto a interface água/sedimento (Lu et al., 2016). As macrófitas aquáticas podem liberar nutrientes, estabilizando o estado nutricional da comunidade, principalmente quando o ambiente é nutricionalmente limitado (Kahlert \& Pettersson, 2002). Além disso, a presença do perifíton pode levar à co-precipitação de fósforo com carbonato de cálcio ou sua adsorção em cristais de $\mathrm{CaCO}_{3}$ (Dodds, 2003; Scinto \& Reddy, 2003). Dessa forma, o fósforo ficaria menos disponível para outros compartimentos do ecossistema, como é possível observar no presente estudo em que as macrófitas aquáticas apresentam concentrações menores desse nutriente em todos os períodos sazonais. 
As lagoas naturais do Cerrado estudadas são formadas, principalmente, pelas contribuições do afloramento do lençol freático e da precipitação. No presente estudo é possível notar que a concentração de fósforo no sedimento é, pelo menos, dez vezes maior que a concentração presente na água, indicando que as concentrações de fósforo da água podem depender das interações sedimento/água. As características biogeoquímicas dos sedimentos desempenham um papel importante na dinâmica do fósforo, influenciando a mobilização e transporte desse nutriente e refletem os tipos de solos das áreas adjacentes e a geologia do local. A classe de solo predominante no Cerrado é Latossolo, enriquecida com óxido de ferro e de alumínio e com baixa quantidade de nutrientes. Como Fe é abundante nos sedimentos de lagos tropicais, os óxidos de ferro têm sido considerados como o fator mais importante na regulação da capacidade de adsorção de fósforo nos sedimentos (Zhang \& Huang, 2007; Fonseca et al., 2011). Além disso, esses ambientes são rasos e bem oxigenados, apresentando valores médios entre 5,64 a 6,76 mg/L, possibilitando uma constante mistura da coluna d'agua. O sedimento desempenha um papel importante no ciclo do fósforo nos ecossistemas aquáticos, agindo como um sumidouro e uma fonte de fósforo devido ao transporte contínuo desse nutriente através da interface sedimento/água (Søndergaard et al., 2003; Jarvie et al., 2005; Jorcin \& Nogueira, 2005). As águas subterrâneas podem ser responsáveis por até $85 \%$ do fósforo total e $67 \%$ do nitrogênio total em ambientes em que a água do lençol freático é o componente principal para o abastecimento do corpo d'água (Périllon \& Hilt, 2016). As águas subterrâneas de Brasília apresentam baixa condutividade elétrica $(<13 \mu \mathrm{S} / \mathrm{cm}), \mathrm{pH}$ ácido $(<5)$ e baixas concentrações de metais alcalinos (inferiores a 0,5 mg/ L), explicados pela falta natural de bases no solo e o alto teor de minerais degradados (Boaventura \& Freitas, 2006). Portanto, o regime regular da mistura da coluna d'água garante as condições necessárias para a produção primária por meio do aumento do fluxo de nutrientes e, consequentemente, favorece o estabelecimento das comunidades perifíticas e das macrófitas aquáticas nesses ambientes oligotróficos e rasos.

Com base na razão estequiométrica N:P 18:1 como indicativa de limitação por $\mathrm{P}$ (Kahlert, 1998), todos os compartimentos em todos os períodos sazonais foram limitados por $\mathrm{P}$, pois a menor razão N:P encontrada foi 72:1 no compartimento macrófita durante a estação chuvosa. As razões de Redfield têm funcionado como uma referência para a determinação de limitação de nutrientes em ambientes aquáticos. Por exemplo, Hillebrand \& Sommer (1999) investigaram as razões celulares de nutrientes em algas 
perifíticas como um indicador do status nutricional desta comunidade e concluíram que razões $\mathrm{N}: \mathrm{P}<13$ indicaram limitação por nitrogênio, enquanto razões $\mathrm{N}: \mathrm{P}>22$ ou C:P >180 indicaram limitação por fósforo. No Brasil, as pesquisas sobre limitação de nutrientes no perifíton estão concentrados nos ambientes da região Sudeste (Huszar et al., 2005). Na maioria dos casos, os dados apontam uma forte limitação por fósforo nos ambientes, com razões N:P variando, em média, de 34 a 320 (Borduqui et al., 2008, Ferragut \& Bicudo, 2009; Santos et al., 2013). Em um lago raso amazônico, a razão N:P tanto da água quanto do perifíton indicou alta limitação por $\mathrm{P}$ e foi influenciada pelo tempo de colonização e pela sazonalidade (França et al., 2009). Portanto, as elevadas razões C:P e N:P encontradas em todos os compartimentos avaliados estariam associadas, conforme citado anteriormente, à limitação por fósforo e, também, a aspectos metabólicos dos compartimentos, enquanto que a ocorrência de maiores razões $\mathrm{C}: \mathrm{N}$ nas macrófitas aquáticas pode ser devido as maiores concentrações de carbono nos tecidos deste compartimento.

As razões molares médias $\mathrm{C}: \mathrm{N}: \mathrm{P}$ encontradas no presente estudo foram muito elevadas quando comparadas a outros estudos, sendo a maior razão encontrada em macrófitas aquáticas (6781:108:1, na estação seca) e a menor no perifíton (1600:103:1, na estação chuvosa). Um estudo experimental simulando lagos rasos temperados encontrou razões C:N:P do sêston iguais a 109:13,6:1, ou seja, muito semelhantes às de Redfield, e indicando ausência de limitação por nutrientes (Ventura et al., 2008); por outro lado, as razões registradas no epifíton (212:21,9:1) e na macrófita submersa Elodea canadensis $(525: 27,4: 1)$ indicaram limitação por fósforo. A comparação da estequiometria de várias espécies de macrófitas submersas em 24 lagos na China não mostrou relação entre as concentrações de $\mathrm{C}, \mathrm{N}$ e $\mathrm{P}$, apontando que o papel estrutural do C foi independente do papel bioquímico do N e P (Xing et al., 2013); por outro lado, houve correlação entre as concentrações de $\mathrm{N}$ e P nos tecidos das macrófitas com razões $\mathrm{N}: \mathrm{P}$ iguais a 5,2:1 em plantas submersas, ou seja, valores menores do que o registrado na literatura para plantas vasculares terrestres $(15,0: 1)$ ou aquáticas $(12,5: 1)$.

A alta diversidade biológica encontrada nessas lagoas naturais rasas do Cerrado (Estrela et al., 2011; Sousa et al., 2014) pode ser infuenciada pelos padrões e estratégias de uso de recursos nutricionais, de acordo com a teoria de partição de recursos. Essa teoria prediz que diferentes estratégias na obtenção de recursos, quando escassos, podem permitir a coexistência de mais espécies em um mesmo local (Begon et al., 2006). Em 
sua hipótese da razão de recursos, Tilman (1985) propõe que a diversidade de espécies coexistentes deve ser proporcional ao número total de recursos limitantes em um sistema e enfatiza o papel da mudança das habilidades competitivas relativas das espécies à medida que as condições mudam com o tempo.

Apesar das macrófitas aquáticas apresentarem menores concentrações de nitrogênio e fósforo quando comparadas ao perifíton, as mesmas representam um importante estoque desses elementos em função da maior biomassa. Dessa forma, é possível que não exista uma interação competitiva por nutrientes entre as macrófitas aquáticas e perifíton, uma vez que esses grupos apresentam estratégias e demandas distintas de utilização dos nutrientes, sendo as macrófitas uma fonte em longo prazo para o ecossistema enquanto o perifíton apresenta uma dinâmica mais lábil para esses nutrientes, revelando um mecanismo de retenção e liberação em curto prazo de nutrientes. A presença de comunidades perifíticas altamente produtivas em sistemas aquáticos que são limitados por fósforo está associada ao aumento da eficiência de absorção e reciclagem de nutrientes, devido à associação de componentes microbianos autotróficos e heterotróficos (Wetzel, 2001).

\section{CONCLUSÕeS}

O funcionamento dos ecossistemas, tanto aquáticos quanto terrestres, está relacionado à produtividade e à ciclagem de nutrientes. Considerando nitrogênio e fósforo, nossa hipótese foi corroborada, uma vez que, para esses nutrientes, as maiores concentrações foram encontradas no perifíton, seguido das macrófitas e sedimento. Nossos resultados demonstraram flutuações de curto prazo (transições entre as estações) nas concentrações dos nutrientes em todos os compartimentos, evidenciado a importância dos primeiros eventos de precipitação nesses ecossistemas. As lagoas naturais estudadas são compostas por diferentes compartimentos, que apesar de distintos mantêm estreita comunicação entre si. Além disso, as concentrações de nutrientes em macrófitas aquáticas e perifíton estão mais associadas à produção de biomassa e à composição de espécies. Dentro dos ecossistemas, há feedbacks entre o ambiente físico e o papel das espécies nos processos biogeoquímicos, dessa forma, existe uma forte relação espacial dos organismos com a dinâmica de nutrientes em nível de ecossistema. Sugerimos que estudos futuros abordem as interações entre macrófitas aquáticas e perifíton nesses ambientes 
oligotróficos onde a disponibilidade de recursos é limitada. Além disso, propomos que seja estudada a distribuição espacial desses organismos, a fim de investigar a existência de partição espacial de recursos.

\section{REFERÊNCIAS}

Begon, M., Townsend, C. R. \& Harper, J. L. 2006. Ecology, from Individuals to Ecosystems. 750pp. Blackwell Publishing.

Boaventura, G. R. \& Freitas, A. L. S. 2006. Inorganic parameters as water quality indicators in acidic groundwater in a tropical region - Brasilia-DF (Brazil). Water, Air, and Soil Pollution, 171: 135-151.

Borduqui, M., Ferragut, C. \& Bicudo, C. E. M. 2008. Chemical composition and taxonomic structure vertical and seasonal variation of periphyton community in a shallow hypereutrophic reservoir (Garças Reservoir, São Paulo, Brazil). Acta Limnologica Brasiliensia, 20: 381-392.

Burkholder, J. M. \& Wetzel, R. G. 1990. Epiphytic alkaline phosphatase on natural and artificial plants in an oligotrophic lake: Re-evaluation of the role of macrophytes as a phosphorus source for epiphytes. Limnology and Oceanography, 35: 736747.

Carmouze, J.P. 1994. O metabolismo dos ecossistemas aquáticos: fundamentos teóricos, métodos de estudo e análises químicas. Editora Edgard Blücher/FAPESP, São Paulo.

Cordeiro, R. S.; Barbosa, J. E. L.; Lima-Filho, G. Q. \& Barbosa, L. G. 2016. Periphytic algae dynamics in lentic ecosystems in the Brazilian semiarid. Brazilian Journal of Biology, DOI: dx.doi.org/10.1590/1519-6984.16815.

Dantas, E. W., Moura, A. N., Bittencourt-Oliveira, M. C., Neto, J. D. T. A. \& Cavalcanti, A. D. C. 2008. Temporal variation of the phytoplankton community at short sampling intervals in the Mundaú reservoir, Northeastern Brazil. Acta Botanica Brasilica, 22: 970-982.

Dodds, W. K. 2003. The role of periphyton in phosphorus retention in shallow freshwater aquatic systems. Journal of Phycology, 39: 840-849.

Esteves, F. A. \& Camargo, A. F. M. 2011. Sedimentos Límnicos. In: Fundamentos de Limnologia (Coord. F. A. Esteves). pp. 339-354. Interciência, Rio de Janeiro. 
Estrela, L. M. B., Fonseca, B. M. \& Bicudo, C. E. M. 2011. Desmídias perifíticas de cinco lagoas do Distrito Federal, Brasil: I - Gênero Cosmarium Corda ex Ralfs. Hoehnea, 38: 527-552.

Ferragut, C. \& Bicudo, D. C. 2009. Efeito de diferentes níveis de enriquecimento por fósforo sobre a estrutura da comunidade perifítica em represa oligotrófica tropical (São Paulo, Brasil). Revista Brasileira de Botânica, 32: 571-585.

Fonseca, B. M. \& Mendonça-Galvão, L. 2014. Pristine aquatic systems in a Long Term Ecological Research (LTER) site of the Brazilian Cerrado. Environmental Monitoring and Assessment, 186: 8683-8695.

Fonseca, B. M., Mendonça-Galvão, L., Padovesi-Fonseca, C., Abreu, L. M. \& Fernandes, A. C. M. 2014. Nutrient baselines of Cerrado low-order streams: comparing natural and impacted sites in the Central Brazil. Environmental Monitoring and Assessment, 186: 19-33.

Fonseca, R., Canário, T., Morais, M. \& Barriga, F. J. A. S. 2011. Phosphorus sequestration in Fe-rich sediments from two Brazilian tropical reservoirs. Applied Geochemistry, 26: 1607-1622.

França, R. C. S., Lopes, M. R. M. \& Ferragut, C. 2009. Temporal variation of biomass and status nutrient of periphyton in shallow Amazonian Lake (Rio Branco, Brazil). Acta Limnologica Brasiliensia, 21: 175-183.

Giordano, M. 2013. Homeostasis: an underestimated focal point of ecology and evolution. Plant Science, 211: 92-101.

Gomes, P. P. 2007. Variação espacial e temporal da comunidade fitoplanctônica da Lagoa Bonita, DF. Brasília, Universidade de Brasília, 76p. Dissertação de Mestrado.

Hammer, Ø., Harper, D. A. T. \& Ryan, P. D. 2001. PAST: Paleontological Statistics software pakage for education and data analysis. Palaeontologia Electronica, 4: $9 \mathrm{pp}$.

Hillebrand, H. \& Sommer, U. 1999. The nutrient stoichiometry of benthic microalgae growth: Redfield proportions are optimal. Limnology \& Oceanography, 44:440446.

Huszar, V. L. M., Bicudo, D. C., Giani, A., Ferragut, C., Martinelli, L. A. \& Henry, R. 2005. Subsídios para compreensão sobre a limitação de nutrientes ao crescimento do fitoplâncton e perifíton em ecossistemas continentais lênticos no Brasil. In: 
Lições em limnologia: fronteiras conceituais (Eds. F. Roldam, D. César \& M. Marinho). pp.243-260. RiMa Editora, São Carlos.

Jarvie, H. P., Jürgens, M. D., Williams, R. J., Neal, C., Davies, J. J. L., Barrett, C. \& White, J. 2005. Role of river bed sediments as sources and sinks of phosphorus across two major eutrophic UK river basins: the Hampshire Avon and Herefordshire Wye. Journal of Hydrology, 304: 51-74.

Jorcin, A. \& Nogueira, M. G. 2005. Temporal and spatial patterns based on sediment and sediment-water interface characteristics along a cascade of reservoirs (Paranapanema River, south-east Brazil). Lakes \& Reservoirs Research \& Management, 10: 1-12.

Kahlert, M. 1998. C:N:P ratios of freshwater benthic algae. Archiv für Hydrobiologie. Supplementband. Advances in Limnology, 51: 105-114.

Kahlert, M. \& Pettersson, K. 2002. The impact of substrate and lake trophy on the biomass and nutrient status of benthic algae. Hydrobiologia, 489: 161-169.

Lu, H., Wan, J., Li, J., Shao, H. \& Wu, Y. 2016. Periphytic biofilm: A buffer for phosphorus precipitation and release between sediments and water. 2016. Chemosphere, 144: 2058-2064.

Luczak, C., Janquin, M. \& Kupka, A. 1997. Simple standard procedure for the routine determination of organic matter in marine sediment. Hydrobiologia, 345: 87-94.

Marker, A. F. H., Nusch, H., Rai, H. \& Riemann, B. 1980. The measurement of photosynthetic pigments in freshwaters and standardization of methods: conclusion and recomendations. Archiv für Hydrobiologie, 14: 91-106.

Moura, R. S. T. \& Henry-Silva, G. G. 2015. Limnological characteristics of a hydrographic basin of the Brazilian semiarid region. Acta Limnologica Brasiliensia, 27: 51-59.

Murdock, J. N. \& Dodds, W. K. 2007. Linking benthic algal to stream substratum topography. Journal of Phycology, 43: 449-460.

Norici, A., Bazzoni A. M., Pugnetti, A., Raven, J. A. \& Giordano, M. 2011. Impact of irradiance on the $\mathrm{C}$ allocation in the coastal marine diatom Skeletonema marinoi Sarno \& Zingone. Plant Cell and Environment, 34: 1666-1677.

O’Farrel, I., Pinto, P. T., Rodríguez, P. L., Chaparro, G. \& Pizarro, H. N. 2009. Experimental evidence of the dynamic effect of free-floating plants on phytoplankton ecology. Freshwater Biology, 54: 363-375. 
Parron, L. M., Bustamante, M. M. C. \& Markewitz, D. 2011. Fluxes of nitrogen and phosphorus in a gallery forest in the Cerrado of central Brazil. Biogeochemistry, 105: 89-104.

Périllon, C. \& Hilt, S. 2016. Groundwater influence differentially affects periphyton and macrophyte production in lakes. Hydrobiologia, 778: 91-103.

R Core Team. 2015. R: A language and environment for statistical computing. $R$ Foundation for Statistical Computing, Vienna, Austria.

Sager, L. 2009. Measuring the trophic status of ponds: Relationships between summer rate of periphytic net primary productivity and water physico-chemistry. Water Research, 43: 1667-1679.

Santos, T. R., Ferragut, C. \& Bicudo, C. E. M. 2013. Does macrophyte architecture influence periphyton? Relationships among Utricularia foliosa, periphyton assemblage structure and its nutrient (C, N, P) status. Hydrobiologia, 714: 71-83.

Sardans. J., Rivas-Ubach, A. \& Peñuelas, J. 2012. The elemental stoichiometry of aquatic and terrestrial ecosystems and its relationships with organismic lifestyle and ecosystem structure and function: a review and perspectives. Biogeochemistry, 111: 1-39.

Sartory, D. P. \& Grobbelaar, J. U. 1984. Extraction of Chlorophyll a from freshwater phytoplankton for spectrophotometric analysis. Hydrobiologia, 114: 177-187.

Scinto, L. J. \& Reddy, K. R. 2003. Biotic and abiotic uptake of phosphorus by periphyton in a subtropical freshwater wetland. Aquatic Botany, 77: 203-222.

Silva, A. M., Assad, E. D. \& Evangelista, B. A. 2008. Caracterização Climática do Bioma Cerrado. In: Cerrado Ecologia e Flora (Eds. S. M Sano, S. P. Almeida \& J. F. Ribeiro). pp. 69-88. Embrapa Cerrado, Brasília.

Silva, J. S. O., Bustamante, M. M. C., Markewitz, D., Krusche, A. V. \& Ferreira, L. G. 2011. Effects of land cover on chemical characteristics of streams in the Cerrado region of Brazil. Biogeochemistry, 105: 75-88.

Soares, M. C., Huszar, V. L. M. \& Roland, F. 2007. Phytoplankton dynamics in two tropical rivers with different degrees of human impact (Southeast Brazil). River Research and Applications, 23: 698-714.

Søndergaard, M., Jensen, J. P. \& Jeppesen, E. 2003. Role of sediment and internal loading of phosphorus in shallow lakes. Hydrobiologia, 506-509: 135-145. 
Søndergaard, M., Johansson, L. S., Lauridsen, T. L., Jørgensen, T. B., Liboriussen, L. \& Jeppesen, E. 2010. Submerged macrophytes as indicators of the ecological quality of lakes. Freshwater Biology, 55: 893-908.

Sousa, F. D. R. 2012. Diversidade da fauna de Cladocera (Crustacea, Branchiopoda) associada à macrófitas em áreas úmidas naturais do Cerrado do Brasil Central. Brasília, Universidade de Brasília, 147p. Dissertação de Mestrado.

Sousa, F. D. R., Elmoor-Loureiro, L. M. A., Mendonça-Galvão, L \& Pujol-Luz, J. R. 2014. Evaluation of a new sampling method for assessing Cladocera richness (Crustacea, Branchiopoda) in macrophyte-rich wetlands. Annales de Limnologie, 50: 143-153.

Sterner, R.W. \& Elser, J. J. 2002. Ecological stoichiometry: the biology of elements from molecules to the biosphere. Princeton University Press.

Tilman, D. 1985. The resource-ratio hypothesis of plant succession. The American Naturalist, 125: 827-852.

Townsend, S. A. \& Gell, P. A. 2005. The role of substrate type on benthic diatom assemblages in the Daly and Roper Rivers of the Australian wet/dry tropics. Hydrobiologia, 548: 101-115.

Vadeboncoeur, Y. \& Steinman. A. D. 2002. Periphyton Function in Lake Ecosystems. The Scientific World Journal, 2: 1-20.

Vadeboncoeur, Y., Vander Zanden, M. J. \& Lodge, D. M. 2002. Putting the lake back together: reintegrating benthic pathways into lake food web models. Bioscience, 52: 44-54.

Ventura, M., Liboriussen, L., Lauridsen, T., Søndergaard, M., Søndergaard, M. \& Jeppesen, E. 2008. Effects of increased temperature and nutrient enrichment on the stoichiometry of primary producers and consumers in temperate shallow lakes. Freshwater Biology, 53: 1434-1452.

Wetzel, R. G. 2001. Limnology: Lake and river ecosystems. 998 p. Academic Press: San Diego.

Xing, W., Wu, H. P., Hao, B. B. \& Liu, G. H. 2013. Stoichiometric characteristics and responses of submerged macrophytes to eutrophication in lakes along the middle and lower reaches of the Yangtze River. Ecological Engineering, 54: 16-21.

Zhang, J. \& Huang, X. 2007. Relative importance of solid-phase phosphorus and iron on the sorption behavior of sediments. Environmental Science \& Technology, 41: 2789-2795. 


\section{Capítulo 2 - Concentrações de elementos-traço EM lagoas NATURAIS RASAS: RELAÇÃO ENTRE COMPARTIMENTOS E BACIAS HIDROGRÁFICAS}

\section{RESUMO}

A concentração e dinâmica de elementos químicos nos ecossistemas aquáticos são influenciadas pelas características das bacias hidrográficas, mas também por sua captação e transferência pela biota em função da demanda e tolerância metabólica. O presente estudo avaliou se as concentrações de elementos-traço diferem em macrófitas aquáticas, perifíton e sedimento de lagoas naturais rasas localizadas nas bacias do Alto Rio Paraná e do Rio São Francisco, ambas localizadas na região central do Cerrado. Além disso, o avaliou-se as concentrações nesses compartimentos são afetadas pela sazonalidade da precipitação. As duas bacias diferem quanto à geologia, sendo que na bacia do Alto Rio Paraná predominam os grupos Paranoá e Canastra, enquanto que na bacia do São Francisco, predomina o grupo Bambuí. As concentrações dos 12 elementos selecionados apresentaram diferença significativa entre os compartimentos. Os metais $\mathrm{Al}, \mathrm{Pb}, \mathrm{Ti}, \mathrm{Cr}$, $\mathrm{Ni}$ e Fe apresentaram diferença significativa entre as bacias hidrográficas, enquanto que os metais $\mathrm{Mn}, \mathrm{Cu}$ e $\mathrm{Zn}$ variaram sazonalmente. Grande parte desses elementos apresentou maiores concentrações na bacia do Paraná e é possível verificar que as diferenças são mais evidentes entre os compartimentos macrófitas aquáticas e perifíton. A similaridade entre as bacias, considerando as macrófitas aquáticas, é muito baixa, indicando que a composição e distribuição florística das bacias pode ser influenciada pela geologia e composição dos elementos (principalmente metais pesados e lantanídeos). Considerando a variação sazonal, é possível verificar que, com o início das chuvas, alguns elementos (Mn, Cu e Zn) apresentaram um aumento em sua concentração no perifíton em relação ao período de estiagem, indicando uma influência da precipitação na entrada desses elementos. Os resultados indicam que a distribuição dos elementos traços nos compartimentos bióticos (perífiton e macrófita) é influenciada pela geologia das duas bacias estudadas o que pode também resultar em diferenças na composição de macrófitas.

Palavras-chave: metais, sazonalidade, Cerrado, composição florística 


\section{INTRODUÇÃ̃o}

Características das bacias hidrográficas tais como geologia, hidrologia e uso e ocupação do solo desempenham papéis fundamentais na composição química dos sedimentos e das águas superficiais em ambientes lênticos, além de influenciar a distribuição de macrófitas aquáticas (Newton et al., 1987; Fraterrigo \& Downing, 2008; Akasaka et al., 2010). O carreamento de nutrientes depende tanto da disponibilidade de nutrientes em uma bacia hidrográfica quanto do seu potencial de deslocamento para os ecossistemas aquáticos, que pode ser influenciado pelo tamanho da bacia, pela permeabilidade dos solos e sua composição (Lewis \& Grimm, 2007). Elementos-traço são elementos químicos que ocorrem na natureza, geralmente, em pequenas concentrações e esse termo tem relação com sua abundância e inclui elementos com diferentes propriedades químicas (Esteves \& Guariento, 2011). Os elementos-traços variam de micronutrientes (p.ex.: $\mathrm{Cu}, \mathrm{Zn}, \mathrm{Mn}, \mathrm{Fe}$ ), que são essenciais em níveis baixos e muitas vezes tóxicos em níveis mais elevados, a metais não essenciais (p.ex.: $\mathrm{Pb}$ e $\mathrm{Hg}$ ) que não apresentam benefícios biológicos conhecidos e são potencialmente tóxicos em qualquer nível. Suas principais fontes naturais são: intemperismo de rocha, erosão de solos ricos nestes materiais, precipitação úmida e seca, aerossol biogênico (desintegração e dispersão de plantas e animais), queimadas naturais e partículas de origem vulcânica (Esteves \& Guariento, 2011).

Em ambientes rasos, as interações água-sedimento são frequentes e têm maior influência na disponibilidade de nutrientes em comparação com ambientes mais profundos, pois a mistura água-sedimento ocorre com frequência e o sedimento é mais propenso a ressuspensão e subsequente liberação de nutrientes (Evans, 1994). Quando as macrófitas aquáticas estão presentes, além de estabilizarem o sedimento, elas formam uma ligação entre a água e o sedimento, desempenhando papel importante na ciclagem de nutrientes nesses ambientes (Nurminen \& Horppila, 2009). O ciclo biogeoquímico de vários elementos também é influenciado pelas mudanças nas reações de oxidação e redução, pelo metabolismo fotossintético e microbiano (Wetzel, 2001), e pela matéria orgânica e conteúdo mineral do sedimento (Kissoon et al., 2015).

As comunidades de macrófitas aquáticas de ambientes lênticos rasos podem ser influenciadas por uma combinação de variáveis dentro do lago e da bacia hidrográfica (Kissoon et al., 2013). As macrófitas aquáticas, por sua vez, influenciam a composição do perifíton, como potenciais locais de colonização (O’Farrel et al., 2009; Søndergaard 
et al., 2010). As macrófitas, principalmente as espécies enraizadas, podem influenciar o estado nutricional do perifíton, uma vez que podem funcionar como uma bomba, mobilizando os nutrientes a partir do sedimento, em contraste com o perifíton que não absorve os nutrientes estocados no sedimento (Hansson, 1992).

Grande parte dos estudos realizados em ambientes rasos tropicais aborda questões sobre regime hidrológico (Loverde-Oliveira et al., 2009), papel dos produtores primários na ciclagem de carbono, nitrogênio e fósforo (Santos et al., 2013), biomassa e dinâmica do fitoplâncton (Figueredo \& Giani, 2009; Rangel et al., 2009; Gomes et al., 2010) e perifíton (França et al., 2011; Dunck et al., 2013), composição da comunidade de macrófitas aquáticas (Meerhoff et al., 2003; Bando, et al., 2015), estrutura e composição de comunidades de invertebrados (Sousa et al., 2014) e peixes (Rejas et al., 2005). A ocorrência de elementos-traço é importante em todos os níveis tróficos dentro do ecossistema aquático, refletindo a disponibilidade no ambiente e a captação e transferência em relação à demanda metabólica ou tolerância da biota (Quiroz-Vázquez et al., 2008). Estudos ecológicos sobre elementos-traço, normalmente, avaliam a influência da limitação desses elementos no ambiente e o efeito da toxicidade no crescimento, na reprodução e na sobrevivência dos organismos (Munk et al., 2002; Barcarolli \& Martinez, 2004) e possibilitam um maior entendimento da mobilidade no ambiente e da tendência de alguns desses elementos biomagnificar por meio da cadeia trófica.

No presente estudo avaliou-se as concentrações de elementos-traço tanto no sedimento quanto na biota (macrófitas aquáticas e perifíton) em lagoas localizadas em diferentes bacias hidrográficas na região central do Cerrado, partindo-se da hipótese de que características geológicas das bacias hidrográficas influenciam as concentrações de elementos-traço nas macrófitas aquáticas, perifíton e sedimento de lagoas naturais rasas do Cerrado.

\section{Material e Métodos}

Áreas de Estudo

O estudo foi realizado em cinco lagoas rasas do Cerrado localizadas na Bacia do Alto Rio Paraná: (1. Lagoa do Henrique (1541'17"S 4756'25"W) e 2. Lagoa do

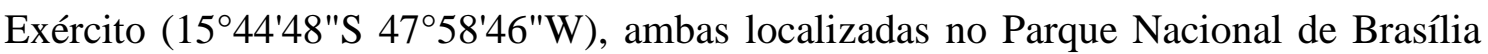


(PNB - DF); 3. Lagoa Bonita (15³5'01"S 4741'19"W), localizada na Estação Ecológica de Águas Emendadas (ESECAE - DF)) e na Bacia do Rio São Francisco (4. Lagoa

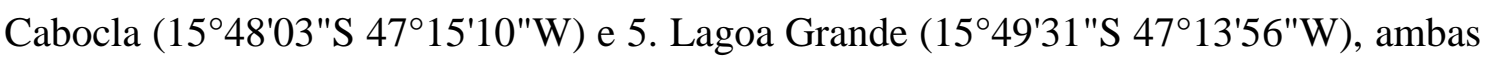
localizadas no Campo de Instrução de Formosa (CIF - GO). As lagoas do PNB estão 30 $\mathrm{km}$ em linha reta distantes da Lagoa Bonita na ESECAE, enquanto que as lagoas do CIF ficam a $60 \mathrm{~km}$ em linha reta da Lagoa Bonita na ESECAE.

\section{Caracterização da Bacia do Alto Rio Paraná}

A Bacia Hidrográfica do Alto Rio Paraná é uma vasta bacia intracratônica sulamericana, que abrange uma área de cerca de $1.400 .000 \mathrm{~km}^{2}$ estendendo-se pelo Brasil, Paraguai, Uruguai e Argentina (Sallun et al., 2007). Nos estados de São Paulo, Paraná e Mato Grosso do Sul ocorrem depósitos arenosos quaternários descontínuos sobre as rochas da Bacia Bauru e da Formação Serra Geral e as unidades geológicas encontradas são: Formação Uberaba, Formação Marília, Formação Adamantina, Formação Serra Geral, Grupo Caiuá e Grupo Bauru (Sallun et al., 2010). No Distrito Federal, três conjuntos litológicos compõem o contexto geológico da bacia hidrográfica do Alto Rio Paraná: os grupos Paranoá, Canastra e Araxá (Campos, 2004).

O PNB pertence ao grupo Paranoá, que representa uma sequência deposicional, com espessura da ordem de 1.600m (Figura 1; Farias et al, 2008). A maior parte do PNB é constituída por um expressivo conjunto de ardósias homogêneas e dobradas e possui forte clivagem ardosiana e intensamente fraturadas em afloramentos (Farias et al, 2008). Segundo o mapa da classificação das unidades de relevo e formas de relevo elaborado por Farias et al. (2008), as lagoas estudadas no PNB estão em áreas de Depressão e Rampa e as classes de solos encontradas são Latossolos Vermelho e Vermelho-Amarelo, Plintossolo, Cambissolo e solo hidromórfico. Segundo Lacerda \& Barbosa (2012), na ESECAE ocorrem rochas psamopelíticas atribuídas ao Grupo Paranoá, que ocupam 97 \% da área, além de cerca de $3 \%$ de ocorrência de rochas do Grupo Canastra (clorita-filitos e quartzitos micáceos) (Figura 2). Entre as classes de solo, destaca-se a ocorrência de Latossolos Vermelho e Vermelho-Amarelo, Gleissolos Háplicos e Neossolos Quartzarênicos na região da Lagoa Bonita (Lacerda, 2008). Na ESECAE, foram identificados quatro compartimentos geomorfológicos denominados Chapadas Elevadas, 
Reborbos, Escarpas e Planos Intermediários, sendo este último o dominante na região da Lagoa Bonita (Nascimento, 2008).

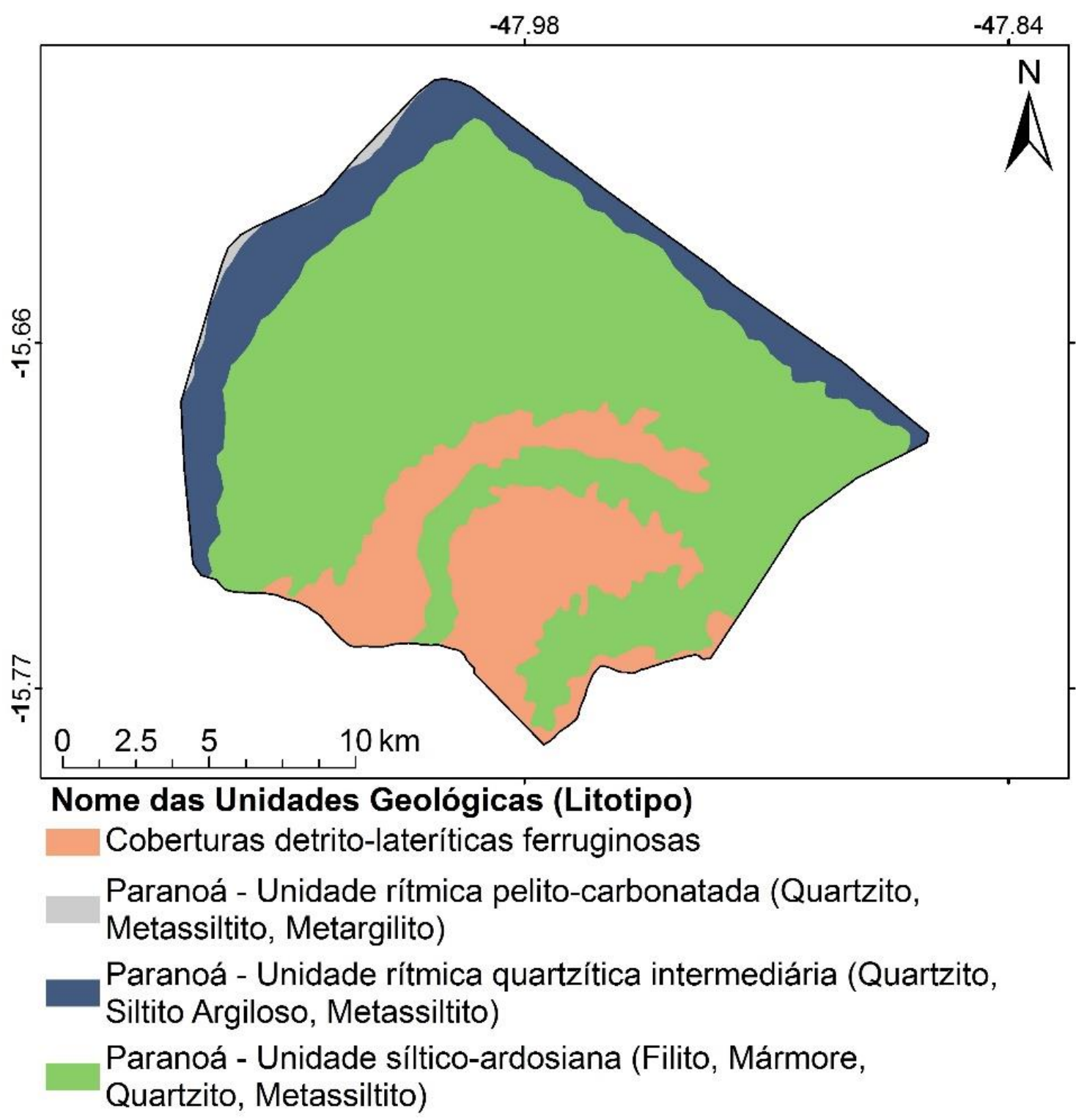

Figura 1. Unidades geológicas do Parque Nacional de Brasília (PNB), sem a extensão referente a área da APA da Cafuringa. Fonte: CPRM. 


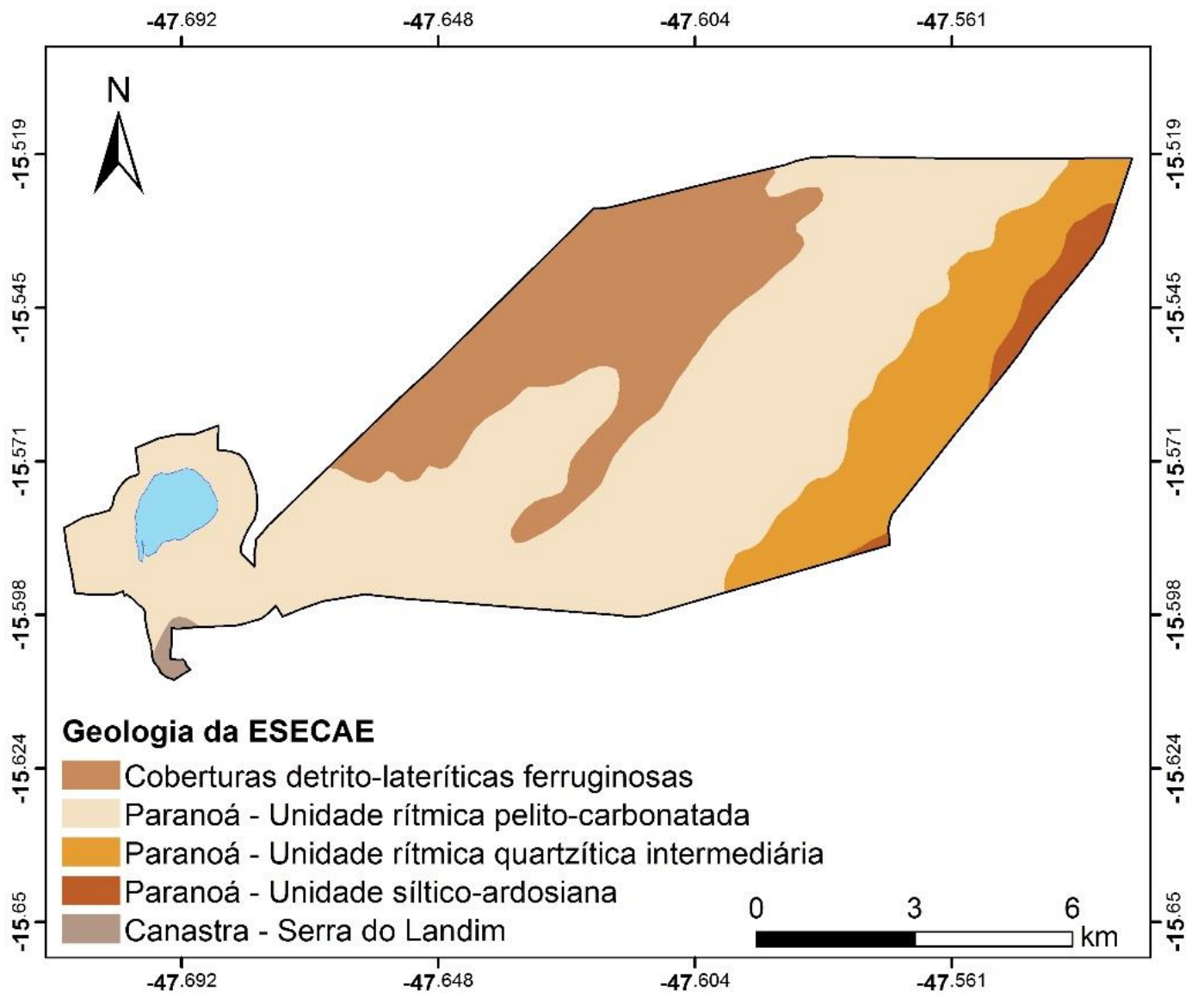

Figura 2. Unidades geológicas da Estação Ecológica de Águas Emendadas (ESECAE). Fonte: CPRM.

\section{Caracterização da Bacia do Rio São Francisco}

A Bacia Hidrográfica do Rio São Francisco tem uma extensão de aproximadamente $640.000 \mathrm{~km}^{2}$ e está localizada nas regiões sudeste, centro-oeste e nordeste do Brasil (Silva et al., 2010). Essa bacia é constituída por várias unidades litoestratigráficas e estruturais, que compõem a geologia da região, e são divididas em regiões fisiográficas: Alto São Francisco, Médio São Francisco, Sub-Médio São Francisco e Baixo São Francisco (MMA, 2006). Segundo esse mesmo trabalho, o trecho da bacia hidrográfica do Rio São Francisco que está localizado no Distrito Federal é o Médio São Francisco, representado predominantemente por rochas cristalinas do PréCambriano e rochas calcárias do Grupo Bambuí.

Na área do CIF são encontradas rochas dos grupos Paranoá e Bambuí, além de pequenas áreas de embasamento cristalino (Figura 3; Sena-Souza et al., 2016). O Grupo Bambuí está distribuído por grande parte da área de estudo, sendo representado pelo Sub- 
Grupo Paraopeba com alternâncias de siltitos e argilitos entremeadas com ocasionais lentes de calcário (Campos et al., 2006). Além disso, o CIF está inserido na Unidade do Planalto Retocado do Alto Rio Preto, formado por saprólitos desenvolvidos sobre rochas pelíticas, que estão intercaladas com lentes de calcário, que formam ambientes cársticos como dolinas e lagoas cársticas (Sena-Souza et al., 2016). O caráter predominantemente fino das rochas correlacionadas ao Grupo Bambuí é responsável pelo potencial aquífero restrito dessas rochas, assim como o grau de fraturamento não muito denso (Campos et al., 2006). Essas altas vazões estão associadas às rochas carbonáticas devido a dissolução cárstica, favorecendo a circulação das águas subterrâneas (Campos et al., 2006). As principais classes de solos encontradas no CIF são os Latossolos Vermelho e VermelhoAmarelo, Cambissolos e Solos Hidromórficos, que estão associados à influência do lençol freático e acúmulo de água nas superfícies deprimidas e côncavas (Sena-Souza et al., 2016).

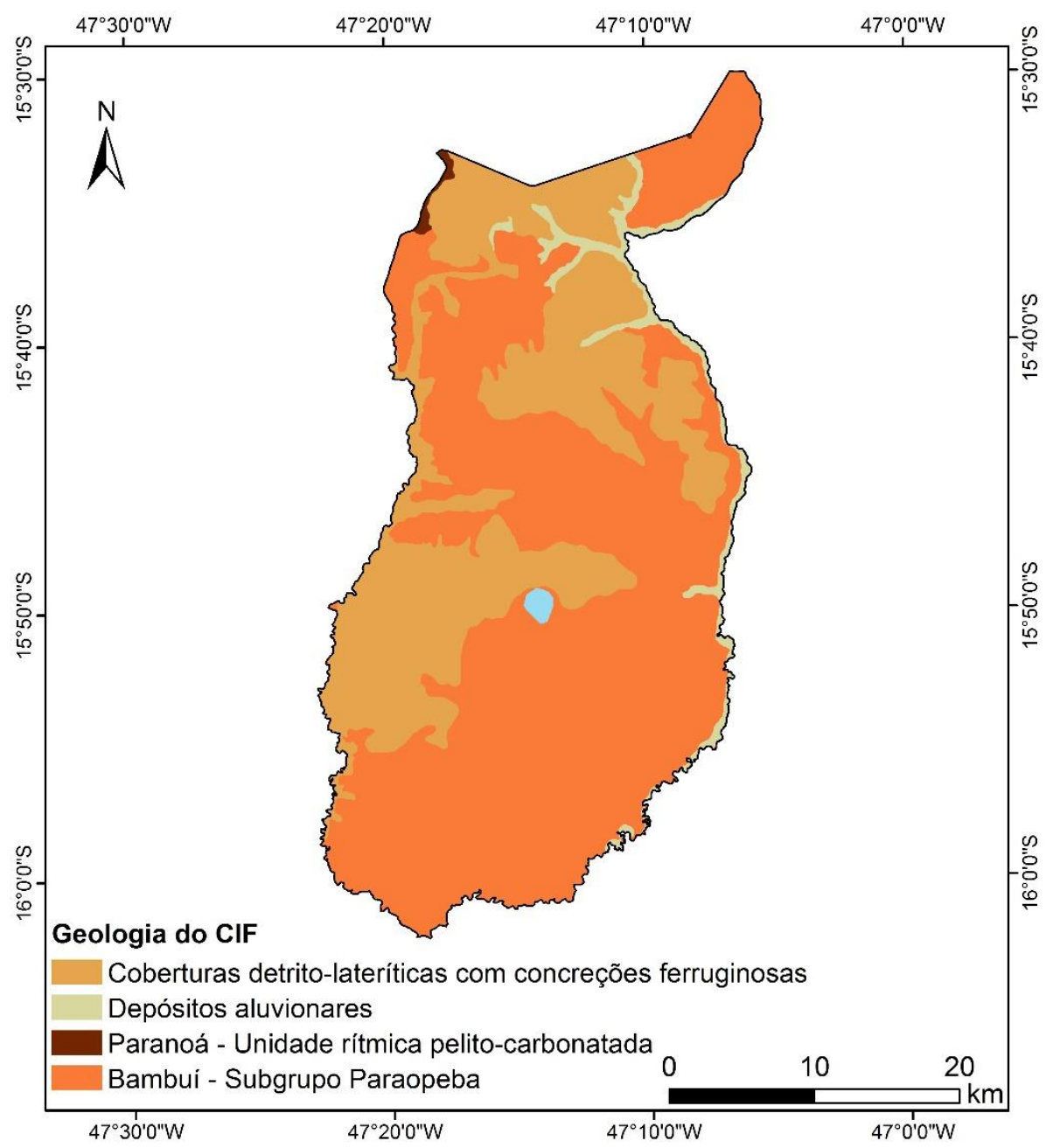

Figura 3. Unidades geológicas do Campo de Instrução de Formosa - GO (CIF-GO). Fonte: CPRM. 
Composição de macrófitas nas áreas de estudo

Além das diferenças geológicas das bacias também é possível observar diferenças na composição da comunidade de macrófitas aquáticas. Nas lagoas da bacia do Paraná são encontradas 41 espécies de macrófitas, sendo 22 exclusivas (em comparação com as lagoas estudadas na Bacia do São Francisco); já nas lagoas da bacia do São Francico são encontradas 47 espécies de macrófitas, sendo 28 exclusivas. A similaridade de Jaccard para as comunidades de macrófitas foi $28 \%$ entre as lagoas estudadas e agrupadas por bacias (Tabela 1).

Coleta dos compartimentos e preparação das amostras

As concentrações elementares foram avaliadas em três compartimentos: macrófitas aquáticas, perifíton e sedimento. Cinco pontos de coleta foram sorteados utilizando grades georreferenciadas das lagoas elaborados no programa ArcGis. As células das grades são distantes $20 \mathrm{~m}$ entre si. Cinco réplicas foram coletadas por lagoa em três compartimentos e em quatro períodos sazonais, totalizando 300 amostras. Maiores detalhes sobre as coletas dos compartimentos são fornecidos no capítulo 1.

Amostras de macrófitas aquáticas, perifíton e sedimento foram liofilizadas durante 72 horas para posterior análise elementar. Posteriormente, as amostras de macrófitas foram trituradas usando um moinho de bola (Planetary Mill PULVERISETTE 5, Fritsch), as amostras de perifíton foram maceradas em um homogeneizador de bancada de alta velocidade (FastPrep®-24), utilizando-se eppendorfs com pérolas de vidro, e as amostras de sedimento foram trituradas usando um almofariz de porcelana e pistilo.

\section{Determinação dos elementos-traço}

Sub-amostras de 1-3 mg de cada material foram colocadas em tubos de plástico tipo eppendorf e foi acrescentado $0,5 \mathrm{~mL}$ de água ultra-pura. Adicionou-se 2,5 $\mu \mathrm{L}$ de padrão de Ga (1.442.495, Sigma) para cada $0,5 \mathrm{~mL}$ de amostra ressuspensa em água ultrapura. Após misturar as amostras, $10 \mu \mathrm{L}$ da mistura foram colocados no disco de acrílico sobre uma placa aquecedora a cerca de $50^{\circ} \mathrm{C}$. Assim que a amostra foi seca, o disco foi levado imediatamente para o espectro de fluorescência de raios X por reflexão total, S2 PICOFOX (Bruker AXS Microanalysis GmbH, Ettlingen, Alemanha). O tempo de leitura 
foi de 1000 s. A identificação dos elementos e a quantificação foi realizada com o software S2 PICOFOX (Bruker AXS Microanalysis GmbH, Ettlingen, Alemanha) no laboratório de Fisiologia de algas e plantas da Universidade Politécnica de Marche, Itália em colaboração com o Prof. Mario Giordano.

\section{Análise dos dados}

Modelos generalizados com efeito misto (glme) foram utilizados para analisar as concentrações dos elementos entre os compartimentos, entre os períodos sazonais e entre as bacias hidrográficas. Todos os dados foram transformados em $\log \mathrm{x}+1$ para as análises estatísticas. Os pacotes lsmeans e pbkrtest do programa R versão 3.2.2 (R Development Core Team, 2015) foram utilizados. 
Tabela 1. Espécies de macrófitas aquáticas encontradas nas lagoas naturais rasas estudadas nas duas bacias hidrográficas Paraná e São Francisco.

Os dados foram obtidos dos seguintes estudos: Guedes et al., 2011; Sousa, 2012; observação pessoal.

\begin{tabular}{|c|c|c|}
\hline Espécies comuns & Espécies nas lagoas da Bacia do Paraná & $\begin{array}{l}\text { Espécies nas lagoas da Bacia do São } \\
\text { Francisco }\end{array}$ \\
\hline Acisanthera divaricata Cogn & Cerarophyllum sp. & Aeschynomene sensitiva $\mathrm{Sw}$. \\
\hline Cabomba sp. & Desmoscelis villosa (Aubl.) NaudX & Andropogon virgatus Desv. ex Ham. \\
\hline Cuphea repens Koehne & Eleocharis sp. & $\begin{array}{l}\text { Arundinella cf. hispida (Humb. \& ex Willd) } \\
\text { Kuntze }\end{array}$ \\
\hline Cyperus articulatus L. & Irlbachia alata (Aubl.) Maas & Borreria latifolia (Aubl.) K. Schum \\
\hline Cyperus sp. & $\begin{array}{l}\text { Irlbachia pedunculata (Cham. \& Schltdl.) } \\
\text { Maas }\end{array}$ & Borreria sp. \\
\hline Mayaca sp. & Lagenocarpus rigidus (Kunth) Ness & Curtia sp. \\
\hline Nymphoides indica (L.) Kuntze & Microlicia sp2 & Cyperus haspan L. \\
\hline Paepalanthus lundii Körn & Mikania officinalis Mart. & Drosera communis (Sundew) \\
\hline Pontederia sp. & Ossea sp. & Eleocharis capillaceae Kunth \\
\hline Rhynchanthera grandiflora (Aubl.) DC. & Panicum sp. & Eleocharis minima Kunth \\
\hline Rhynchospora consanguinea (Kunth) Boeck. & Polygala galioides Poir & Eryngium ebracteatum Lam \\
\hline Rhynchospora globosa (Kunth) Roem.\& Schult & Polygala tenuis DC. & Hyptis sp. \\
\hline Rhynchospora tenuis Willd. ex Link & Polygala sp. & Lepidaploa cf. aurea (Mart. ex DC.) H. Rob. \\
\hline Rhynchospora sp. & Sauvagesia linearifolia A. St. - Hill & Lepidaploa sp. \\
\hline Syngonanthus sp5 & Sauvagesia sp1 & Ludwigia octovalis (Jacq.) P.H. Raven \\
\hline Utricularia hispida Lam & Syngonanthus sp4 & Mayaca sellowiana Kunth \\
\hline Xyris caroliniana Walter & Syngonanthus sp6 & Mimosa sp. \\
\hline Xyris guaranitica Malme & Trembleya parviflora (Don) Cogn & Monopera perennis (Hassl.) Barringer \\
\hline \multirow[t]{10}{*}{ Xyris laxifolia Mart. } & Utricularia nervosa Weber ex Benj. & Nitella sp. \\
\hline & Utricularia sp. & Rhynchospora emaciata (Ness) Boeck. \\
\hline & Xyris hymenachne Mart. & Scleria hirtella $\mathrm{Sw}$ \\
\hline & Xyris sp. & Syngonanthus sp2 \\
\hline & & Syngonanthus sp3 \\
\hline & & Utricularia erectiflora A. St.-Hil \& Girard \\
\hline & & Utricularia myriocista A. St.-Hil \& Girard \\
\hline & & Utricularia neottioides A. St.-Hil \& Girard \\
\hline & & Websteria confervoides (Poir.) S.S. Hooper \\
\hline & & Xyris iupicai Rich. \\
\hline
\end{tabular}




\section{RESULTADOS}

\section{Diferenças entre compartimentos}

As concentrações de todos os elementos estudados apresentaram diferença significativa entre os compartimentos ( $p<0,001$; Tabela 2$)$. Do total dos 12 elementos selecionados, 9 elementos apresentaram as maiores concentrações no perifíton, enquanto que Ni apresentou maior concentração nas macrófitas $(45,1 \mu \mathrm{g} / \mathrm{g}$ PS) e os metais V e Cr no sedimento (144,3 $\mu \mathrm{g} / \mathrm{g}$ PS e 99,3 $\mu \mathrm{g} / \mathrm{g}$ PS, respectivamente).

\section{Diferenças entre bacias hidrográficas}

Os metais $\mathrm{Al}, \mathrm{Pb}, \mathrm{Ti}, \mathrm{Cr}, \mathrm{Ni}$ e $\mathrm{Fe}$ apresentaram diferenças significativas entre as bacias hidrográficas estudadas (Tabela 2) sendo que as concentrações para todos os elementos foram maiores nas lagoas bacia do Paraná em comparação com as lagoas da bacia do São Francisco (Figuras 4 e 5).

As maiores concentrações médias de Al na bacia do Paraná foram encontradas no perifíton e sedimento $(21111,8 \pm 2442,6 \mu \mathrm{g} / \mathrm{g}$ PS e $21688,8 \pm 1966,9 \mu \mathrm{g} / \mathrm{g}$ PS, respectivamente) (Figura 4A). Igualmente, as maiores concentrações médias de $\mathrm{Pb}$ e $\mathrm{Ti}$ foram encontradas no perifíton e sedimento ( $\mathrm{Pb}: 102,0 \pm 16,5 \mu \mathrm{g} / \mathrm{g}$ PS e 43,1 $\pm 5,6 \mu \mathrm{g} / \mathrm{g}$ PS, respectivamente; Ti: $3010,9 \pm 387,8 \mu \mathrm{g} / \mathrm{g}$ PS e $3439,5 \pm 313,1 \mu \mathrm{g} / \mathrm{g}$ PS, respectivamente; Figura 4B e 4C). Os menores valores médios foram encontrados em macrófitas na bacia

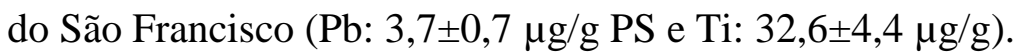

A concentração média de cromo nos compartimentos perifíton e sedimento não diferiu significativamente $(\mathrm{p}=0,076)$. Quanto às macrófitas o maior valor médio

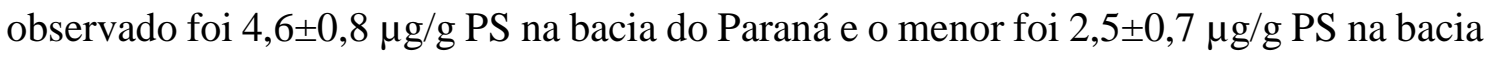
do São Francisco (Figura 4D). Já as concentrações de ferro não apresentaram diferenças significativas entre os compartimentos macrófita e sedimento $(\mathrm{p}=0,956)$. No perifíton, o maior valor médio foi observado na bacia do Paraná enquanto o menor foi observado na bacia do São Francisco $(45302,0 \pm 5184,3 \mu \mathrm{g} / \mathrm{g}$ PS e $35368,4 \pm 4530,1 \mu \mathrm{g} / \mathrm{g}$ PS, respectivamente; Figura 4E). 

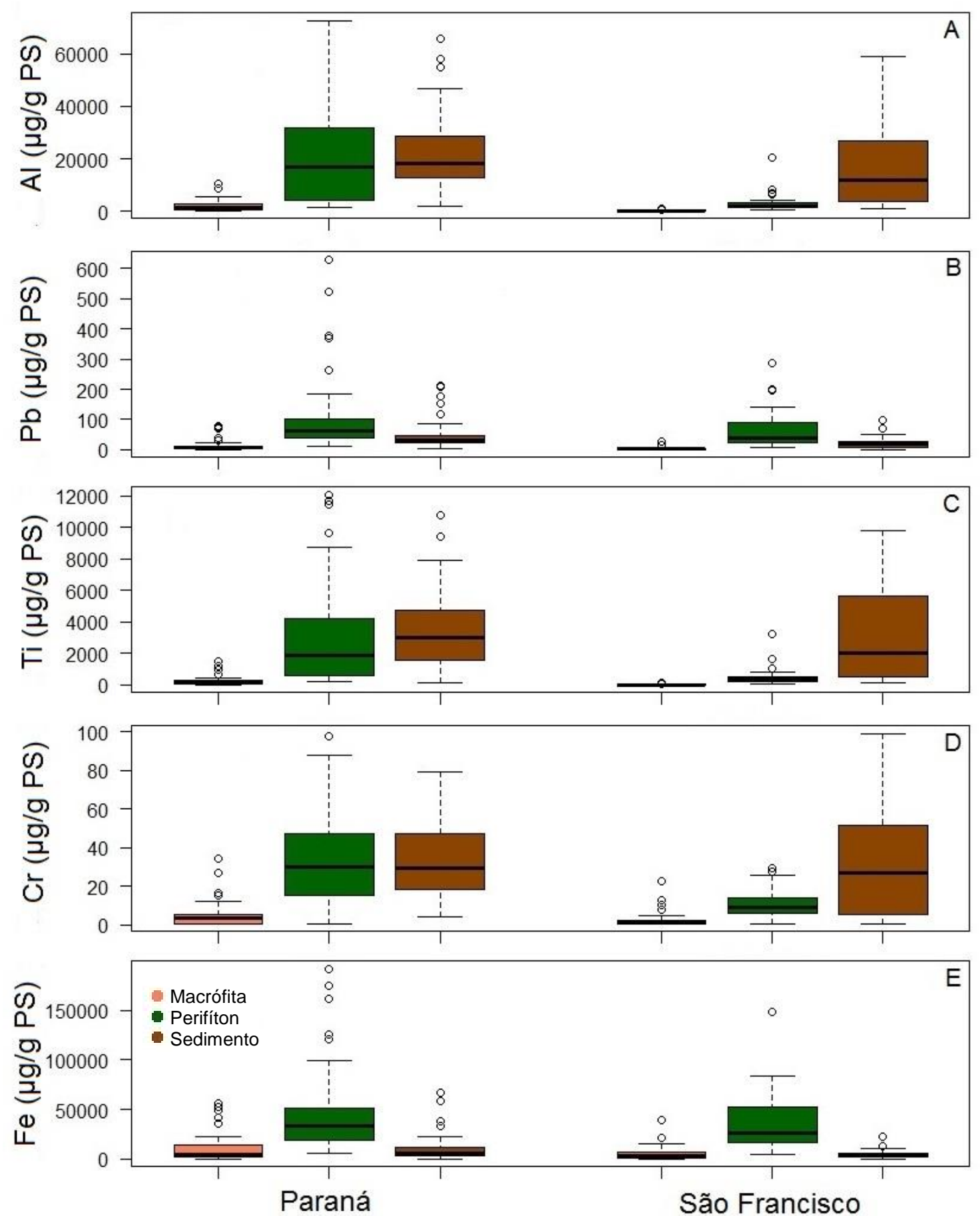

Figura 4. Concentração ( $\mu \mathrm{g} / \mathrm{g}$ PS) de alumínio (A), chumbo (B), titânio (C), cromo (D) e ferro (E) nos compartimentos macrófitas aquáticas, perifíton e sedimento nas duas bacias hidrográficas estudadas (Paraná e São Francisco) em lagoas rasas do Distrito Federal e Goiás agrupadas por bacia hidrográfica estudada (Paraná: Lagoas do Henrique, Exército e Bonita e São Francisco: Lagoas Cabocla e Grande). 
A concentração de $\mathrm{Ni}$ apresentou diferenças significativas entre os três compartimentos, entre as bacias e entre as estações sazonais (Tabela 2). O maior valor médio encontrado de níquel foi $12,2 \pm 2,3 \mu \mathrm{g} / \mathrm{g}$ PS no sedimento na estação seca na bacia do Paraná, enquanto que o menor valor foi $0,6 \pm 0,2 \mu \mathrm{g} / \mathrm{g}$ peso seco em macrófita na estação seca na bacia do São Francisco (Figura 5).
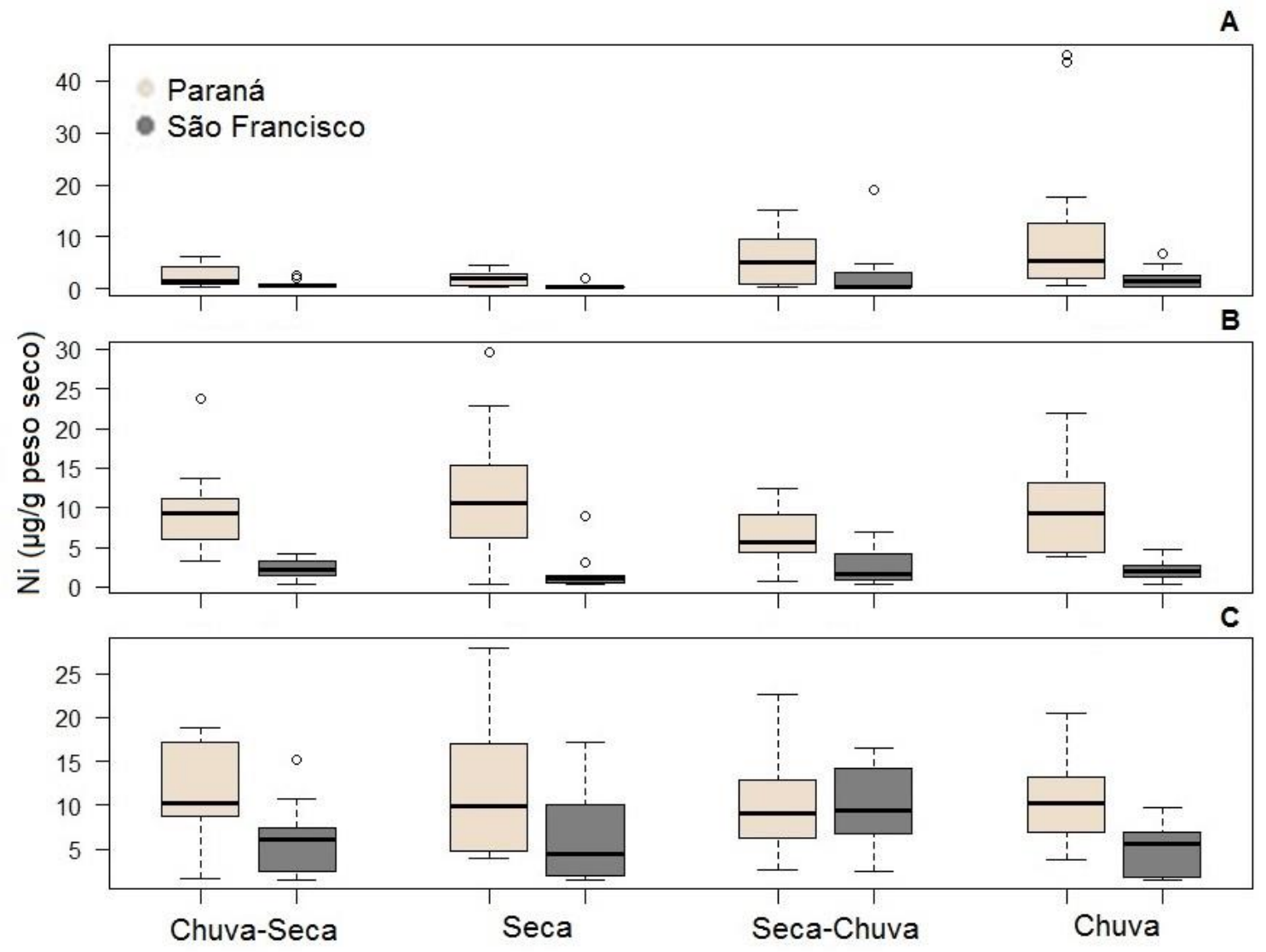

Figura 5. Concentração de níquel ( $\mu \mathrm{g} / \mathrm{g}$ PS) nos compartimentos macrófitas aquáticas (A), perifíton (B) e sedimento (C) nos períodos sazonais (transição chuva/seca, seca, transição seca/chuva e chuva) nas duas bacias hidrográficas estudadas (Paraná - boxplot claro e São Francisco - boxplot escuro) em lagoas rasas do Distrito Federal e Goiás agrupadas por bacia hidrográfica estudada (Paraná - boxplot claro: Lagoas do Henrique, Exército e Bonita e São Francisco - boxplot escuro: Lagoas Cabocla e Grande). 
Diferenças entre estações sazonais

As concentrações de $\mathrm{Mn}, \mathrm{Cu}$ e $\mathrm{Zn}$ variaram sazonalmente com maiores valores

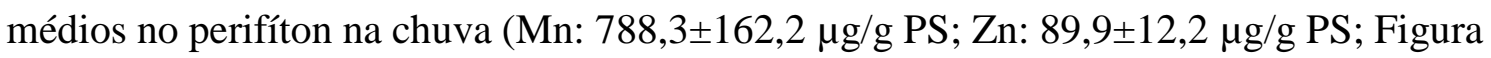
6A e 6C) ou na transição chuva/seca (Cu: 28,8 $45,6 \mu \mathrm{g} / \mathrm{g}$ PS; Figura 6B). Já as concentrações de $\mathrm{Sn}, \mathrm{V}$ e $\mathrm{Hg}$ não apresentaram diferença significativa entre bacias hidrográficas e entre as estações (Tabela 2).

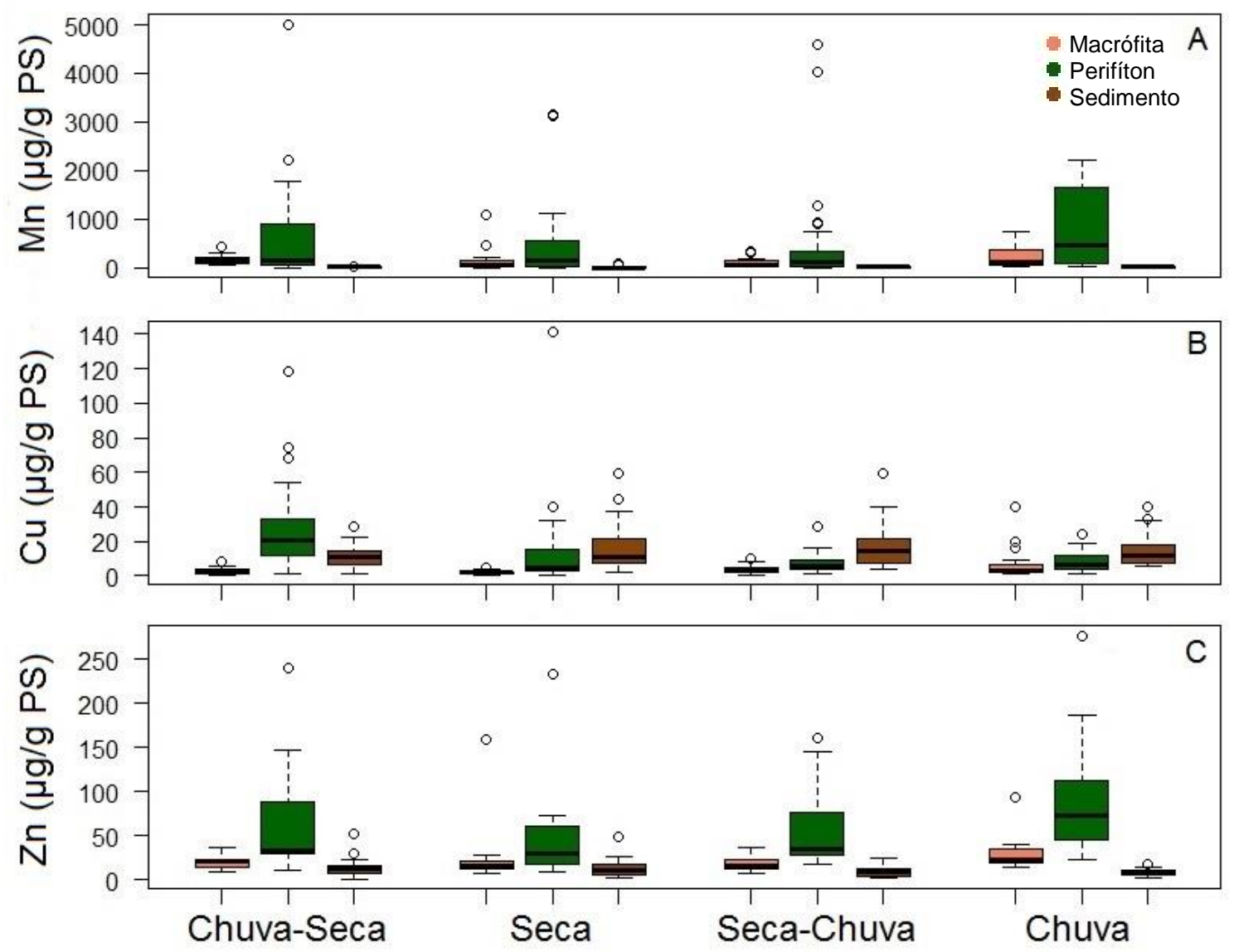

Figura 6. Concentração ( $\mu \mathrm{g} / \mathrm{g}$ PS) de manganês (A), cobre (B) e zinco (C) nos compartimentos macrófitas aquáticas, perifíton e sedimento nos períodos sazonais (transição chuva/seca, seca, transição seca/chuva e chuva) em lagoas rasas do Distrito Federal e Goiás. 
Tabela 2. Resultados dos modelos generalizados com efeito misto para avaliar se as concentrações dos elementos variam entre os compartimentos em função da bacia hidrográfica e sazonalidade em lagoas naturais rasas do Cerrado.

\begin{tabular}{|c|c|c|c|c|c|}
\hline Grupo & Variável resposta & Variável explicativa & DF & $\mathbf{F}$ & $\mathbf{P}$ \\
\hline \multirow{48}{*}{ 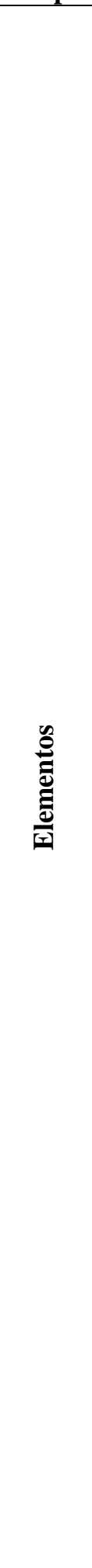 } & \multirow{4}{*}{ 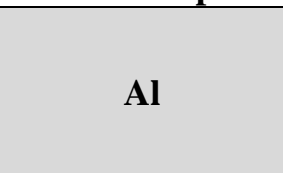 } & Compartimento & 2 & 267,53 & $<0,001$ \\
\hline & & Período & 3 & 0,6 & 0.442 \\
\hline & & Bacia & 1 & 26,49 & $<0,001$ \\
\hline & & Compartimento*Período*Bacia & 6 & 1,06 & 0,334 \\
\hline & \multirow{4}{*}{ Sn } & Compartimento & 2 & 110,02 & $<0,001$ \\
\hline & & Período & 3 & 1,22 & 0,302 \\
\hline & & Bacia & 1 & 1,03 & 0,295 \\
\hline & & Compartimento*Período*Bacia & 6 & 0,54 & 0,746 \\
\hline & \multirow{4}{*}{$\mathbf{P b}$} & Compartimento & 2 & 206,21 & $<0,001$ \\
\hline & & Período & 3 & 1,03 & 0,376 \\
\hline & & Bacia & 1 & 14,83 & 0,001 \\
\hline & & Compartimento*Período*Bacia & 6 & 1,31 & 0,207 \\
\hline & \multirow{4}{*}{$\mathbf{T i}$} & Compartimento & 2 & 326,40 & $<0,001$ \\
\hline & & Período & 3 & 0,79 & 0,527 \\
\hline & & Bacia & 1 & 12,21 & 0,004 \\
\hline & & Compartimento*Período*Bacia & 6 & 1,95 & $\mathbf{0 , 0 5 3}$ \\
\hline & \multirow{4}{*}{ V } & Compartimento & 2 & 170,84 & $<0,001$ \\
\hline & & Período & 3 & 0,68 & 0,569 \\
\hline & & Bacia & 1 & 2,54 & 0,079 \\
\hline & & Compartimento*Período*Bacia & 6 & 1,04 & 0,347 \\
\hline & \multirow{4}{*}{$\mathrm{Cr}$} & Compartimento & 2 & 170,51 & $<0,001$ \\
\hline & & Período & 3 & 1,36 & 0,268 \\
\hline & & Bacia & 1 & 16,72 & 0,002 \\
\hline & & Compartimento*Período*Bacia & 6 & 0,92 & 0,428 \\
\hline & \multirow{4}{*}{ Mn } & Compartimento & 2 & 147,81 & $<0,001$ \\
\hline & & Período & 3 & 7,55 & $<0,001$ \\
\hline & & Bacia & 1 & 0,56 & 0,354 \\
\hline & & Compartimento*Período*Bacia & 6 & 0,71 & 0,596 \\
\hline & \multirow{4}{*}{$\mathbf{F e}$} & Compartimento & 2 & 141,31 & $<0,001$ \\
\hline & & Período & 3 & 1,51 & 0,225 \\
\hline & & Bacia & 1 & 3,15 & 0,058 \\
\hline & & Compartimento*Período*Bacia & 6 & 2,96 & 0,004 \\
\hline & \multirow{4}{*}{$\mathbf{N i}$} & Compartimento & 2 & 95,87 & $<0,001$ \\
\hline & & Período & 3 & 3,66 & 0,022 \\
\hline & & Bacia & 1 & 10,11 & 0,006 \\
\hline & & Compartimento*Período*Bacia & 6 & 0,68 & 0,618 \\
\hline & \multirow{4}{*}{$\mathbf{C u}$} & Compartimento & 2 & 107,42 & $<0,001$ \\
\hline & & Período & 3 & 4,33 & $\mathbf{0 , 0 2 2}$ \\
\hline & & Bacia & 1 & 1,48 & 0,161 \\
\hline & & Compartimento*Período*Bacia & 6 & 2,81 & 0,006 \\
\hline & \multirow{4}{*}{$\mathbf{Z n}$} & Compartimento & 2 & 187,24 & $<0,001$ \\
\hline & & Período & 3 & 3,69 & 0,014 \\
\hline & & Bacia & 1 & 0,02 & 0,853 \\
\hline & & Compartimento*Período*Bacia & 6 & 0,73 & 0,582 \\
\hline & \multirow{4}{*}{ Hg } & Compartimento & 2 & 16,39 & $<0,001$ \\
\hline & & Período & 3 & 0,46 & 0,722 \\
\hline & & Bacia & 1 & 0.19 & 0,581 \\
\hline & & Compartimento*Período*Bacia & 6 & 2,06 & 0,041 \\
\hline
\end{tabular}




\section{DISCUSSÃO}

O conhecimento sobre as reações biogeoquímicas é fundamental para entender o que controla a disponibilidade dos diferentes elementos no ambiente aquático. As características físicas e químicas do sedimento nas lagoas estudadas (elevado teor de matéria orgânica e textura argilosa) podem ter facilitado a mobilidade dos elementos do sedimento para a coluna de água e, consequentemente, para as macrófitas aquáticas e perifíton. A relação da concentração de elementos e características do sedimento reflete as características do solo e da vegetação adjacente, que são provavelmente as principais fontes de matéria orgânica e partículas de sedimento de grãos finos (Kissoon et al., 2015). Os ambientes estudados são rasos e possuem uma área de superfície ampla, que permite a entrada direta de luz solar e ação do vento, o que pode contribuir para maiores taxas de ressuspensão do sedimento e subsequentemente, maior carga interna de nutrientes e taxas mais altas de produtividade primária (Wetzel, 2001). Além disso, as concentrações dos metais pesados e lantanídeos foram maiores na bacia do Alto Rio Paraná, podendo ser reflexo da geologia da região (grupos Paranoá e Canastra), enquanto que a bacia do Rio São Francisco apresenta maior presença de rochas carbonáticas devido a dissolução cárstica.

As características intrínsecas de solos do tipo Latossolos possibilitam o desenvolvimento de importantes aquíferos porosos e áreas de recarga para aquíferos fraturados e juntamente com o relevo aplainado, permitem a infiltração eficiente da água e, consequentemente, a recarga natural da bacia (Campos et al., 2006). Os óxidos de Fe e Al têm elevada afinidade para metais, tais como $\mathrm{V}, \mathrm{Ni}, \mathrm{Co}, \mathrm{Cr}, \mathrm{Zn}, \mathrm{Cu}, \mathrm{Pb}$ e Ti, o que conduz a absorção e coprecipitação (Rao et al., 2010). Em um estudo onde foram analisados elementos-traço em sedimentos de lagoas formadas pela água da chuva em ambientes urbanos de Ontário, Canadá, as concentrações desses elementos apresentaram correlação positiva com o teor de $\mathrm{Al}$ do sedimento (Frost et al., 2015). Nossos resultados apontam uma maior concentração de $\mathrm{Al}, \mathrm{Ti}, \mathrm{V}$ e Cr também no sedimento entre as duas bacias, que pode constituir uma reserva desses metais nos ambientes aquáticos estudados.

Apesar das bacias terem apresentado diferença significativa para alguns elementos (Tabela 2), é possível verificar que as diferenças são mais evidentes entre os compartimentos macrófitas aquáticas e perifíton que entre o sedimento das bacias. A similaridade entre as bacias, considerando as macrófitas aquáticas, é muito baixa (Tabela 1), indicando que a composição e distribuição florística das bacias pode ser influenciada 
pela geologia e composição dos elementos (principalmente metais pesados e lantanídeos) e essa biota exerce um importante papel na ciclagem desses elementos. Kissoon et al. (2013) relataram que as características dos lagos (principalmente turbidez, pH e matéria orgânica do sedimento) e das bacias hidrográficas (uso e ocupação do solo) estavam relacionadas à abundância e à composição da comunidade de macrófitas aquáticas em lagos de Minnesota, EUA.

No presente estudo, Fe apresentou diferença entre as bacias e Mn não, apesar disso, esses dois elementos apresentaram maiores concentrações no compartimento do perifíton, podendo estar associados ao metabolismo desses organismos. O Fe e Mn são elementos indispensáveis ao metabolismo dos organismos e possuem importante função na ciclagem de outros nutrientes, como o fosfato (Esteves et al., 2011). Além disso, os valores encontrados no presente estudo para a concentração de $\mathrm{Fe}$, $\mathrm{Al}$ e Ti nos três compartimentos são elevados quando comparados às concentrações na água no Rio Descoberto, localizado no Distrito Federal (Carmo et al., 2005) e podem ser explicados em função dos aspectos geológicos regionais. Considerando a toxicidade desses elementos, comparando com valores no tecido foliar (Guilherme et al., 2005), alguns elementos apresentaram concentrações elevadas e dessa forma, considerados tóxicos (Tabela 4). Entretanto, como os ambientes estudados estão localizados em áreas de conservação, é possível que as elevadas concetrações encontradas estejam relacionadas às características geológicas das áreas.

As concentrações de Al no perifíton e nas macrófitas aquáticas foram elevadas na bacia do Paraná (máximo de $72869 \mu \mathrm{g} / \mathrm{g}$ PS e $8792 \mu \mathrm{g} / \mathrm{g}$ PS, respectivamente), indicando que esses produtores primários podem acumular alumínio. Em geral, nos ambientes terrestres, a acumulação de alumínio é uma característica comum das plantas nativas, ocorrendo em áreas com elevada diversidade, como nas florestas tropicais e savanas (Haridasan, 2008).

Em lagoas rasas, a concentração de elementos-traço pode apresentar uma variação sazonal, como encontrado no presente estudo. Comparando os quatro períodos estudados, é possível verificar que, com o início das chuvas (período de transição seca-chuva e período de chuva, propriamente dito), os elementos $\mathrm{Mn}, \mathrm{Cu}$ e $\mathrm{Zn}$ apresentaram um aumento em sua concentração no perifíton em relação ao período de estiagem, indicando uma contribuição da precipitação no pool de entrada desses elementos. O carreamento de material alóctone é intensificado durante a estação chuvosa, disponibilizando nutrientes 
para as lagoas e, consequentemente, aumentando as concentrações desses elementos nos compartimentos estudados. Além disso, esses elementos essenciais para o metabolismo da biota não apresentaram concentrações consideradas tóxicas (Tabela 3), exceto Mn no perifíton. Dessa forma, apesar da maioria dos elementos avaliados estar relacionada às características geológicas das bacias hidrográficas, elementos relacionados ao metabolismo da biota, tais como $\mathrm{Mn}, \mathrm{Cu}$ e $\mathrm{Zn}$, indicam uma influência do regime de precipitação na dinâmica desses elementos em lagoas rasas.

\section{CONCLUSÕES}

Os dados apresentados no presente estudo são inéditos para as lagoas naturais rasas do Cerrado, acrescentando informações importantes sobre a dinâmica de elementostraço nos diferentes compartimentos. Nossa hipótese foi corroborada e esses elementos apresentaram diferenças significativas entre bacias hidrográficas relacionadas a geologia regional, considerando, principalmente, as macrófitas aquáticas e perifíton, destacando o papel da composição florística na ciclagem dos elementos e implicações importantes para a ecologia e manejo. Além disso, o perifíton apresentou elevadas concentrações para alguns elementos ( $\mathrm{Al}, \mathrm{Pb}, \mathrm{Ti}, \mathrm{Fe}, \mathrm{Mn}$ e $\mathrm{Dy})$ que, potencialmente, possuem importância no metabolismo desse grupo. Assim, estudos futuros que tentem explicar a dinâmica desses elementos para as comunidades, principalmente em ambientes limitados por macronutrientes, são necessários. Dessa forma, as lagoas naturais rasas do Cerrado são ecossistemas importantes para a conservação da biodiversidade aquática. Os resultados obtidos no presente estudo contribuem para a interpretação de análises biogeoquímicas de lagoas naturais rasas do Cerrado. Portanto, além da geologia, nossos resultados enfatizam a importância das respostas biogeoquímicas aos fatores que conduzem a distribuição dos organismos em diferentes escalas e essa linha de pesquisa ainda é promissora e importante para a ecologia e manejo de lagoas rasas. 
Tabela 3. Concentração média dos elementos ( $\mu \mathrm{g} / \mathrm{g}$ PS) em cada compartimento avaliado (macrófita, perifíton e sedimento) nas duas bacias hidrográficas estudadas (Alto Rio Paraná e São Francisco) do Distrito Federal e Goiás.

\begin{tabular}{|c|c|c|c|c|c|c|c|c|c|c|c|}
\hline & Compartimento & Al & $\mathbf{P b}$ & $\mathbf{T i}$ & $\mathrm{Cr}$ & $\mathbf{F e}$ & $\mathbf{N i}$ & $\mathbf{B a}$ & Mn & $\mathbf{C u}$ & $\mathbf{Z n}$ \\
\hline & Macrófita & 2464 & 12 & 218 & 6 & 10864 & 5,5 & 17 & 154 & 4,6 & 26 \\
\hline \multirow[t]{3}{*}{ Paraná } & Perífiton & 21111 & 102 & 3011 & 35 & 45302 & $\mathbf{9 , 4}$ & 68 & 672 & 15 & 77 \\
\hline & Sedimento & 21688 & 43 & 3439 & 33 & 11474 & 11 & 7,1 & 14 & 12 & 10 \\
\hline & Macrófita & 372 & 3,9 & 33 & 2,5 & 5996 & 1,6 & 39 & 160 & 2,4 & 18 \\
\hline \multirow[t]{2}{*}{ São Francisco } & Perífiton & 2749 & 62 & 483 & 11 & 35368 & 2,2 & 121 & 591 & 25 & 68 \\
\hline & Sedimento & 16464 & 21 & 2898 & 31 & 4595 & 6,9 & 5,2 & 16 & 19 & 12 \\
\hline 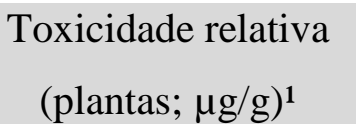 & & $\begin{array}{l}50- \\
200\end{array}$ & $\begin{array}{l}30- \\
300\end{array}$ & 20 & $\begin{array}{l}5- \\
30\end{array}$ & $>1000$ & $\begin{array}{l}10- \\
100\end{array}$ & 500 & $\begin{array}{c}300- \\
500\end{array}$ & $\begin{array}{l}20- \\
100\end{array}$ & $\begin{array}{r}100- \\
400\end{array}$ \\
\hline
\end{tabular}

${ }^{1}$ Dados obtidos de Guilherme et al. (2005). 


\section{REFERÊNCIAS}

Akasaka, M., Takamura, N., Mitsuhashi, H. \& Kadono, Y. 2010. Effects of land use on aquatic macrophyte diversity and water quality of ponds. Freshwater Biology, 55:909-922.

Bando, F. M., Michelan, T. S., Cunha, E. R., Figueiredo, B. R. S., \& Thomaz, S. M. 2015. Macrophyte species richness and composition are correlated with canopy openness and water depth in tropical floodplain lakes. Brazilian Journal of Botany, 38: 289-294.

Barcarolli, I. F. \& Martinez, C. B. R. 2004. Effects of aluminium in acidic water on haematological and physiological parameters of the neotropical fish Leporinus macrocephalus (Anostomidae). Bulletin of Environmental Contamination and Toxicology, 72: 639-646.

Campos, J. E. G. 2004. Hidrogeologia do Distrito Federal: bases para a gestão dos recursos hídricos subterrâneos. Revista Brasileira de Geociência, 34: 41-48.

Campos, J. E. G., Monteiro, C. F. \& Rodrigues, L. N. 2006. Geologia e zoneamento hidrogeológico da bacia do Rio Preto, DF/GO/MG. Embrapa Cerrados, Planaltina, $54 \mathrm{p}$.

Carmo, M. S., Boaventura, G. R. \& Oliveira, E. C. 2005. Geoquímica das águas da Bacia Hidrográfica do Rio Descoberto, Brasília/DF - Brasil. Química Nova, 28: 565574.

Dunck, B., Bortolini, J. C., Rodrigues, L., Rodrigues, L. C., Jati, S. \& Train, S. 2013. Functional diversity and adaptative strategies of planktonic and periphytic algae in isolated tropical floodplain lake. Brazilian Journal of Botany, 36: 257-266.

Esteves, F. A., Figueiredo-Barros, M. P. \& petrucio, M. M. 2011. Principais Cáions e Ânions. In: Fundamentos de Limnologia (Coord. F. A. Esteves). pp. 299-321. Interciência, Rio de Janeiro.

Esteves, F. A. \& Guariento, R. D. 2011. Elementos-traço. In: Fundamentos de Limnologia (Coord. F. A. Esteves). pp. 323-337. Interciência, Rio de Janeiro.

Evans, R. D. 1994. Empirical evidence of the importance of sediment resuspension in lakes. Hydrobiologia, 284: 5-12.

Farias, M. F. R., Carvalho, A. P. F., Martins, E. S., Júnior, O. A. C., Reatto, A. \& Gomes, R. A. T. 2008. Levantamento de Solos do Parque Nacional de Brasília, Escala 1:50.000. Embrapa Cerrados, Planaltina, 66 p. 
Figueredo, C. C. \& Giani, A. 2009. Phytoplankton community in the tropical lake of Lagoa Santa (Brazil): Conditions favoring a persistent bloom of Cylindrospermopsis raciborskii. Limnologica, 39: 264-272.

França, R. C. S., Lopes, M. R. M. \& Ferragut, C. 2011. Structural and successional variability of periphytic algal community in a Amazonian lake during the dry and rainy season (Rio Branco, Acre). Acta Amazonica, 41: 257-266.

Fraterrigo, J. M. \& Downing, J. A. 2008. The influence of land use on lake nutrients varies with watershed transport capacity. Ecosystems, 11: 1021-1034.

Frost, P. C., Song, K., Buttle, J. M., Marsalek, J., McDonald, A. \& Xenopoulos, M. A. 2015. Urban biogeochemistry of trace elements: What can the sediments of stormwater ponds tell us? Urban Ecosystems, 18: 763-775.

Gomes, P. P., Ibañez, M. S. R. \& Freitas, J. S. 2010. Spatial and temporal variation of Peridinium umbonatum F. Stein, 1883 (Dinophyceae) and its relationship with total phytoplankton of a shallow, oligotrophic lake in central Brazil (Lagoon Bonita, Distrito Federal). Acta Limnologica Brasiliensia, 22: 317-324.

Guedes, F. L., Linhares, B. P., Carvalho, E. C. \& Brand, D. H. 2011. Fauna associada às macrófitas aquáticas da Lagoa Bonita, Planaltina - DF. Revista de Biologia e Ciências da Terra, 11: 89-96.

Guilherme, L. R. G., Marques, J. J., Pierangeli, M. A. P., Zuliani, D. Q., Campos, M. L. \& Marchi, G. 2005. Elementos-traço em solos e sistemas aquáticos. Tópicos em Ciência do Solo, 4: 345-390.

Hansson, L. A. 1992. Factors regulating periphytic algal biomass. Limnology and Oceanography, 37: 322-328.

Haridasan, M. 2008. Nutritional adaptations of native plants of the Cerrado biome in acid soils. Brazilian Journal of Plant Physiology, 20: 183-195.

Kissoon, L. T. T., Jacob, D. L., Hanson, M. A., Herwig, B. R., Bowe, S. E. \& Otte, M. L. 2013. Macrophytes in shallow lakes: relationships with water, sediment and watershed characteristics. Aquatic Botany, 109: 39-48.

Kissoon, L. T. T., Jacob, D. L., Hanson, M. A., Herwig, B. R., Bowe, S. E. \& Otte, M. L. 2015. Multi-Elements in Waters and Sediments of Shallow Lakes: Relationships with Water, Sediment, and Watershed Characteristics. Wetlands, 35: 443-457.

Lacerda, M. P. C. 2008. Solos. In: Águas Emendadas (Org. F. O. Fonseca). pp. 140-147. Seduma, Brasília. 
Lacerda, M. P. C. \& Barbosa, I. O. 2012. Relações Pedomorfogeológicas e Distribuição de Pedoformas na Estação Ecológica de Águas Emendadas, Distrito Federal. Revista Brasileira de Ciências do Solo, 36: 709-721.

Lewis, D. B. \& Grimm, N. B. 2007. Hierarchical regulation of nitrogen export from urban catchments: interactions of storms and landscapes. Ecological Applications, 17: 2347-2364.

Loverde-Oliveira, S. M., Huszar, V. L. M., Mazzeo, N. \& Scheffer, M. 2009. HydrologyDriven Regime Shifts in a Shallow Tropical Lake. Ecosystems, 12: 807-819.

Meerhoff, M., Mazzeo, N., Moss, B., Rodríguez-Gallego, L. 2003. The structuring role of free-floating versus submerged plants in a subtropical shallow lake. Aquatic Ecology, 37: 377-391.

MMA. 2006. Caracterização Geral da Região Hidrográfica do São Francisco. In: Caderno da Região Hidrográfica do São Francisco (Ministério do Meio Ambiente, Secretaria de Recursos Hídricos). pp. 21-35. MMA, Brasília.

Munk, L., Faure, G., Pride, D. E. \& Bigham, J. M. 2002. Sorption of trace metals to an aluminum precipitate in a stream receiving acid rock-drainage; Snake River, Summit County, Colorado. Applied Geochemistry, 17: 421-430.

Nascimento, R. O. 2008. Geomorfologia. In: Águas Emendadas (Org. F. O. Fonseca). pp. 132-139. Seduma, Brasília.

Newton, R. M., Weintraub, J. \& April, R. 1987. The relationship between surface water chemistry and geology in the North Branch of the Moose River. Biogeochemistry, 3: 21-35.

Nurminen, L. \& Horppila, J. 2009. Life form dependent impacts of macrophyte vegetation on the ratio of resuspended nutrients. Water Research, 43: 3217-3226.

O’Farrel, I., Pinto, P. T., Rodríguez, P. L., Chaparro, G. \& Pizarro, H. N. 2009. Experimental evidence of the dynamic effect of free-floating plants on phytoplankton ecology. Freshwater Biology, 54: 363-375.

Quiroz-Vázquez, P., White, K. N. \& Sigee, D. C. 2008. Aluminium, silicon and transition metal dynamics in a non-polluted lake: aquatic concentrations and phytoplankton uptake. Hydrobiologia, 607: 131-142.

R Core Team. 2015. R: A language and environment for statistical computing. $R$ Foundation for Statistical Computing, Vienna, Austria.

Rangel, L. M., Silva, L. H. S., Arcifa, M. S. \& Perticarrari, A. 2009. Driving forces of the diel distribution of phytoplankton functional groups in a shallow tropical lake (Lake Monte Alegre, Southeast Brazil). Brazilian Journal of Biology, 69: 75-85. 
Rao, K. S., Mohapatra, M., Anand, S. \& Venkateswarlu, P. 2010. Review on cadmium removal from aqueous solutions. International Journal of Engineering, Science and Technology, 2: 81-103.

Rejas, D., Declerck, S., Auwerkerken, J., Tak, P. \& de Meester, L. 2005. Plankton dynamics in a tropical floodplain lake: fish, nutrients, and the relative importance of borrom-up and top-down control. Freshwater Biology, 50: 52-69.

Santos, T. R., Ferragut, C. \& Bicudo, C. E. M. 2013. Does macrophyte architecture influence periphyton? Relationships among Utricularia foliosa, periphyton assemblage structure and its nutrient (C, N, P) status. Hydrobiologia, 714: 71-83.

Sallun, A. E. M., Suguio, K. \& Stevaux, J. C. 2007. Proposição Formal do Alogrupo Alto Rio Paraná (SP, PR e MS). Geologia USP Série Científica, 7: 49-70.

Sallun, A. E. M., Christofoletti, S. R., Sallun-Filho, W., Amaral, R. \& Azevedo-Sobrinho, J. M. 2010. Argilominerais da Aloformação Paranavaí (SP, PR e MS). Geociência, 29: 311-319.

Sena-Souza, J. P., Júnior, O. A. C., Martins, E. S., Vasconcelos, V., Júnior, A. F. C., Gomes, R. A. T. \& Guimarães, R. F. 2016. Comparação dos métodos de classificação por ângulo espectral e distância euclidiana no mapeamento das formas de terreno. Revista Brasileira de Geomorfologia, 17: 591-613.

Silva, D. F., Galvíncio, J. D. \& Almeida, H. R. R. C. 2010. Variabilidade da qualidade de água na Bacia Hidrográfica do Rio São Francisco e atividades antrópicas relacionadas. Qualitas Revista Eletrônica, 9: 1-17.

Søndergaard, M., Johansson, L. S., Lauridsen, T. L., Jørgensen, T. B., Liboriussen, L. \& Jeppesen, E. 2010. Submerged macrophytes as indicators of the ecological quality of lakes. Freshwater Biology, 55: 893-908.

Sousa, F. D. R. 2012. Diversidade da fauna de Cladocera (Crustacea, Branchiopoda) associada à macrófitas em áreas úmidas naturais do Cerrado do Brasil Central. Brasília, Universidade de Brasília, 147p. Dissertação de Mestrado.

Sousa, F. D. R., Elmoor-Loureiro, L. M. A., Mendonça-Galvão, L \& Pujol-Luz, J. R. 2014. Evaluation of a new sampling method for assessing Cladocera richness (Crustacea, Branchiopoda) in macrophyte-rich wetlands. Annales de Limnologie, 50: 143-153.

Wetzel, R. G. 2001. Limnology: Lake and river ecosystems. 998 p. Academic Press: San Diego. 


\section{CApítulo 3 - RelaÇões tróficas entre Produtores PRimários e fauna associada em uma lagoa Prístina do Cerrado do Brasil Central}

\section{RESUMO}

Em ambientes lênticos tropicais, a estrutura da teia alimentar pode ser influenciada pelos regimes de precipitação e variações na produtividade primária por meio da alteração da disponibilidade de fontes de carbono. Lagoas rasas oriundas de água freática no Cerrado são ambientes oligotróficos, mas com elevada diversidade biológica, no entanto, as interações tróficas nessas lagoas sobretudo da fauna fitófila (que inclui diferentes mecanismos de alimentação) ainda não foi investigada extensivamente. No presente estudo identificou-se, por meio do uso de isótopos estáveis de $\mathrm{C}$ e $\mathrm{N}$, as relações e a estrutura tróficas em uma lagoa rasa prístina do Cerrado colonizada por macrófitas aquáticas com diferentes hábitos de vida (submersa $\mathrm{x}$ emergente). As assinaturas isotópicas de $\mathrm{C}$ e $\mathrm{N}$ das fontes primárias de alimento (macrófitas e perifiton) e da fauna associada às macrófitas foram mensuradas e os dados foram analisados através de modelos de mistura bayesiana. Os valores de $\delta^{13} \mathrm{C}$ permitiram separar as macrófitas em função de seu hábito de vida (emergente x submersa) assim como o perifíton. As assinaturas isotópicas de $\mathrm{C}$ e $\mathrm{N}$ das fontes não apresentaram diferença significativa entre os períodos sazonais estudados. Em relação à fauna associada, os valores de $\delta^{13} \mathrm{C}$ não diferiram significativamente entre os predadores e as outras guildas. Já os valores de $\delta^{15} \mathrm{~N}$ diferiram significativamente entre as guildas com valores mais enriquecidos nos predadores (valor médio de 5,43\%o). O perifíton predominou como principal fonte de alimento para toda a comunidade da fauna associada, com contribuição média de $63 \%$, enquanto a macrófita emergente e a submersa contribuíram com $31 \%$ e 6\%, respectivamente. A macrófita submersa apresentou maior abundância de fauna associada e biomassa de algas (clorofila- $a$ ) quando comparada a macrófita emergente. Portanto, os dados indicam diferentes funções das macrófitas emergente e submersa na teia trófica desse ecossistema, onde a macrófita emergente é um recurso alimentar, enquanto que a submersa é abrigo e refúgio contra predadores e substrato para a colonização do perifíton. Palavras-chave: Perifíton, macrófitas aquáticas, isótopos estáveis, cadeia trófica, oligotrófico 


\section{INTRODUÇÃ̃o}

As cadeias tróficas são macrodescritores das interações alimentares da comunidade que podem ser usadas para mapear os fluxos de energia e matéria nos ecossistemas (Jepsen \& Winemiller, 2002). Identificar a base trófica das cadeias alimentares é fundamental para entender a dinâmica das populações, comunidades ou ecossistemas. Segundo Lopes \& Benedito-Cecílio (2002), o entendimento do fluxo de energia no ecossistema inicia-se pela investigação dos processos que ocorrem a partir dos produtores primários e de como a variabilidade nutricional nesse nível pode influenciar nos níveis subsequentes da teia trófica.

Em ambientes lênticos tropicais, a estrutura da teia alimentar pode ser influenciada pelos regimes de precipitação e variações na produtividade primária por meio da alteração da disponibilidade de fontes de carbono (Reis et al., 2016; Saigo et al., 2016). Além disso, a dinâmica da teia trófica pode ser influenciada pela ocorrência de diferentes tipos de produtores primários e quando vários recursos co-ocorrem, podem existir caminhos mais complexos para essa transferência de energia (Vadeboncoeur et al., 2005; Vander Zanden et al., 2011).

O bioma Cerrado (savana brasileira e segundo maior bioma da América do Sul), compreende aproximadamente 2 milhões de quilômetros quadrados do território brasileiro, ocupando principalmente o Planalto Central do Brasil (IBGE, 2017). Esse bioma apresenta importância central para as bacias hidrográficas brasileiras. Devido às suas características de relevo, os ecossistemas aquáticos do Cerrado são predominantemente representados por nascentes, sistemas lóticos de baixa ordem, áreas úmidas e lagoas naturais rasas, que compreendem a zona superior de três grandes bacias hidrográficas (Paraná, São Francisco e Tocantins/Araguaia). Esses sistemas, quando conservados, apresentam alta limitação por fósforo e baixas concentrações de macronutrientes, baixa condutividade elétrica e são considerados oligotróficos (Fonseca et al., 2014). O Cerrado é reconhecido por possuir uma elevada riqueza biológica e um alto grau de endemismo, porém é fortemente ameaçado, pela conversão de ambientes naturais, sendo considerado um dos hotspots mundiais de biodiversidade (Myers et al., 2000). A compreensão da ciclagem de nutrientes em ecossistemas oligotróficos permite a previsão e detecção de mudanças ambientais futuras, principalmente pelo enriquecimento de nutrientes e alterações no uso do solo. Entretanto, a relação entre a estrutura da comunidade e as redes tróficas em lagoas rasas do Cerrado, sobretudo da 
fauna fitófila (que inclui diferentes mecanismos de alimentação e uma riqueza elevada de espécies dentro dos grupos funcionais) ainda não foi investigada extensivamente.

Conhecer a composição elementar dos consumidores é um pré-requisito para a avaliação da eficiência no uso dos nutrientes em teias alimentares e de seus efeitos sobre os processos-chave do ecossistema (Frost et al., 2005). O papel da interação entre produtores primários e herbívoros na dinâmica dos nutrientes pode ser indicado pela estequiometria ecológica, pois autótrofos apresentam uma variabilidade expressiva na concentração de nutrientes (Quigg et al., 2003; Klausmeier et al., 2004), enquanto que os herbívoros apresentam uma estequiometria mais limitada (DeMott \& Pape, 2005). Isso ocorre, principalmente, porque os organismos autotróficos dispõem de uma maior variabilidade na oferta de elementos disponíveis em comparação com os herbívoros, que obtêm esses elementos ligados entre si nos constituintes bioquímicos do alimento (Frost et al., 2005).

Estudos sobre cadeias tróficas vem utilizando os isótopos estáveis de carbono e nitrogênio $\left(\delta^{13} \mathrm{C}\right.$ e $\left.\delta^{15} \mathrm{~N}\right)$ como uma importante ferramenta para o melhor entendimento do funcionamento de ecossistemas aquáticos (Arcagni et al., 2013; Mendonça et al., 2013; Lopes et al., 2015; Iglesias et al., 2016). O uso de isótopos estáveis como traçadores biológicos baseia-se na premissa de que as razões isotópicas são conservativas e que a combinação de distintas fontes determina o fluxo de nutrientes entre os organismos (Fry, 2006). Este método fornece informações integradas no tempo sobre o material assimilado pelos organismos. $\mathrm{O} \delta^{13} \mathrm{C}$ caracteriza-se por distinguir as contribuições das fontes autotróficas de energia nos ecossistemas, enquanto que o $\delta^{15} \mathrm{~N}$ é fracionado consistentemente ao longo da teia trófica, possibilitando inferências sobre as relações tróficas dos consumidores com sua dieta (Peterson, 1999). O $\delta^{15} \mathrm{~N}$ também pode diferir entre as fontes, fornecendo informações sobre a dieta, especialmente quando combinado com $\delta^{13} \mathrm{C}$ (Vander Zanden \& Rasmussen, 1999).

Dessa forma, o presente estudo investigou as relações e a estrutura tróficas em uma lagoa rasa natural do Cerrado com colonização por macrófitas aquáticas com diferentes hábitos de vida (submersa x emergente). As seguintes hipóteses foram testadas: 1) as assinaturas isotópicas de $\mathrm{C}$ e $\mathrm{N}$ das fontes alimentares (perífiton, macrófita emergente e submersa) diferem entre si em função das formas de aquisição desses nutrientes, permitindo a identificação dos recursos alimentares utilizados pela fauna associada, 2) as assinaturas isotópicas de $\mathrm{C}$ e $\mathrm{N}$ das fontes alimentares (perífiton, 
macrófita emergente e submersa) variam sazonalmente devido às variações das características limnológicas do ambiente, 3) o perifíton é a principal fonte de alimento para a fauna associada às macrófitas em função de sua menor razão $\mathrm{C}: \mathrm{N}$ quando comparada às macrófitas.

\section{MAterial e MÉtodos}

Área de Estudo

O estudo foi realizado na Lagoa do Henrique (1541'17"S 4756'25"W), caracterizada como lagoa oligotrófica rasa e localizada no Parque Nacional de Brasília, no Distrito Federal. O Parque Nacional de Brasília (PNB) é a maior Unidade de Conservação na categoria Proteção Integral do Distrito Federal, com área total de 42.389 ha. Os ecossistemas aquáticos do PNB pertencem à bacia do alto Rio Paraná. A Lagoa do Henrique possui mais de $80 \%$ da lâmina d'água ocupada por macrófitas aquáticas, é formada pelo afloramento do lençol freático e pela precipitação, área total de $0,04 \mathrm{~km}^{2} \mathrm{e}$ a declividade do terreno permite o elevado acúmulo de água, podendo apresentar profundidade máxima de $1,20 \mathrm{~m}$.

Segundo os dados do Instituto Nacional de Meteorologia (INMET, disponível em http://www.inmet.gov.br/portal/), a precipitação anual total em 2015 foi 1252,7 mm. No presente estudo, foram considerados dois períodos sazonais: estação chuvosa (outubro a março, com precipitação acumulada $975,2 \mathrm{~mm}$ ) e estação seca (abril a setembro, com precipitação acumulada $277,5 \mathrm{~mm}$ ).

\section{Coletas para levantamento das macrófitas}

As coletas foram realizadas em duas parcelas perpendiculares (1 metro de largura cada uma, com comprimento de $235 \mathrm{~m}$ e $175 \mathrm{~m}$ ) estabelecidas dentro da lagoa, totalizando $410 \mathrm{~m}^{2}$ amostrados (Figura 1). Todas as macrófitas dentro das parcelas foram coletadas e armazenadas em bolsas plásticas do tipo Zip-Lock e mantidas em caixa térmica até transporte para o laboratório. Essa coleta foi realizada para selecionar quais espécies de macrófitas seriam utilizadas para avaliação das relações trófica. Em laboratório, no mesmo dia, as macrófitas foram lavadas com água destilada e escova de dente de cerdas macias para remoção do perifíton aderido, separadas e identificadas. As macrófitas foram 
liofilizadas durante 72 horas e trituradas usando um moinho de bola (Planetary Mill PULVERISETTE 5, Fritsch) a fino pó para análise isotópica.

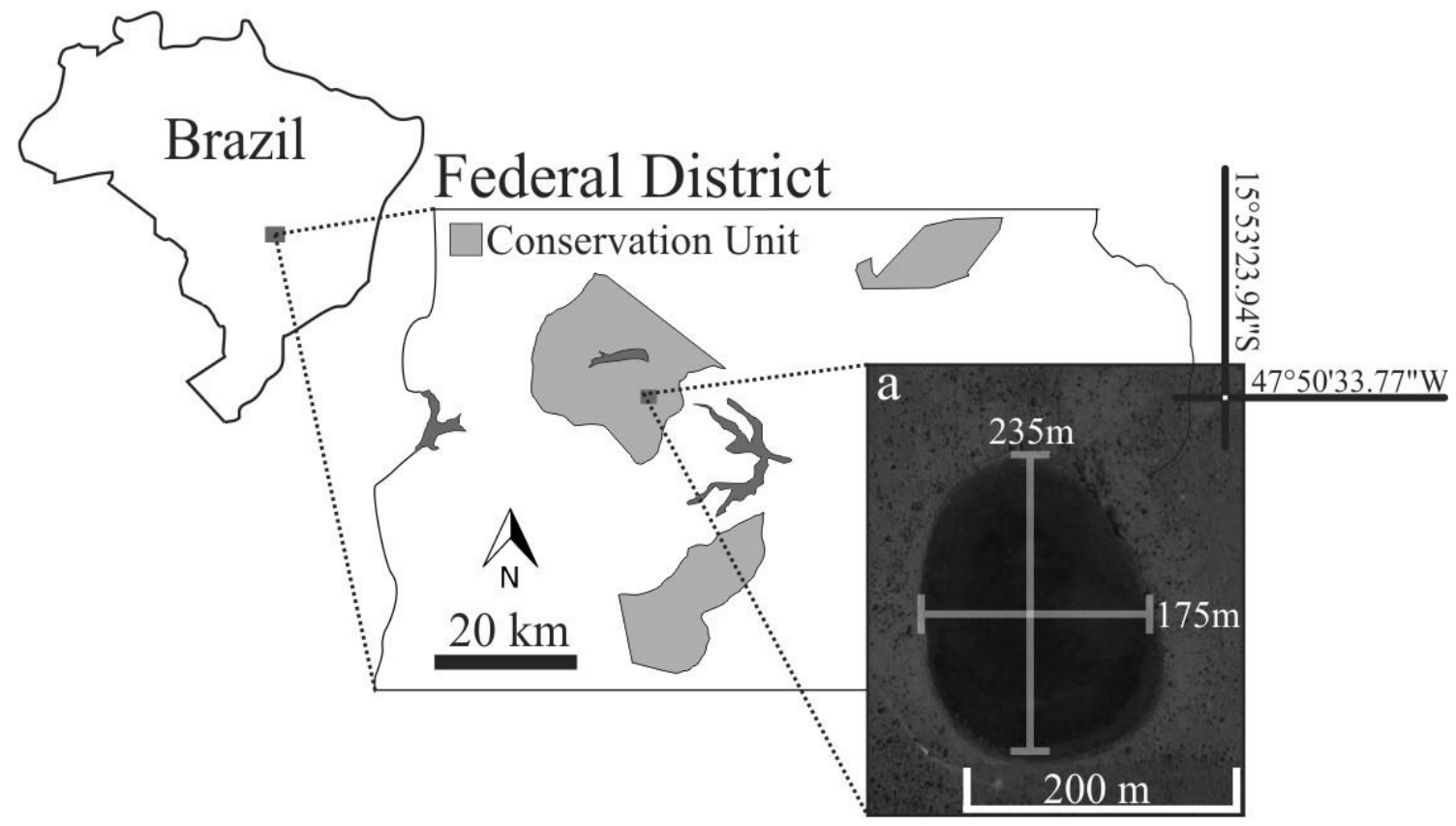

Figura 1. Localização da Lagoa do Henrique no Parque Nacional de Brasília, Distrito Federal, Brasil. a) Destaque para a zona de coleta de macrófitas aquáticas na lagoa.

Coletas de macrófitas e fauna associada para avaliação das relações tróficas

Após o levantamento de todas as macrófitas presentes nas parcelas, a macrófita emergente pertencente ao gênero Cyperus L. (Cyperaceae) e a macrófita submersa ao gênero Cabomba Aubl. (Cabombaceae) foram selecionadas para o estudo. Essas macrófitas foram escolhidas por apresentarem hábitos de vidas diferentes e serem abundantes na lagoa ao longo de todos os períodos sazonais (observação pessoal). Em cada período sazonal de coleta, cinco pontos com macrófita emergente e cinco pontos com macrófita submersa foram amostrados utilizando um quadrado de $20 \mathrm{~cm}$ x $20 \mathrm{~cm}$. Os pontos de coleta foram selecionados considerando a presença das macrófitas e distantes, pelo menos, três metros entre si.

Em cada ponto, as macrófitas foram coletadas e armazenadas em bolsas plásticas do tipo Zip-Lock. Apenas as partes vegetativas maduras que estavam dentro da água foram coletadas. Plantas jovens e senescentes não foram coletadas. As amostras de perifíton foram provenientes da lavagem das macrófitas, ou seja, cada macrófita tem uma 
amostra correspondente de perifíton. A lavagem do perifíton foi feita utilizando-se 300 $\mathrm{mL}$ de água deionizada e escovas de dente de cerdas macias. Após essa lavagem, as macrófitas foram congeladas e o restante do material filtrado em peneira de $250 \mu \mathrm{m}$ de malha para retirar detritos grosseiros e macroinvertebrados. Do total de $300 \mathrm{~mL}$ de amostra, $100 \mathrm{~mL}$ foram destinados para análise de clorofila-a do perifíton (Marker et al., 1980; Sartory \& Grobblelar, 1984), 100 mL para análise de massa seca livre de cinzas do perifíton (APHA, 2005) e 100 mL para análise isotópica.

A fauna associada foi coletada com uma rede de $100 \mu \mathrm{m}$ de malha arrastada entre as macrófitas aquáticas no raio de 20 metros por ponto de coleta. Em cada ponto ( $\mathrm{n}=5$ para cada tipo de macrófita) foi coletada uma amostra qualitativa fixada em álcool 70\%. As amostras foram totalmente triadas e os organismos foram identificados em nível de família para as larvas de insetos, ordem para microcrustáceos e o restante em classe. Os organismos foram classificados em grupos tróficos funcionais segundo literatura especializada (Elmoor-Loureiro, 1997; Ramírez \& Gutiérrez-Fonseca, 2014). Após a triagem, os indivíduos foram colocados em eppendorfs com água e congelados.

\section{Variáveis limnológicas}

Avaliou-se in situ, em cada período de coleta e em cada ponto de coleta, a temperatura da água (Oximeter YSI 55), a concentração de oxigênio dissolvido (Oximeter YSI 55), pH (Digimed MD 20), condutividade elétrica (Minipa MCD-2000). Além disso, foi coletada uma amostra de água (1L) para análise de alcalinidade total pelo método de Gram (Carmouze, 1994) e turbidez (HACH 2100 NA). Essa amostra de água foi armazenada em caixa térmica e transportada para o laboratório. A análise de turbidez foi realizada no mesmo dia da coleta, enquanto a análise de alcalinidade total foi realizada no dia seguinte.

\section{Análise isotópica}

As amostras de macrófitas aquáticas e perifíton congeladas foram liofilizadas durante 72 horas e, após a liofilização, foram trituradas a fino pó. As amostras de macrófitas foram trituradas usando um moinho de bola (Planetary Mill PULVERISETTE 5, Fritsch) e as amostras de perifíton foram maceradas em um homogeneizador de bancada de alta velocidade (FastPrep $\left.{ }^{\circledR}-24\right)$, utilizando-se eppendorfs com pérolas de 
vidro. Todas as amostras congeladas de fauna associada foram secas a $60^{\circ} \mathrm{C}$, os organismos maiores que $1 \mathrm{~cm}$ foram triturados usando um almofariz de ágata e pistilo e os organismos menores que $1 \mathrm{~cm}$ foram colocados inteiros para análise isotópica.

Como os animais estudados não são sésseis, para alcançar a massa mínima necessária para a análise isotópica da fauna associada foi preciso compor as amostras. Tanto as amostras de macrófitas e perifíton quanto as da fauna associada foram pesadas (mínimo de 1,5 mg e 0,9 mg, respectivamente) em balança analítica e colocadas em cápsulas de estanho. As amostras foram enviadas ao laboratório de Ecologia Isotópica no Centro de Energia Nuclear na Agricultura (CENA/USP) para determinação das suas concentrações isotópicas de nitrogênio e carbono através da combustão das amostras sob fluxo contínuo de hélio, em um analisador elementar (Carlo Erba, CHN - 1110) acoplado ao espectrômetro de massa Thermo Finnigan Delta Plus.

Os resultados foram expressos em notação delta $(\delta)$, em partes por mil (\%o), em relação aos padrões internacionais (Vienna Pee Dee Belemnite, rocha calcária da região do Grand Canyon, EUA, para $\mathrm{C}$ e ar atmosférico para $\mathrm{N}$ ) e foram calculados utilizando a seguinte equação:

$$
\delta X=\left(R_{\text {amostra }} / \mathrm{R}_{\text {padrão }}\right)-1
$$

onde (1), $\mathrm{X}$ é ${ }^{13} \mathrm{C}$ ou ${ }^{15} \mathrm{~N}$ e $\mathrm{R}$ é a razão entre o isótopo mais pesado e o mais leve, em particular ${ }^{13} \mathrm{C} /{ }^{12} \mathrm{C}$ para o carbono $\mathrm{e}^{15} \mathrm{~N} /{ }^{14} \mathrm{~N}$ para o nitrogênio. O erro analítico é da ordem de $0,3 \%$ para o $\delta^{13} \mathrm{C}$ e de $0,5 \%$ para o $\delta^{15} \mathrm{~N}$.

\section{Análise dos dados}

O teste de ShapiroWilk foi aplicado para avaliar se os dados abióticos e de isótopos estáveis apresentavam distribuição normal. A análise descritiva dos dados abióticos utilizou média aritmética como medida da tendência central e o grau de dispersão dos dados foi calculado usando o erro padrão (EP). Todos os dados abióticos, exceto o $\mathrm{pH}$, foram transformados (log na base 10). Aplicou-se o teste-t para comparar as variáveis limnológicas entre períodos sazonais. 
Diferenças sazonais entre os recursos alimentares foram avaliadas com teste-t para dados paramétricos e teste de Wilcoxon para dados não-paramétricos. Diferenças entre as macrófitas emergente e submersa e o perifíton aderido às macrófitas foram avaliadas por meio do teste-t para dados paramétricos e teste de Wilcoxon para dados não-paramétricos. Diferenças entre os valores de $\delta^{13} \mathrm{C}, \delta^{15} \mathrm{~N}$ e $\mathrm{C}: \mathrm{N}$ entre os recursos alimentares foram avaliadas por meio de uma análise de variância (ANOVA 1-fator). O teste de comparação múltipla de Tukey foi utilizado para comparar as médias e determinar a diferença mínima significativa. Diferenças entre a abundância da fauna associada entre as macrófitas e entre as estações sazonais foram avaliadas por meio de uma análise de variância (ANOVA 2-way). As análises estatísticas foram realizadas utilizando o software R versão 3.2.2 (R Development Core Team). As diferenças no nível de 0,05 foram relatadas como significativas.

Com o objetivo de estimar a assimilação isotópica da fauna associada, foram utilizados modelos de mistura de isótopos estáveis com base em análise Bayesiana. Essa abordagem estima a contribuição proporcional dos possíveis recursos para o tecido do consumidor e considera a composição isotópica de carbono e nitrogênio das fontes (Parnell et al., 2010). Como recursos alimentares foram selecionados a macrófita emergente, macrófita submersa e o perifíton. O fracionamento médio de $0,5 \%$ para $\delta^{13} \mathrm{C}$ e de 2,3\% para $\delta^{15} \mathrm{~N}$ foi considerado de acordo com McCutchan et al. (2003). Essas análises foram realizadas por meio do pacote SIAR (Parnell et al., 2010) no software R versão 3.2.2 (R Development Core Team, 2015). Estimamos a área de elipse padrão $\left(\mathrm{SEAc}\right.$, em $\%^{2}$ ) como medida bivariada da média central do nicho isotópico (Jackson et al., 2011). O SEAc permite calcular o grau de sobreposição de nicho da comunidade (em\%, onde $100 \%$ indica sobreposição total) e pode ser usado como medida quantitativa de similaridade de dieta entre os diferentes grupos (Hill et al., 2015).

\section{RESUlTADOS}

\section{Variáveis limnológicas}

Temperatura da água $\left(23,0^{\circ} \mathrm{C}\right)$, condutividade elétrica $(3,87 \mu \mathrm{S} / \mathrm{cm})$ e turbidez da água (2,55 NTU) foram significativamente maiores na estação seca em relação à estação chuvosa (Tabela 1). Somente a concentração de oxigênio dissolvido $(6,60 \mathrm{mg} / \mathrm{L})$ foi 
maior na estação chuvosa. As demais variáveis (pH, alcalinidade, clorofila-a do perifiton e massa seca livre de cinzas do perifíton) não apresentaram diferenças entre as estações.

Tabela 1. Valores médios e erro padrão das variáveis limnológicas da Lagoa do Henrique, Parque Nacional de Brasília, Distrito Federal, Brasil, durante as estações chuvosa e seca de 2015.

\begin{tabular}{lccc}
\hline \multicolumn{1}{c}{ Variável } & Chuva & Seca & p \\
\hline Temperatura da água $\left({ }^{\circ} \mathrm{C}\right)$ & $22,7 \pm 0,1$ & $23,9 \pm 0,2$ & $<\mathbf{0 , 0 0 1}$ \\
$\mathrm{pH}$ & $5,61 \pm 0,04$ & $5,49 \pm 0,05$ & 0,085 \\
Condutividade Elétrica $(\mu \mathrm{S} / \mathrm{cm})$ & $3,68 \pm 0,5$ & $3,87 \pm 0,2$ & $\mathbf{0 , 0 1 9}$ \\
Oxigênio Dissolvido $(\mathrm{mg} / \mathrm{L})$ & $6,60 \pm 0,1$ & $5,81 \pm 0,1$ & $<\mathbf{0 , 0 0 1}$ \\
Turbidez $(\mathrm{NTU})$ & $0,98 \pm 0,1$ & $2,55 \pm 0,2$ & $<\mathbf{0 , 0 0 1}$ \\
Alcalinidade $\left(\mathrm{mg} \mathrm{CaCO}^{3} / \mathrm{L}\right)$ & $1,62 \pm 0,1$ & $1,70 \pm 0,1$ & 0,458 \\
Clorofila-a do perifíton $(\mu \mathrm{g} / \mathrm{L})$ & $16,07 \pm 4,4$ & $12,18 \pm 2,9$ & 0,706 \\
Massa seca livre de cinzas do perifíton $(\mathrm{g} / \mathrm{g})$ & $0,006 \pm 0,002$ & $0,002 \pm 0,001$ & 0,487 \\
\hline
\end{tabular}

\section{Análises das fontes alimentares}

Das 12 espécies de macrófitas encontradas, seis eram emergentes e seis submersas (Tabela 2). Os valores de $\delta^{13} \mathrm{C}$ apresentaram diferença significativa entre os hábitos de vida emergente $x$ submersa $(-27,73$ e $-23,32 \%$, respectivamente; $p=0,001)$, enquanto os valores de $\delta^{15} \mathrm{~N}$ não diferiram estatisticamente $(\mathrm{p}=0,533)$. 
Tabela 2. Valores de $\delta^{13} \mathrm{C}$ e $\delta^{15} \mathrm{~N}$ das macrófitas aquáticas coletadas na Lagoa do Henrique, Parque Nacional de Brasília, Distrito Federal, Brasil.

\begin{tabular}{|c|c|c|c|}
\hline Hábito & Macrófita aquática & $\delta^{13} \mathrm{C}(\% \%)$ & $\delta^{15} \mathrm{~N}(\%)$ \\
\hline \multirow{9}{*}{ Emergente } & CYPERACEAE & & \\
\hline & Cyperus sp. & $-27,37$ & 5,75 \\
\hline & Rhynchosphora sp. & $-29,84$ & 3,06 \\
\hline & Morfo 1 & $-25,97$ & 1,65 \\
\hline & MELASTOMATACEAE & & \\
\hline & Morfo 1 & $-29,22$ & 2,22 \\
\hline & POACEAE & & \\
\hline & Otachyrium sp. & $-25,33$ & 2,28 \\
\hline & Panicum sp. & $-28,65$ & $-0,96$ \\
\hline \multirow{9}{*}{ Submersa } & CABOMBACEAE & & \\
\hline & Cabomba sp. & $-22,87$ & 3,56 \\
\hline & MENYANTHACEAE & & \\
\hline & Nymphoides indica & $-26,01$ & 4,64 \\
\hline & Família não identificada & & \\
\hline & Morfo 1 & $-23,66$ & 2,95 \\
\hline & Morfo 2 & $-23,63$ & 1,00 \\
\hline & Morfo 3 & $-23,07$ & 0,89 \\
\hline & Morfo 4 & $-20,67$ & 5,49 \\
\hline
\end{tabular}

As assinaturas isotópicas de $\mathrm{C}$ e $\mathrm{N}$ das fontes não apresentaram diferença significativa entre os períodos sazonais estudados (Tabela 3). Em função da ausência de variações sazonais na assinatura isotópica das fontes alimentares, amostras de seca e chuva foram compostas para todas as fontes. Além disso, as amostras de perifíton associado à macrófita emergente não apresentaram diferença significativa em relação às amostras de perifíton associado à macrófita submersa quanto as assinaturas isotópicas $\left(\delta^{13} \mathrm{C}: \mathrm{p}=0,17 ; \delta^{15} \mathrm{~N}: \mathrm{p}=0,78\right)$, assim essas amostras também foram compostas. 
Tabela 3. Resultados estatísticos relacionados às assinaturas isotópicas dos recursos alimentares entre os períodos sazonais seca e chuva na Lagoa do Henrique, Parque Nacional de Brasília, Distrito Federal, Brasil.

\begin{tabular}{cccccc}
\hline Recurso alimentar & & Chuva (\%o) & Seca (\%o) & DF & p \\
\hline Cyperus sp. & $\delta^{15} \mathrm{~N}$ & 1,28 & 0,40 & 8 & 0,55 \\
(macrófita emergente) & $\delta^{13} \mathrm{C}$ & $-25,95$ & $-25,24$ & 8 & 0,06 \\
Cabomba sp. & $\delta^{15} \mathrm{~N}$ & 1,32 & $-0,76$ & 7 & 0,41 \\
(macrófita submersa) & $\delta^{13} \mathrm{C}$ & $-21,55$ & $-20,77$ & 7 & 0,21 \\
\hline Perifíton associado à & $\delta^{15} \mathrm{~N}$ & 2,38 & 1,90 & 5 & 0,63 \\
macrófita emergente & $\delta^{13} \mathrm{C}$ & $-27,58$ & $-25,20$ & 5 & 0,63 \\
Perifíton associado à & $\delta^{15} \mathrm{~N}$ & 1,41 & 2,53 & 7 & 0,41 \\
macrófita submersa & $\delta^{13} \mathrm{C}$ & $-24,44$ & $-24,49$ & 7 & 0,97
\end{tabular}

$\overline{\text { Os dados de } \delta^{13} \mathrm{C} \text { de Cyperus sp. (macrófita emergente) e do perifíton associado à macrófita }}$ emergente e os dados de $\delta^{15} \mathrm{~N}$ do perifíton associado à macrófita submersa foram analisados usando o teste de Wilcoxon. Todos os outros dados foram analisados com o teste-t. DF $=$ graus de liberdade.

A avaliação das assinaturas isotópicas das fontes alimentares foi realizada em 10 amostras de Cyperus sp., nove amostras de Cabomba sp. e 16 amostras de perifíton. As fontes alimentares foram diferentes com relação aos valores de $\delta^{13} \mathrm{C}(\mathrm{p}<0,001$; Figura 2), enquanto não houve diferença significativa para os valores de $\delta^{15} \mathrm{~N}(\mathrm{p}=0,21)$. O valor isotópico médio para Cyperus sp. foi de $-25,59 \%$ para $\delta^{13} \mathrm{C}$ e $0,84 \%$ para $\delta^{15} \mathrm{~N}$ e para Cabomba sp. foi de $-21,20 \%$ para $\delta^{13} \mathrm{C}$ e $0,40 \%$ para $\delta^{15} \mathrm{~N}$. Já para o perifíton, o valor isotópico médio foi de $-25,23 \%$ para $\delta^{13} \mathrm{C}$ e $1,99 \%$ para $\delta^{15} \mathrm{~N}$. 


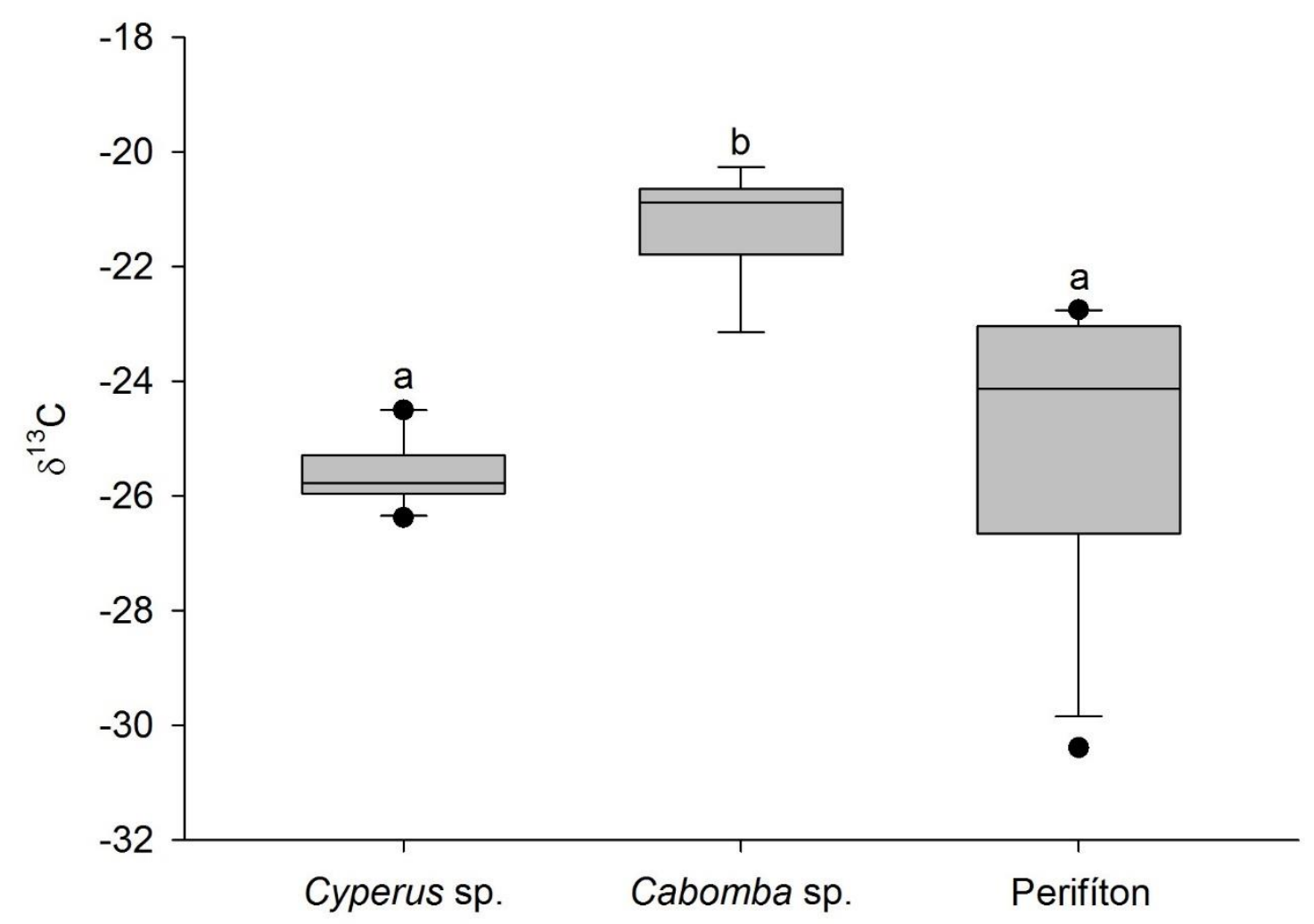

Figura 2. Assinatura isotópica de carbono $\left(\delta^{13} \mathrm{C}\right)$ das fontes alimentares macrófita emergente Cyperus sp., macrófita submersa Cabomba sp. e perifíton da Lagoa do Henrique, Parque Nacional de Brasília, Distrito Federal, Brasil. Box-plot com letras diferentes são estatisticamente diferentes $\alpha=0,05$.

As macrófitas apresentaram diferenças significativas quanto a clorofila- $a$ e a massa seca livre de cinzas (MSLC) do perifíton $(\mathrm{p}<0,001)$ com maiores valores encontrados na macrófita submersa $(23,68 \mu \mathrm{g} / \mathrm{L}$ e 0,009 g/g, respectivamente) (Figuras 3A e 3B) apesar do valor mais elevado de biomassa de Cyperus sp. comparado ao de Cabomba sp. (p < 0,001; Figura 3C).

A razão $\mathrm{C}: \mathrm{N}$ das fontes diferiu significativamente entre as fontes alimentares $(\mathrm{p}<$ 0,001). O perifíton apresentou a menor razão C:N $(12,1)$ enquanto que a macrófita emergente Cyperus sp. apresentou a maior razão (90,1; Figura 3). A macrófita submersa Cabomba sp. apresentou valor de razão C:N de 28,3, mais próximo ao perifíton. 

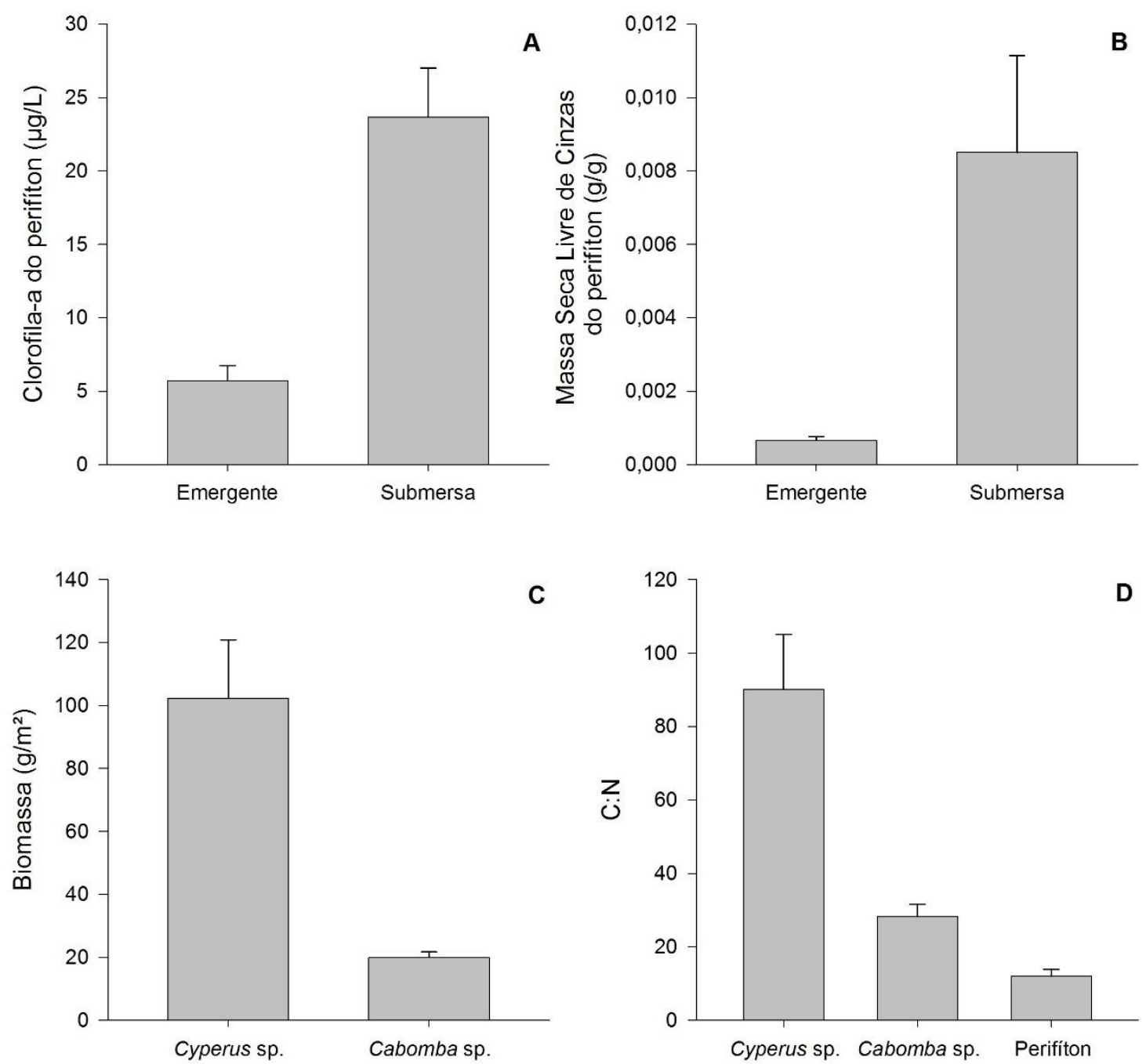

Figura 3. Comparação da clorofila-a do perifíton (A), massa seca livre de cinzas do perifíton (B) associado às macrófitas, biomassa das macrófitas aquáticas Cyperus sp. e Cabomba sp. (C) e razão C:N das fontes alimentares macrófita emergente Cyperus sp., macrófita submersa Cabomba sp. e perifíton associado (D) da Lagoa do Henrique, Parque Nacional de Brasília, Distrito Federal. Barras indicam o erro padrão.

\section{Fauna associada às macrófitas}

No total foram encontrados 3.983 indivíduos na fauna associada às macrófitas. A maioria dos táxons encontrados pertencem a Classe Insecta (78,2\%), mas ácaros, microcrustáceos e girinos também estavam presentes (Tabela 4). A macrófita submersa Cabomba sp. apresentou maior abundância média da maioria dos organismos amostrados, tanto na chuva quanto na seca. Sazonalmente, a estação seca apresentou as maiores abundâncias médias de táxon para as duas macrófitas estudadas ( $<<0,001)$. 
Tabela 4. Abundância média e erro padrão dos táxons encontrados associados às macrófitas aquáticas Cyperus sp. e Cabomba sp. na Lagoa do Henrique, Parque Nacional de Brasília, Distrito Federal, Brasil, durante as estações chuvosa e seca de 2015.

\begin{tabular}{|c|c|c|c|c|}
\hline \multirow{2}{*}{ Táxon } & \multicolumn{2}{|c|}{ Chuva } & \multicolumn{2}{|c|}{ Seca } \\
\hline & Cyperus sp. & Cabomba sp. & Cуреrus sp. & Cabomba sp. \\
\hline \multicolumn{5}{|l|}{ EPHEMEROPTERA } \\
\hline Baetidae & $4,4 \pm 2,7$ & $1,0 \pm 0,4$ & $2,6 \pm 2,1$ & $4,6 \pm 3,1$ \\
\hline Caenidae & & & & $2,8 \pm 1,7$ \\
\hline Leptophlebiidae & $1,0 \pm 0,6$ & $3,2 \pm 1,6$ & $0,4 \pm 0,2$ & $3,0 \pm 2,3$ \\
\hline \multicolumn{5}{|l|}{ ODONATA } \\
\hline Aeshnidae & $0,2 \pm 0,2$ & & & \\
\hline Coenagrionidae & $0,6 \pm 0,6$ & $2,8 \pm 1,6$ & & $3,6 \pm 1,0$ \\
\hline Dicteriadidae & $1,4 \pm 0,7$ & $0,6 \pm 0,6$ & & \\
\hline Lestidae & & & $3,2 \pm 1,8$ & $2,2 \pm 0,8$ \\
\hline Libellulidae & $8,6 \pm 2,2$ & $10,2 \pm 6,1$ & $10,2 \pm 3,4$ & $11,4 \pm 3,8$ \\
\hline \multicolumn{5}{|l|}{ COLEOPTERA } \\
\hline Noteridae & & & $0,2 \pm 0,2$ & $0,2 \pm 0,2$ \\
\hline \multicolumn{5}{|l|}{ TRICHOPTERA } \\
\hline Hydroptilidae & $2,0 \pm 1,3$ & $5,6 \pm 3,0$ & $2,8 \pm 1,2$ & $6,4 \pm 1,4$ \\
\hline \multicolumn{5}{|l|}{ HEMIPTERA } \\
\hline Belostomatidae & & & $0,2 \pm 0,2$ & $0,2 \pm 0,2$ \\
\hline Corixidae & $0,6 \pm 0,4$ & & $0,4 \pm 0,2$ & \\
\hline Gerridae & $0,4 \pm 0,4$ & & & \\
\hline Mesoveliidae & $0,4 \pm 0,4$ & & & \\
\hline Naucoridae & $1,6 \pm 0,9$ & $0,2 \pm 0,2$ & $0,4 \pm 0,2$ & $0,6 \pm 0,4$ \\
\hline Nepidae & & & $0,2 \pm 0,2$ & \\
\hline Veliidae & & $0,2 \pm 0,2$ & & \\
\hline \multicolumn{5}{|l|}{ DIPTERA } \\
\hline Ceratopogonidae & $2,4 \pm 1,1$ & $8,4 \pm 3,6$ & $2,0 \pm 0,5$ & $16,4 \pm 3,8$ \\
\hline \multicolumn{5}{|l|}{ Chironomidae } \\
\hline Chironominae & $3,0 \pm 0,7$ & $29,4 \pm 12,5$ & $5,4 \pm 1,4$ & $61,6 \pm 18,5$ \\
\hline Tanypodinae & $26,6 \pm 10,3$ & $53,6 \pm 27,5$ & $40,4 \pm 6,0$ & $258,6 \pm 37,7$ \\
\hline Culicidae & $1,2 \pm 0,7$ & $0,8 \pm 0,6$ & $5,8 \pm 2,2$ & $6,8 \pm 1,4$ \\
\hline \multicolumn{5}{|l|}{ ACARI } \\
\hline Trombidiformes & $7,0 \pm 3,6$ & $32,4 \pm 11,7$ & $6,0 \pm 2,0$ & $14,4 \pm 5,8$ \\
\hline \multicolumn{5}{|l|}{ CRUSTACEA } \\
\hline Cladocera & $1,8 \pm 1,6$ & $8,8 \pm 5,6$ & $7,6 \pm 2,7$ & $49,6 \pm 14,6$ \\
\hline \multicolumn{5}{|l|}{ Copepoda } \\
\hline Calanoida & $0,4 \pm 0,4$ & & $4,2 \pm 2,1$ & $15,2 \pm 10,5$ \\
\hline Cyclopoida & & $0,2 \pm 0,2$ & $4,8 \pm 2,1$ & $16,8 \pm 5,9$ \\
\hline Ostradoca & $0,2 \pm 0,2$ & $0,8 \pm 0,8$ & & $1,2 \pm 0,7$ \\
\hline \multicolumn{5}{|l|}{ AMPHIBIA } \\
\hline Anura (girino) & $1,0 \pm 0,3$ & & $0,6 \pm 0,2$ & $0,6 \pm 0,4$ \\
\hline
\end{tabular}




\section{Análise isotópica da fauna associada}

Mesmo com uma abundância alta de indivíduos, não foi possível realizar a análise isotópica de todos os táxons encontrados em função da baixa massa. Dessa forma, a análise isotópica foi realizada em 11 táxons (Coenagrionidae, Dicteriadidae, Lestidae, Libellulidae, Ceratopogonidae, Tanypodinae, Chironominae, Culicidae, Hydroptilidae, Cladocera e girino; Tabela 5).

Os valores de $\delta^{13} \mathrm{C}$ não apresentaram diferença significativa entre os predadores (exclusivamente) e as demais guildas agrupadas $(\mathrm{p}=0,33)$. Os valores de $\delta^{13} \mathrm{C}$ variaram de $-26,15$ a $-24,14 \%$ para a fauna associada (Tabela 5). Já para os valores de $\delta^{15} \mathrm{~N}$ houve diferença significativa $(\mathrm{p}=0,02)$. Os valores de $\delta^{15} \mathrm{~N}$ foram mais enriquecidos nos predadores (valor médio de 5,43\%o).

Tabela 5. Média e desvio padrão (DP) dos valores de $\delta^{13} \mathrm{C}$ e $\delta^{15} \mathrm{~N}$ dos táxons da fauna associada às macrófitas na Lagoa do Henrique, Parque Nacional de Brasília, Distrito Federal, Brasil. $\mathrm{N}=$ número de amostras, $\mathrm{GTF}=$ grupo trófico funcional, segundo Ramírez \& Gutiérrez-Fonseca (2014). CG = Coletores-Catadores, $\operatorname{Pr}=$ Predadores, $\mathrm{Sc}=$ Raspadores

\begin{tabular}{lcccccc}
\hline \multicolumn{1}{c}{ Táxon } & GTF & N & $\begin{array}{r}\text { Média } \boldsymbol{\delta}^{\mathbf{1 3}} \mathbf{C} \\
\mathbf{( \% o )}\end{array}$ & DP & $\begin{array}{r}\text { Média } \boldsymbol{\delta}^{\mathbf{1 5}} \mathbf{N} \\
\mathbf{( \% o )}\end{array}$ & DP \\
\hline Coenagrionidae & Pr & 5 & $-24,97$ & 1,61 & 5,17 & 1,00 \\
Dicteriadidae & Pr & 1 & $-25,68$ & & 6,95 & \\
Lestidae & Pr & 1 & $-24,14$ & & 7,22 & \\
Libellulidae & Pr & 5 & $-23,19$ & 2,08 & 3,71 & 1,08 \\
Tanypodinae & Pr & 8 & $-24,17$ & 1,88 & 4,09 & 1,01 \\
Ceratopogonidae & Pr & 1 & $-24,54$ & & 3,69 & \\
Chironominae & CG & 2 & $-24,34$ & & 3,75 & \\
Culicidae & CG & 2 & $-25,22$ & & 3,75 & \\
Hydroptilidae & Sc & 1 & $-26,15$ & & 1,69 & \\
Cladocera & Sc & 1 & $-25,24$ & & 3,28 & \\
Girino & Sc & 3 & $-24,24$ & 1,36 & 4,27 & 0,80 \\
\hline
\end{tabular}


O perifíton predominou como principal fonte de alimento para toda a comunidade da fauna associada, com contribuição média de 63\% (24 a 98\%; Figura 4). A contribuição média da macrófita emergente Cyperus sp. foi $31 \%(<0,1$ a $70 \%)$ e da macrófita submersa Cabomba sp. foi $6 \%$ (<0,1 a 29\%; Figura 4).

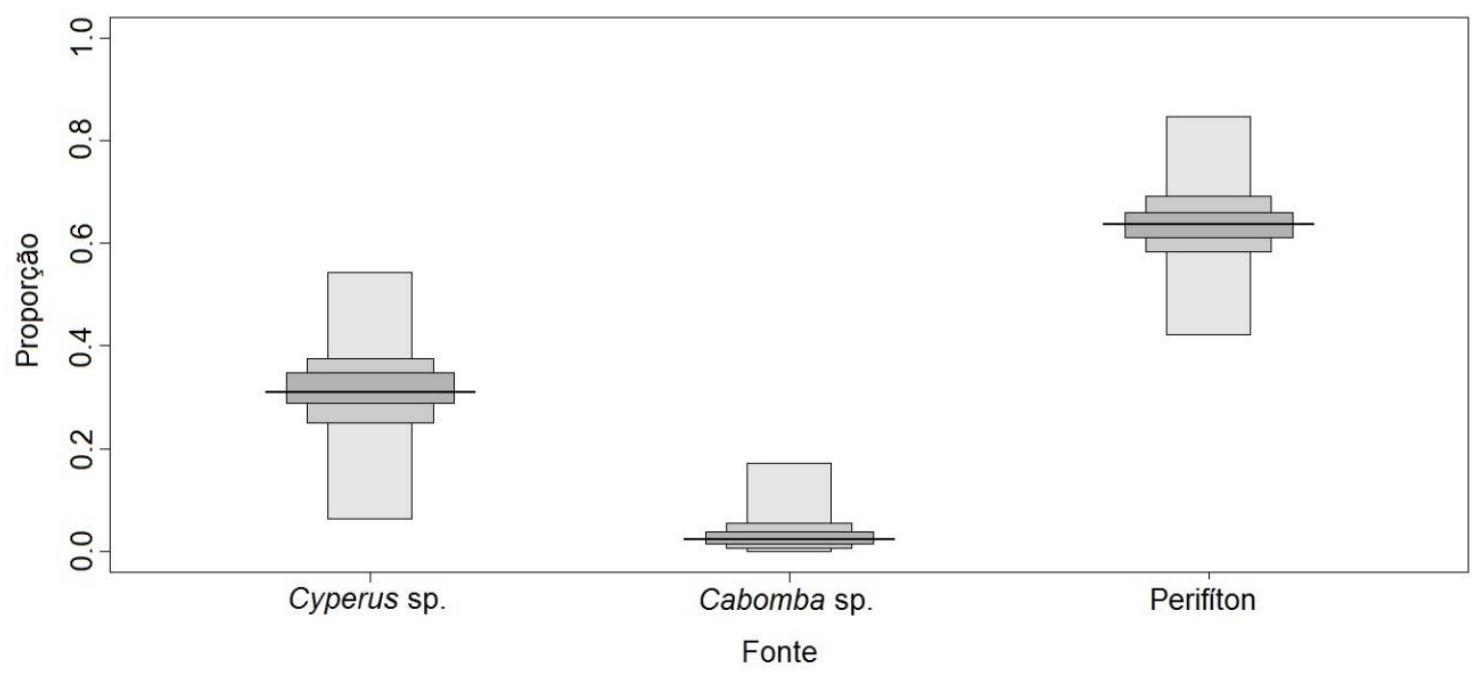

Figura 4. Contribuição relativa das fontes alimentares macrófita emergente Cyperus sp., macrófita submersa Cabomba sp. e perifíton para os invertebrados aquáticos da Lagoa do Henrique, Parque Nacional de Brasília, Distrito Federal.

A figura 5 apresenta a composição isotópica de carbono e nitrogênio da fauna associada e suas fontes. A assinatura isotópica de $\delta^{13} \mathrm{C}$ de todos os indivíduos indicou o consumo de Cyperus sp. e perífiton. Os predadores apresentaram valores de $\delta^{15} \mathrm{~N}$ mais enriquecidos (mínimo de 3,69\%o e máximo de 7,22 \%o) em comparação com as demais guildas agrupadas. 


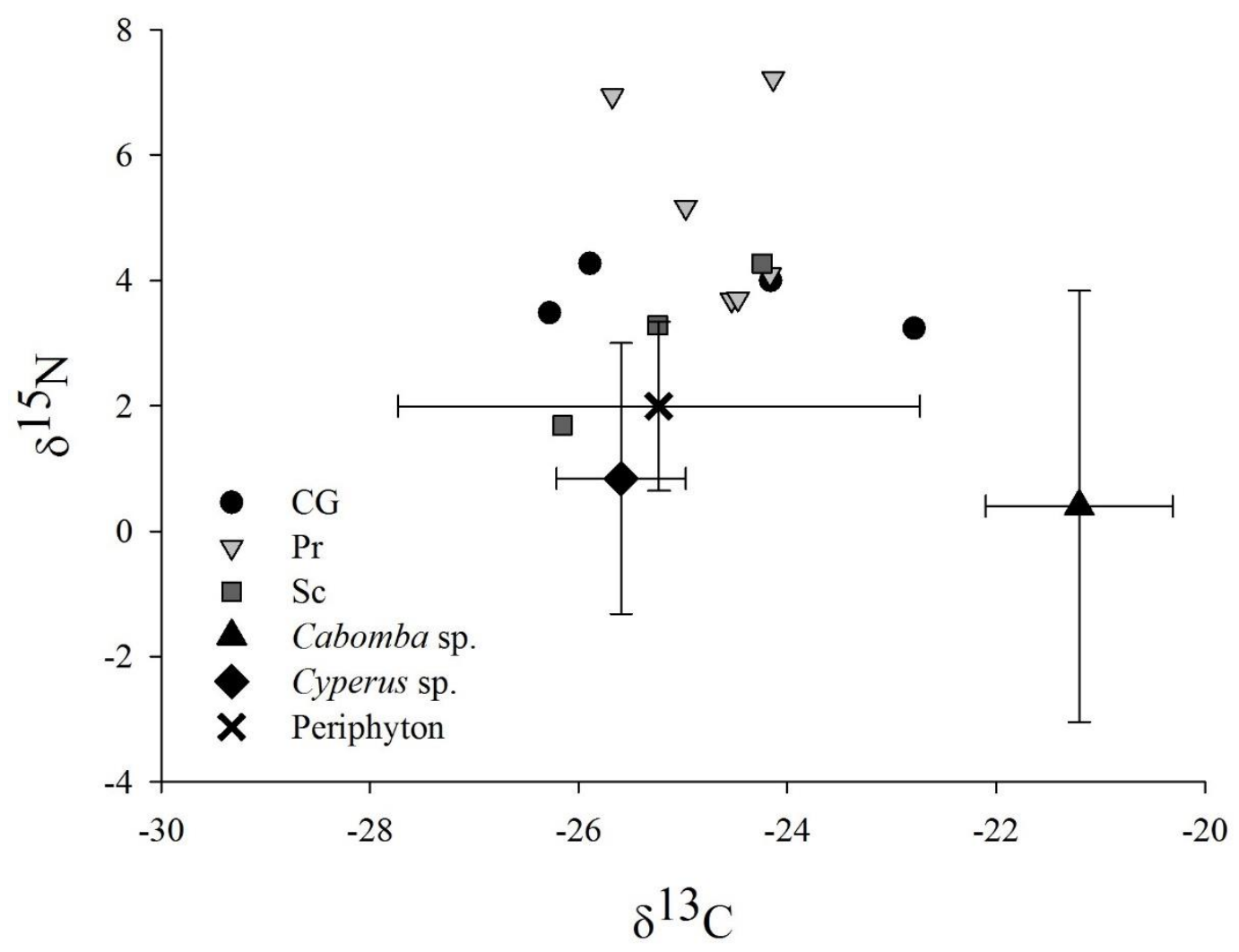

Figura 5. Assinaturas isotópica de carbono $\left(\delta^{13} \mathrm{C}\right)$ e nitrogênio $\left(\delta^{15} \mathrm{~N}\right)$ da fauna associada e valores isotópicos médios de macrófita emergente (Cyperus sp.), macrófita submersa (Cabomba sp.) e perifíton da Lagoa do Henrique, Parque Nacional de Brasília, Distrito Federal, Brasil. Barras = desvio-padrão; $\mathrm{CG}=$ Coletores-Catadores, Pr $=$ Predadores, $\mathrm{Sc}=$ Raspadores.

As elipses produzidas pelo SEAc com base nas razões isotópicas dos grupos tróficos da fauna associada diferiram no tamanho e posição espacial no biplot de $\delta^{13} \mathrm{C}$ versus $\delta^{15} \mathrm{~N}$ (Figura 6). Os predadores exibiram maior SEAc $\left(3,41 \%{ }^{2}\right)$, seguido pelos coletores $\left(3,17 \%{ }^{2}\right)$ e raspadores $\left(1,25 \%{ }^{2}\right)$. É possível observar sobreposições entre todos os grupos tróficos. Os predadores se sobrepuseram aos nichos coletores $(9,76 \%)$ e raspadores $(7,58 \%)$, enquanto os coletores e raspadores também se sobrepuseram $(8,23 \%)$. 


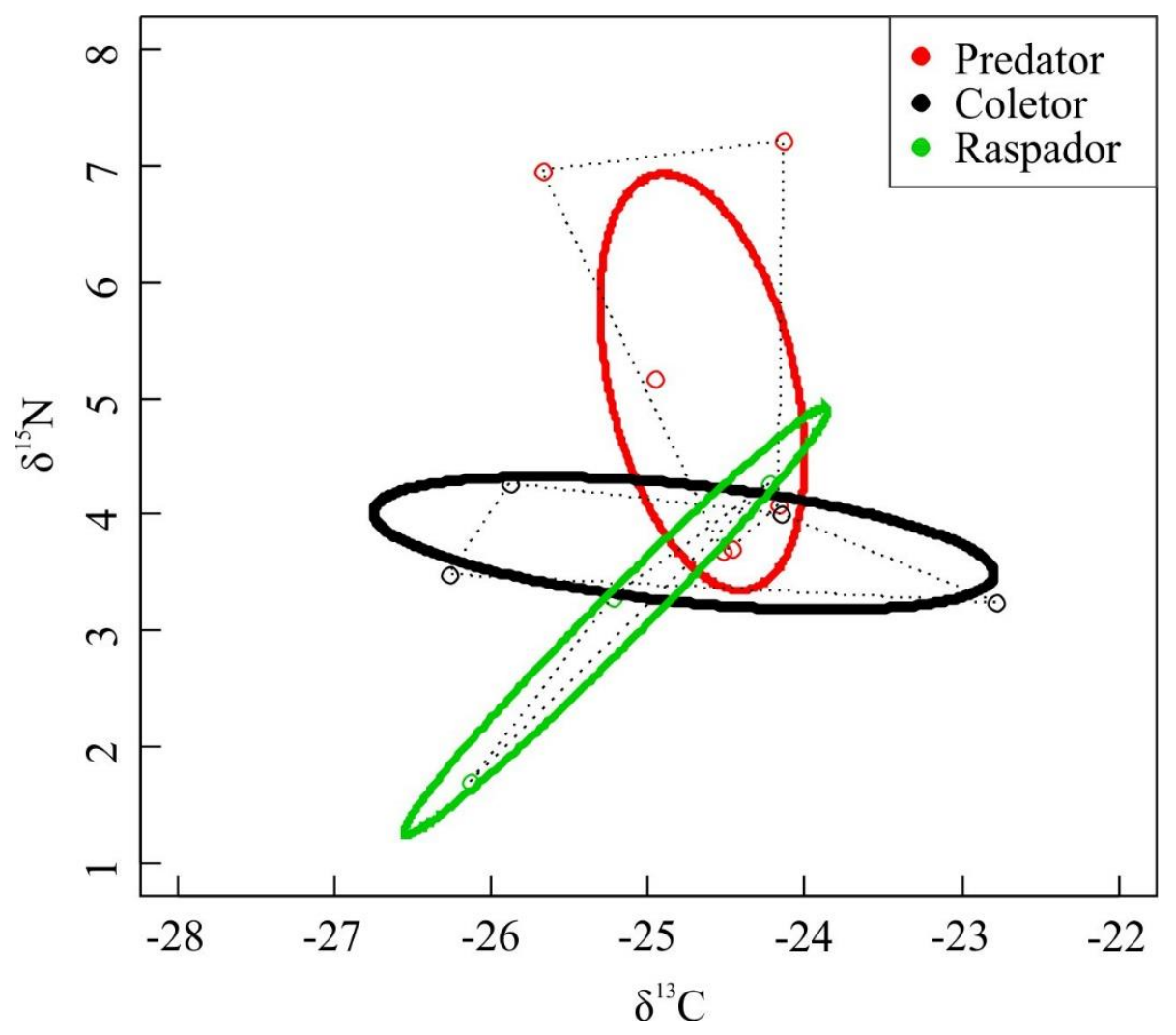

Figura 6. Áreas de elipse padrão (SEA, linhas contínuas), representando o espaço do nicho isotópico central dos grupos tróficos da fauna associada, conforme determinado por modelos SIBER para a Lagoa do Henrique, Parque Nacional de Brasília, Distrito Federal, Brasil. As linhas tracejadas delimitam a área total dos conjuntos da fauna associada.

\section{DISCUSSÃO}

Os produtores primários são a base da cadeia alimentar nos ecossistemas, sintetizando compostos orgânicos e disponibilizando os nutrientes para os demais níveis tróficos. Para a Lagoa do Henrique, as fontes basais de energia avaliadas foram macrófitas (emergentes e submersas) e perifiton associado às macrófitas. De um modo geral, as fontes primárias de carbono da Lagoa do Henrique estão isotopicamente próximas às de outros ambientes tropicais (Tabela 6). As assinaturas isotópicas de C permitiram separar as macrófitas em função de seu hábito de vida (emergente x submersa), entretanto o perifíton apresentou uma assinatura similar à da macrófita emergente, corroborando em parte a primeira hipótese. Os valores de $\delta^{13} \mathrm{C}$ de todas as fontes foram próximos do valor médio para plantas $\mathrm{C}_{3}$, no entanto, Cabomba sp. foi isotopicamente diferente entre as fontes, apresentando um valor mais enriquecido de $\delta^{13} \mathrm{C}$. Em uma avaliação das macrófitas aquáticas nas teias tróficas em 19 lagos rasos da América do Sul, Mendonça 
et al. (2013) sugeriram que o sinal de $\delta^{13} \mathrm{C}$ das macrófitas submersas depende de características intrínsecas das espécies e da disponibilidade de $\mathrm{CO}_{2}$ dissolvido. As macrófitas submersas, diferentemente das flutuantes e emergentes, retiram seus recursos quase que totalmente da água e sedimento, dessa forma, as macrófitas submersas desenvolveram várias adaptações morfológicas e fisiológicas para evitar a limitação do carbono no ambiente aquático, tais como: metabolismo $\mathrm{C}_{4}$, metabolismo CAM, utilização do $\mathrm{HCO}_{3}{ }^{-}$e utilização do $\mathrm{CO}_{2}$ da água intersticial do sedimento (Pierini \& Thomaz, 2004). Como as assinaturas isotópicas não indicaram diferenças no metabolismo fotossintético $\left(\mathrm{C}_{3}\right.$ e $\left.\mathrm{C}_{4}\right)$, a diferença na assinatura isotópica de carbono encontrada no presente estudo entre as macrófitas emergentes e submersas pode ser explicada por diferenças na fonte de carbono (dissolvido na água ou atmosférico).

Apesar das variações sazonais das características limnológicas (Tabela 1), as assinaturas isotópicas de $\mathrm{C}$ e $\mathrm{N}$ das fontes basais de energia não variaram sazonalmente, contrariando nossa segunda hipótese. Reis et al. (2016) investigaram as fontes basais de carbono em um lago tropical no sudeste do Brasil (remanescente de Mata Atlântica) e, em geral, as razões isotópicas $\mathrm{C}$ foram mais negativas durante a estação seca do que durante a estação chuvosa, entretanto esta diferença foi significativa apenas para o seston e a macrófita emergente (Eleocharis interstincta). Os autores, no entanto, não observaram diferenças nos valores de $\delta^{15} \mathrm{~N}$ entre as estações.

Os resultados do presente estudo demonstraram que o perifíton é a principal fonte de alimento para a fauna associada às macrófitas na lagoa, corroborando nossa terceira hipótese. Isso pode ser parcialmente explicado pela baixa razão $\mathrm{C}: \mathrm{N}$, indicando uma alta palatabilidade dessa fonte. Brett et al. (2009) sugeriram que as fontes autóctones (fitoplâncton) apresentam alta qualidade alimentar e regulam o crescimento, reprodução e composição lipídica do zooplâncton. Apesar da macrófita submersa Cabomba sp. apresentar uma menor razão C:N comparada com a macrófita emergente Cyperus sp., ela apresentou uma baixa contribuição (6\%) como fonte de alimento pelos consumidores da Lagoa do Henrique. Isso pode ser explicado pela maior biomassa de Cyperus sp. encontrada nesse ambiente (Figura 3C). 
Tabela 6. Comparação do range de $\delta^{13} \mathrm{C}(\%)$ e $\delta^{15} \mathrm{~N}(\%)$ das fontes alimentares entre estudos em ambientes tropicais e o presente estudo.

\begin{tabular}{|c|c|c|c|}
\hline Fonte & Range $\delta^{13} \mathrm{C}(\%)$ & Range $\delta^{15} \mathbf{N}(\%)$ & Referência \\
\hline Macrófitas emergentes & $-28,6$ a $-27,4$ & $-0,9$ a 5,7 & Presente estudo \\
\hline $\begin{array}{c}\text { Macrófita emergente } \\
\text { (Cyperus sp.) }\end{array}$ & $-26,4$ a $-25,5$ & $-3,1$ a 3,8 & Presente estudo \\
\hline Macrófitas submersas & $-22,9$ a $-20,7$ & 0,9 a 5,5 & Presente estudo \\
\hline $\begin{array}{l}\text { Macrófita submersa } \\
\text { (Cabomba sp.) }\end{array}$ & $-23,1$ a $-20,3$ & $-3,9$ a 5,1 & Presente estudo \\
\hline Macrófitas $\mathrm{C}_{3}$ & -31 a -27 & 4 a 9,5 & Wantzen et al., 2002 \\
\hline Macrófitas aquáticas & $-33 a-24$ & 1 a 3 & Iglesias et al., 2016 \\
\hline $\begin{array}{l}\text { Macrófita emergente } \\
\text { (Eleocharis } \\
\text { interstincta) }\end{array}$ & $-30,2$ a $-28,9$ & $-1,3$ a 5,1 & Reis et al., 2016 \\
\hline $\begin{array}{l}\text { Macrófita flutuante } \\
\text { (Nymphaea caerulea e } \\
\text { Nymphoides indica) }\end{array}$ & $-27,2$ a $-24,5$ & 0,5 a 3,9 & Reis et al., 2016 \\
\hline Perifíton & $-30,4 \mathrm{a}-22,7$ & $-0,2$ a 3,9 & Presente estudo \\
\hline Perifíton & -33 a -26 & 1 a 3 & Wantzen et al., 2002 \\
\hline Perifíton & $-26,9$ a $-18,4$ & 4,1 a 5,6 & Reis et al., 2016 \\
\hline
\end{tabular}

Segundo os dados do capítulo 1, o perifíton, comparado às macrófitas aquáticas, apresenta maiores concentrações de P. Assim, juntamente com a baixa razão C:N encontrada no presente estudo, o perifíton da Lagoa do Henrique constitui uma fonte de alimento rica em nutrientes e capaz de manter a cadeia trófica desse sistema. Portanto, a estequiometria dos elementos parece estar fortemente relacionada às características funcionais dos diferentes produtores primários nesse ambiente. Ventura et al. (2008) analisaram a estequiometria da fauna associada às macrófitas, e observaram que os organismos são capazes de ajustar sua razão C:N:P dentro de faixas mais estreitas que a razão de sua fonte de alimento, ou seja, consumidores tendem a ser mais homeostáticos em suas composições estequiométricas em comparação aos produtores primários. Em outro estudo, Ferrão-Filho et al. (2005) compararam espécies tropicais filtradoras do zooplâncton em um gradiente de qualidade nutricional de alimentos provenientes de lagos 
rasos e profundos. Os autores observaram que, aparentemente, lagos rasos dispunham de alimento com maior qualidade nutricional, sobretudo disponibilidade de P. As espécies testadas também mostraram respostas de crescimento relacionadas ao gradiente nutricional, com maiores taxas em experimentos com alimento mais rico em $\mathrm{P}$.

Embora, no presente estudo, a sazonalidade não tenha influenciado as assinaturas isotópicas, é possível verificar que a estrutura da comunidade da fauna associada, considerando a abundância de indivíduos, difere entre as estações e em relação às macrófitas analisadas. Na estação seca, a macrófita submersa apresentou maior abundância de organismos em relação a macrófita emergente (Tabela 4). Além disso, considerando a concentração de clorofila- $a$ no perifíton, as macrófitas submersas apresentaram uma maior biomassa de algas aderidas (Figura 3A. Alguns estudos descrevem a relação da complexidade da arquitetura da macrófita com a estrutura das comunidades de invertebrados (Vieira et al., 2007; Thomaz \& Cunha, 2010; LucenaMoya \& Duggan, 2011) e do perifíton (Santos et al., 2013; Souza et al., 2015; Pettit et al., 2016). Portanto, o perifíton é a principal fonte de alimento e a macrófita submersa Cabomba sp. é utilizada como abrigo e refúgio pela fauna associada, além de ser substrato para a colonização do perifíton.

Já a macrófita emergente Cyperus sp. também contribuiu para os consumidores avaliados, mesmo apresentando a maior razão $\mathrm{C}: \mathrm{N}$, principalmente para o grupo trófico raspador. Os indivíduos de Cladocera encontrados (Chydoridae e Machrotricidae, principalmente) são capazes de forragear recursos presentes no perifíton, apresentando a assinatura de $\delta^{13} \mathrm{C}$ bem próxima dessa fonte. No presente estudo, as sobreposições de nichos foram baixas, o que pode indicar que os grupos tróficos da fauna associada dessa lagoa apresentam hábitos alimentares mais seletivos e, consequentemente, menor competição pelo recurso. Parreira de Castro et al. (2016) concluíram que mudanças no uso da terra podem alterar o comportamento alimentar dos macroinvertebrados, tornandoos mais generalistas e com maior sobreposição de nicho trófico. Portanto, a preservação da integridade ecológica dos ecossistemas aquáticos é fundamental para a dinâmica trófica e manutenção do funcionamento desses sistemas.

Os valores de $\delta^{15} \mathrm{~N}$ variaram de 3,7 a 7,2\% para os predadores e 1,7 a 4,3\% para os outros grupos funcionais encontrados (coletor-catador e raspador). Essa variação pode estar relacionada às diferentes estratégias de alimentação adotadas, além das diferenças nas vias bioquímicas e no metabolismo dos organismos (Vander Zanden \& Rasmussen, 
2001; Cremona et al., 2010). Em um estudo que avaliou a discriminação isotópica de oito táxons de invertebrados bentônicos tropicais (predadores: cinco gêneros de Odonata e um gênero de Hemiptera; fragmentadores: dois gêneros de Trichoptera), os valores de $\delta^{15} \mathrm{~N}$ variaram de 6,9 a $13,3 \%$ para os predadores e 3,2 a 4,5\% para os fragmentadores (Carvalho et al., 2015). Os resultados aqui apresentados corroboram a indicação que os valores de $\delta^{15} \mathrm{~N}$ dos consumidores diferem entre os grupos tróficos funcionais com uma separação entre predadores e demais guildas agrupadas, apesar de apresentaram uma alta variabilidade entre táxons do mesmo grupo trófico funcional.

\section{Conclusões}

As assinaturas isotópicas das fontes alimentares não variaram sazonalmente, mas sim em função do hábito de vida das macrófitas aquáticas (emergente x submersa). Logo, apesar da sazonalidade ser um fator importante para a dinâmica dos ecossistemas aquáticos do Cerrado, não foi um fator determinante nas assinaturas isotópicas dos recursos alimentares avaliados e a diferença encontrada nas assinaturas isotópicas de $\mathrm{C}$ de macrófitas emergente e submersa pode estar relacionada as diferentes fontes de carbono no ambiente aquático. O perifíton é a principal fonte primária de recurso nesse ambiente, o que pode ser explicado por sua baixa razão C:N e maior concentração de $P$ (capítulo 1), indicando maior qualidade do recurso. A macrófita emergente estudada (Cyperus sp.) também contribui para a teia alimentar, apesar da alta razão C:N. Já a macrófita submersa (Cabomba sp.), embora tenha abrigado maior abundância de fauna associada e biomassa de algas (clorofila-a), contribuiu relativamente menos para a teia trófica da lagoa, mesmo apresentando uma razão $\mathrm{C}: \mathrm{N}$ intermediária entre as fontes. Portanto, os dados indicam diferentes papéis entre os produtores primários na teia trófica desse ecossistema. A macrófita emergente é um recurso alimentar, enquanto que a submersa garante estruturação física do ambiente e é abrigo e refúgio contra predadores e substrato para a colonização do perifíton. 


\section{REFERÊNCIAS}

APHA. 2005. Standard Methods for the Examination of Water and Wastewater. 18th ed. American Public Health Association, Washington.

Arcagni, M., Campbell, L. M., Arribére, M. A., Kyser, K., Klassen, K., Casaux, R., Miserendino, M. L. \& Guevara, E. R. 2013. Food web structure in a double-basin ultra-oligotrophic lake in Northwest Patagonia, Argentina, using carbon and nitrogen stable isotopes. Limnologica, 43: 131-142.

Brett, M. T., Kainz, M. J., Taipale, S. J. \& Seshan, H. 2009. Phytoplankton, not allochthonous carbon, sustain herbivorous zooplankton production. PNAS, 106: 21197-21201.

Carmouze, J.P. 1994. O metabolismo dos ecossistemas aquáticos: fundamentos teóricos, métodos de estudo e análises químicas. Editora Edgard Blücher/FAPESP, São Paulo.

Carvalho, A. P. C., Gücker, B., Brauns, M. \& Boëchat, I. G. 2015. High variability in carbon and nitrogen isotopic discrimination of tropical freshwater invertebrates. Aquatic Science, 77: 307-314.

Cremona F., Planas, D. \& Lucotte, M. 2010. Influence of functional feeding groups and spatiotemporal variables on the $\mathrm{d} 15 \mathrm{~N}$ signature of littoral macroinvertebrates. Hydrobiologia, 647:51-61.

DeMott, W. R. \& Pape, B. J. 2005. Stoichiometry in an ecological context: testing for links between Daphnia P-content, growth rate and habitat preference. Oecologia, 142: $20-27$.

Elmoor-Loureiro L. M. A. 1997. Manual de identificação de cladóceros límnicos do Brasil. 156 p. Universa, Brasília.

Ferrão-Filho, A. S., DeMott, W. R. \& Tessier, A. J. 2005. Responses of tropical cladocerans to a gradient of resource quality. Freshwater Biology, 50: 954-964.

Fonseca, B. M., Mendonça-Galvão, L., Padovesi-Fonseca, C., Abreu, L. M., Fernandes, A. C. M. 2014. Nutrient baselines of Cerrado low-order streams: comparing natural and impacted sites in the Central Brazil. Environmental Monitoring and Assessment, 186: 19-33.

Frost, P. C., Evans-White, M. A., Finkel, Z. V., Jensen, T. C. \& Matzek, V. 2005. Are you what you eat? Physiological constraints on organismal stoichiometry in an elementally imbalanced world. Oikos, 109: 18-28. 
Fry, B. 2006. Stable isotope ecology. Vol. 521. New York: Springer.

Hill, J. M., Jones, R. W., Hill, M. P. \& Weyl, O. L. F. 2015. Comparisons of isotopic niche widths of some invasive and indigenous fauna in a South African river. Freshwater Biology, 60: 893-902.

IBGE. 2017. Disponível em:

<http://www.ibge.gov.br/home/presidencia/noticias/21052004biomashtml.shtm>

Iglesias, C., Meerhoff, M., Johansson, L. S.; et al. 2016. Stable isotope analysis confirms substantial diferences between subtropical and temperate shallow lake food webs. Hydrobiologia, DOI 10.1007/s 10750-016-2861-0.

Jackson, A. L., Inger, R., Parnell, A. C. \& Bearhop, S. 2011. Comparing isotopic niche widths among and within communities: SIBER—Stable Isotope Bayesian Ellipses in R. Journal of Animal Ecology, 80: 595-602.

Jepsen, D. B. \& Winemiller, K. O. 2002. Structure of tropical river food webs revealed by stable -isotope ratios. Oikos, 96: 46-55.

Klausmeier, C. A., Litchman, E., Daufresne, T. \& Levin, S.A. 2004. Optimal nitrogento-phosphorus stoichiometry of phytoplankton. Nature, 429: 171-174.

Lopes, C. A. \& Benedito-Cecílio, E. 2002. Variabilidade isotópica $\left(\delta^{13} \mathrm{C}\right.$ e $\left.\delta^{15} \mathrm{~N}\right)$ em produtores primários de ambientes terrestres e de água doce. Acta Scientiarum, 24: 303-312.

Lopes, C. A., Manetta, G. I., Figueiredo, B. R. S., Martinelli, L. A. \& Benedito, E. 2015. Carbon from littoral producers is the major source of energy for bottom-feeding fish in a tropical floodplain. Environmental Biology of Fishes, 98:1081-1088.

Lucena-Moya P. \& Duggan, I. C. 2011. Macrophyte architecture affects the abundance and diversity of littoral microfauna. Aquatic Ecology, 45: 279-287.

Marker, A. F. H., Nusch, H., Rai, H. \& Riemann, B. 1980. The measurement of photosynthetic pigments in freshwaters and standardization of methods: conclusion and recomendations. Archiv für Hydrobiologie, 14: 91-106.

McCutchan, J. H., Lewis, W. M., Kendall, C. \& McGrath, C. C. 2003. Variation in trophic shift for stable isotope ratios of carbon, nitrogen, and sulfur. Oikos, 102: 378-390.

Mendonça, R., Kosten, S., Lacerot, G. et al. 2013. Bimodality in stable isotope composition facilitates the tracing of carbon transfer from macrophytes to higher trophic levels. Hydrobiologia, 710: 205-218.

Myers, N., Mittermler, R. A., Mittermiler, C. G., Fonseca, G. A. B. \& Kent, J. 2000. Biodiversity hotspots for conservation priorities. Nature, 403: 853-858. 
Parnell, A. C., Inger, R., Bearhop, S. \& Jackson, A.L. 2010. Source partitioning using stable isotopes: Coping with too much variation. PLoS One, 5: 1-5.

Parreira de Castro, D. M., Reis de Carvalho, D., Pompeu, P. S., Moreira, M. Z., Nardoto, G. B. \& Callisto, M. 2016. Land Use Influences Niche Size and the Assimilation of Resources by Benthic Macroinvertebrates in Tropical Headwater Streams. PLoS One, doi:10.1371/journal.pone.0150527

Peterson, B. J. 1999. Stable isotopes as tracers of organic matter input and transfer in benthic food webs: a review. Acta Oecologica, 20: 479-487.

Pettit, N. E., Ward, D. P., Adame, M. F., Valdez, D. \& Bunn, S. E. 2016. Influence of aquatic plant architecture on epiphyte biomass on a tropical river floodplain. Aquatic Botany, 129: 35-43.

Pierini, S. A. \& Thomaz, S. M. 2004. Adaptações de plantas submersas à absorção do carbono inorgânico. Acta Botanica Brasilica, 18: 629-641.

Quigg A., Finkel, Z. V., Irwin, A. J., Rosenthal, Y., Ho, T., Reinfelder, J. R., Schofield, O., Morel, F. M. M. \& Falkowski, P. G. 2003. The evolutionary inheritance of elemental stoichiometry in marine phytoplankton. Nature, 425: 291-294.

R Core Team. 2015. R: A language and environment for statistical computing. $\mathrm{R}$ Foundation for Statistical Computing, Vienna, Austria.

Ramírez, A. \& Gutiérrez-Fonseca, P. E. 2014. Functional feeding groups of aquatic insect families in Latin America: a critical analysis and review of existing literature. Revista de Biología Tropical, 62: 155-167.

Reis, P. C. J., Martinelli, L. A. \& Barbosa, F. A. 2016. Basal carbon sources and planktonic food web in a tropical lake: an isotopic approach. Marine and Freshwater Research, doi.org/10.1071/MF14322.

Saigo, M., Marchese, M. R. \& Wantzen, K. M. 2016. Sources contribution for benthic invertebrates: an inter-lake comparison in a flood plain system. Hydrobiologia, 770: $27-36$.

Santos, T. R., Ferragut, C. \& Bicudo, C. E. M. 2013. Does macrophyte architecture influence periphyton? Relationships among Utricularia foliosa, periphyton assemblage structure and its nutrient (C, N, P) status. Hydrobiologia, 714: 71-83.

Sartory, D. P. \& Grobbelaar, J. U. 1984. Extraction of Chlorophyll a from freshwater phytoplankton for spectrophotometric analysis. Hydrobiologia, 114: 177-187. 
Souza, M. L., Pellegrini, B. G. \& Ferragut, C. 2015. Periphytic algal community structure in relation to seasonal variation and macrophyte richness in a shallow tropical reservoir. Hydrobiologia, 755: 183-196.

Thomaz, S. M. \& Cunha, E. R. 2010. The role of macrophytes in habitat structuring in aquatic ecosystems: methods of measurement, causes and consequences on animal assemblages' composition and biodiversity. Acta Limnologica Brasiliensia, 22: 218-236.

Vadeboncoeur, Y., McCann, K., Zanden, M. \& Rasmussen, J. 2005. Effects of multichain omnivory on the strength of trophic control in lakes. Ecosystems, 8: 682693.

Vander Zanden, M. J. \& Rasmussen, J. B. 1999. Primary consumer $\delta^{13} \mathrm{C}$ and $\delta^{15} \mathrm{~N}$ and the trophic position of aquatic consumers. Ecology, 80: 1395-1404.

Vander Zanden, M. J. \& Rasmussen, J. B. 2001. Variation in $\delta^{15} \mathrm{~N}$ and $\delta^{13} \mathrm{C}$ trophic fractionation: Implications for aquatic food web studies. Limnology and Oceanography, 46: 2061-2066.

Vander Zanden, M. J., Vadeboncoeur, Y. \& Chandra, S. 2011. Fish reliance on littoralbenthic resources and the distribution of primary production in lakes. Ecosystems, 14: 894-903.

Ventura, M., Liboriussen, L., Lauridsen, T., Søndergaard, M., Søndergaard, M. \& Jeppensen, E. 2008. Effects of increased temperature and nutrient enrichment on the stoichiometry of primary producers and consumers in temperate shallow lakes. Freshwater Biology, 53: 1434-1452.

Vieira, L. C. G., Bini, L. M., Velho, L. F. M. \& Mazão, G. R. 2007. Influence of spatial complexity on the density and diversity of periphytic rotifers, microcrustaceans and testate amoebae. Fundamental and Applied Limnology, 170/1: 77-85. 


\section{Conclusões Gerais}

Em função das condições de limitação de nutrientes encontradas nos ambientes estudados, no capítulo 1 foi proposta a hipótese de que as concentrações de $\mathrm{N}$ e $\mathrm{P}$ seriam maiores no perifíton, seguido pelas macrófitas aquáticas e finalmente, no sedimento considerando as variações sazonais, a entrada de nutrientes será maior nas estações relacionadas com a precipitação (transição seca/chuva e chuva). Macrófitas aquáticas apresentaram maiores concentrações de carbono, independente da sazonalidade, que pode estar relacionado ao investimento em sustentação, enquanto o perifíton apresentou maiores concentrações de nitrogênio, fósforo e cálcio, principalmente nos períodos com influência da precipitação (transição seca/chuva e chuva), corroborando nossa hipótese. Com base na razão estequiométrica N:P proposta por Kahlert (1998) de 18:1, todos os compartimentos em todos os períodos sazonais indicaram limitação por fósforo. Apesar das macrófitas apresentarem menores concentrações de nutrientes, esse compartimento apresentou o maior estoque de nitrogênio e fósforo. Dessa forma, as macrófitas podem ser consideradas uma fonte a longo prazo de nutrientes, enquanto o perifíton apresenta uma dinâmica mais lábil para esses nutrientes. Os compartimentos que formam as lagoas naturais rasas do Cerrado são diferentes com relação à concentração de nutrientes e estudos futuros podem abordar as interações entre esses compartimentos para melhor entendimento sobre a dinâmica desses ecossistemas.

Considerando diferenças nas características das bacias hidrográficas presentes no Distrito Federal, no capítulo 2 foi proposta a hipótese de que as características geológicas das bacias hidrográficas influenciam as concentrações de elementos-traço nas macrófitas aquáticas, perifíton e sedimento de lagoas naturais rasas do Cerrado. A hipótese foi corroborada, considerando os elementos-traço nas duas bacias hidrográficas estudadas, as maiores diferenças foram encontradas entre os compartimentos macrófitas aquáticas e perifíton, evidenciando o papel da composição florística na dinâmica desses elementos e implicações importantes para a ecologia e manejo. Para elementos que estão ligados diretamente à fisiologia e metabolismo dos produtores primários, como $\mathrm{Mn}$, a sazonalidade foi um fator importante na sua distribuição no ambiente. Além disso, o perifíton apresentou elevadas concentrações para alguns elementos (Al, $\mathrm{Pb}, \mathrm{Ti}, \mathrm{Fe}$ e $\mathrm{Mn}$ ) que, potencialmente, possuem importância no metabolismo desse grupo. Portanto, além da geologia, nossos resultados enfatizam a importância das respostas biogeoquímicas aos 
fatores que conduzem a distribuição dos organismos em diferentes escalas e essa linha de pesquisa ainda é promissora e importante para a ecologia e manejo de lagoas rasas.

Identificar as ligações alimentares e descrever a estrutura trófica é fundamental para o entendimento do funcionamento dos ecossistemas aquáticos do Cerrado. Portanto, no capítulo 3 , foram propostas as hipóteses de que 1) as assinaturas isotópicas de $\mathrm{C}$ e $\mathrm{N}$ das fontes alimentares (perífiton, macrófita emergente e submersa) diferem entre si em função das formas de aquisição desses nutrientes permitindo a identificação dos recursos alimentares utilizados pela fauna associada, 2) as assinaturas isotópicas de $\mathrm{C}$ e $\mathrm{N}$ das fontes alimentares (perífiton, macrófita emergente e submersa) variam sazonalmente devido às variações das características limnológicas do ambiente, 3) o perifíton é a principal fonte de alimento para a fauna associada às macrófitas em função de sua menor razão C:N quando comparada às macrófitas. As assinaturas isotópicas das fontes alimentares não variaram sazonalmente, mas sim em função do hábito de vida das macrófitas aquáticas (emergente x submersa), corroborando nossa primeira hipótese, mas não a segunda. $\mathrm{O}$ perifíton foi considerado a principal fonte alimentar nesse ambiente, $\mathrm{o}$ que pode ser explicado por sua baixa razão $\mathrm{C}: \mathrm{N}$ e maior concentração de $\mathrm{P}$, indicando maior qualidade do recurso e corroborando nossa terceira hipótese. Apesar da maior razão $\mathrm{C}: \mathrm{N}$, a macrófita emergente estudada (Cyperus sp.) também contribui para a teia alimentar. Já a macrófita submersa (Cabomba sp.) apresentou baixa contribuição para a teia trófica da lagoa, entretanto obteve a maior abundância de organismos (tanto fauna associada quanto algas). Dessa forma, os dados indicam que a sazonalidade não foi um fator determinante para as assinaturas isotópicas dos recursos alimentares estudados e que os produtores primários exercem diferentes papéis na teia trófica desse ecossistema. A macrófita emergente é um recurso alimentar, enquanto que a submersa garante estruturação física do ambiente e é abrigo e refúgio contra predadores e substrato para a colonização do perifíton.

Portanto, uma vez que esses ambientes tão peculiares têm recebido pouca atenção, este estudo permitiu o aprofundamento do conhecimento acerca do funcionamento de lagoas naturais rasas do Cerrado, a partir do detalhamento de suas razões de nutrientes, das relações entre diferentes componentes da cadeia trófica e da diversidade encontrada nesses ambientes. 